\title{
Molecular imaging of programmed cell death in the heart
}

Citation for published version (APA):

Dumont, E. A. W. J. (2003). Molecular imaging of programmed cell death in the heart. [Doctoral Thesis, Maastricht University]. Universiteit Maastricht. https://doi.org/10.26481/dis.20031203ed

Document status and date:

Published: 01/01/2003

DOI:

10.26481/dis.20031203ed

Document Version:

Publisher's PDF, also known as Version of record

\section{Please check the document version of this publication:}

- A submitted manuscript is the version of the article upon submission and before peer-review. There can be important differences between the submitted version and the official published version of record.

People interested in the research are advised to contact the author for the final version of the publication, or visit the DOI to the publisher's website.

- The final author version and the galley proof are versions of the publication after peer review.

- The final published version features the final layout of the paper including the volume, issue and page numbers.

Link to publication

\footnotetext{
General rights rights.

- You may freely distribute the URL identifying the publication in the public portal. please follow below link for the End User Agreement:

www.umlib.nl/taverne-license

Take down policy

If you believe that this document breaches copyright please contact us at:

repository@maastrichtuniversity.nl

providing details and we will investigate your claim.
}

Copyright and moral rights for the publications made accessible in the public portal are retained by the authors and/or other copyright owners and it is a condition of accessing publications that users recognise and abide by the legal requirements associated with these

- Users may download and print one copy of any publication from the public portal for the purpose of private study or research.

- You may not further distribute the material or use it for any profit-making activity or commercial gain

If the publication is distributed under the terms of Article $25 \mathrm{fa}$ of the Dutch Copyright Act, indicated by the "Taverne" license above, 
MOLECULAR IMAGING OF PROGRAMMED

CELL DEATH IN THE HEART 
Front cover image: Binding of Annexin-A5 (green) to the cardiomyocyte cell nembrane in the beating and living mouse heart. Propidium lodide (red) binds to DNA vithin the nucleus.

Back cover image: dual probe imaging with Annexin-A5 in the beating ind living mouse heart. Binding of Annexin-A5 (red) after 30 minutes of reperfision and Annexin-A 5 binding (green) after 24 hours of reperfusion indicating infarct exansion.

Design, layout and book production: Datawyse Maastricht

(c) E.A.W.J. Dumont, MD, Maastricht 2003

ISBN 90-9017551-2 


\section{MOLECULAR IMAGING OF PROGRAMMED CELl DeATH IN THE HEART}

Proefschrift ter verkriiging van de graad van doctor aan de Universiteit Maastricht, op gezag van de Rector Magnificus, Prof. Dr. A.C. Nieuwenhuijzen Kruseman volgens het besluit van het College van Decanen, in het openbaar te verdedigen op woensdag 3 december 2003 om 14.00 uur door

EWALD A.W.J. DUMONT 


\section{PROMOTORES}

Prof. dr. H.J.J. Wellens

Prof. dr. J.F.M. Smits

\section{CO-PROMOTORES}

Dr. L. Hofstra

Dr. C.P.M. Reutelingsperger

BEOORDELINGSCOMMISSIE / ASSESSMENT COMMITTEE

Prof. dr. H.J.G.M. Crijns (voorzitter)

Prof. dr. W.D. Boeckx

Prof. dr. M. Borgers

Prof. dr. E.E. Hack (Vrije Universiteit Amsterdam, Amsterdam)

Prof. dr. C.E. v.d. Wall (Leids Universitair Medisch Centrum, Leiden)

This study was performed at the Cardiovascular Research Institute Maastricht (CARIM). Financial support by the Netherlands Heart Foundation for the publication of this thesis is gratefully acknowledged. The study described in this thesis was supported by a grant of the Netherlands Heart Foundation (NHF 98.195) and the Wynand M. Pon Foundation, Leusden, The Netherlands.

Financial support for publication of this thesis was given by Nexins Research, Theseus Imaging / North American Scientific, Leica, Hamamatsu Photonics and RESCAR. 


\section{CONTENTS}

CHAPTER 1 | GENERAL INTRODUCTION: ACUTE MYOCARDIAL INFARCTION AND APOPTOSIS

CHAPTER 2 GENERAL INTRODUCTION: DETECTION OF APOPTOSIS

CHAPTER 3 | CARDIOMYOCYTE DEATH INDUCED BY MYOCARDIAL ISCHEMIA AND REPERFUSION; MEASUREMENT WITH RECOMBINANT HUMAN ANNEXIN-V IN A MOUSE MODEL

CHAPTER $4 \mid$ REAL-TIME IMAGING OF APOPTOTIC CELL-MEMBRANE CHANGES AT THE SINGLE-CELL LEVEL IN THE BEATING MURINE HEART

CHAPTER 5 | RECOVERY FROM APOPTOSIS IN THE ISCHEMIC HEART

CHAPTER 6 VISUALISATION OF CELL DEATH IN VIVO IN PATIENTS WITH ACUTE MYOCARDIAL INFARCTION

CHAPTER 7 | IN YIVO DETECTION OF APOPTOSIS IN AN INTRA CARDIAC TUMOR

CHAPTER B| GENERAL DISCUSSION

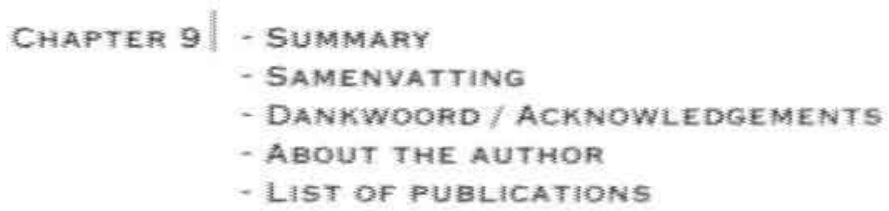





\section{GENERAL INTRODUCTION}

Parts of this introduction are published in:

Visualization of cell death in vivo with the annexin A5 imaging protocol. Reutelingsperger C.P., Dumont E.A., Thimister P.W., van Genderen H., Kenis, H., van den Eijnde S.M., Heidendal G., Hofstra L. I immunol Methods. 2002 Jul $1 ; 265(1-2): 123-32$

Markers of apoptosis in cardiovascular tissues: focus on Annexin V. Van Heerde W.L., Robbert-Offerman S., Dumont E.A., Hofstra L., Doevendans P.A., Smits J.F., Daemen M.J., Reutelingsperger C.P. Cardiovasc. Res. 2000 Feb; 45(3):549-59

Molecular imaging of cell death in intracardiac tumours. Kietselaer B.L., Thimister P.W., Reutelingsperger C.P., Heidendal G.A., Dumont E.A., Boersma H.H., de Bruïne A.P., Hofstra L. Netherlands Heart Journal vol 10 number 7/8, august 2002

Bringing cell death alive. Dumont E.A., Reutelingsperger C.P., Heidendal G.A., Hofstra L. Cardiovascular Toxicology 2003, accepted

Annexin V, the novel tool in in vivo molecular imaging. Dumont E.A., Hofstra L., Crijns H., Wellens H.J., Reutelingsperger C.P., Current Molecular Medicine, invited review, in preparation

Book Chapter: Membrane Alterations in Dying cells. Book: Cell Proliferation and Apoptosis. Van Genderen H., Kenis H., Dumont E.A., van Heerde W., Hofstra L., Reutelingsperger C.P. Editors: Hughes D, Mehmet H. 2003 BIOS Scientific Publishers Ltd, Oxford p. 185-200 
CHAPTER 1

GENERAL INTRODUCTION:

ACUTE MYOCARDIAL INFARCTION AND APOPTOSIS 
In the first part of the chapter we will outline the impact of apoptosis on myocardial ischemia and infarction. Next, we will discuss the role of apoptosis in disease in general and in cardiac disease. The field of apoptosis has developed quickly during the last 10-15 years, and provides us with potential targets for intervention in apoptosis in different diseases, including acute myocardial infarction.

\subsection{ACUTE MYOCARDIAL INFARCTION}

\section{THE BURDEN OF MYOCARDIAL INFARCTION}

Acute myocardial infarction (AMI) is a clinical syndrome that results from injury of myocardial tissue caused by an imbalance between myocardial oxygen supply and demand.'AMI usually occurs bec!ause of a sudden rupture of a vulnerable atherosclerotic plaque in a coronary artery leading to coronary occlusion. ${ }^{2-5}$ Patients with AMI frequently have risk factors for the development of coronary artery disease such as increased cholesterol levels, diabetes, hypertension, smoking, a sedentary life style, and a family history of early coronary artery disease. ${ }^{\prime}$ However, absence of risk factors does not eliminate the possibility of AMI. Each year there are about 1.5 million patients with AMI in the United States and there are approximately 950,000 deaths. ${ }^{1}$ This is 40.6 percent of all deaths or 1 in every 2.5 deaths. Cardiovascular disease claims more lives each year than the next 6 leading causes of death combined. ${ }^{6}$ In patients who survive the acute stage of an AMI, the morbidity and mortality range from 1.5 to 15 times that of the general population. The incidence of re-infarction, sudden death, angina pectoris, cardiac failure, and stroke are substantial. Within 6 years following survival from an AMI, 18 percent of men and 35 percent of women have a recurrent infarction. 8 percent of men and 11 percent of women will have a stroke and sudden death occurs in 7 percent. ${ }^{1}$ Therefore, the disease burden arising from cardiovascular disease remains high and continues to have a high emotional, social and financial impact on our society.

\subsubsection{TREATMENT OF ACUTE MYOCARDIAL INFARCTION}

Treatment of AMI today is focused on re-opening, as early as possible, of the occluded coronary artery: the so-called reperfusion therapy. Large clinical trials have shown that reperfusion therapy with thrombolytic agents and/or invasive coronary intervention (balloon and/or stent) results in smaller infarctions and better survival. However, despite these successes, up to $40 \%$ of patients with acute myocardial infarction develop heart failure, due to loss of myocardial cells during infarction. ${ }^{7}$ Since the heart is minimally able to replace cardiomyocytes lost following myocardial infarction, it is important to find ways to protect the cardiac cells from dying during infarction. ${ }^{8}$ Therefore, 
treatments that aim to inhibit cell death during myocardial infarction deserve serious attention. Despite many promising results in experimental models of myocardial infarction, no benefit of cell death inhibiting compounds has yet been shown in the patient with AMI. ${ }^{9-13}$ Most of these novel treatments attempt to intervene in the apoptotic program, the intrinsic suicide program of the cell.

\section{CELL DEATH DURING AMI: WHEN AND HOW?}

In the last decade, there has been a continuing debate on the presence and contribution of apoptosis to the amount of myocardial injury during ischemia and reperfusion. ${ }^{14-17}$ Until the nineties, most researchers believed that during myocardial ischemia cardiomyocytes mostly died from necrotic cell death. In 1994, the group of Gottlieb showed that rabbit cardiomyocytes in vitro exhibit many features of apoptosis, when subjected to ischemia and reperfusion. ${ }^{18}$ The controversy on apoptosis and necrosis was stirred by a paper of Anversa's group, demonstrating that a substantial fraction of cells dying during ischemia and reperfusion showed signs of apoptotic cell death in a rat model of cardiac ischemia. ${ }^{19}$ The apoptotic cells were identified by morphological criteria, the terminal dUTP nick end labelling assay (TUNEL) and DNA laddering. This finding was intriguing, since it implied that cell death during infarction might be amenable to anti-apoptotic interventions, for instance by novel anti-apoptotic compounds. After the initial finding of apoptosis in the heart following ischemia, many research groups started to focus on this topic. ${ }^{13,20-24}$ In post mortem studies in patients suffering form myocardial infarction and undergoing percutaneous intervention, TUNEL positive cardiomyocytes were observed, suggesting that in myocardial ischemia in humans apoptosis could be an important contributing factor. ${ }^{25,26}$ in addition, researchers reported a decreased infarct size in rats treated with apoptosis inhibiting compounds, like caspase inhibitors. ${ }^{15,27}$ These data suggest that inhibition of one of the key steps in the apoptotic program may be of benefit to limit myocardial injury following infarction.

The finding that apoptosis in the heart occurs following ischemia and reperfusion, has been an inspiration for cardiac researchers, but also fuelled controversy. First, investigators using electron microscopic (EM) analysis to demonstrate apoptosis of cardiomyocytes failed to find the typical apoptotic cardiomyocytes in the myocardium following ischemia. ${ }^{14}$ Instead, they observed cell swelling, swelling of mitochondria and disruption of microtubuli. These are characteristics of necrotic or oncotic cell death. Secondly, other research groups observed that oncotic cardiomyocytes, exhibiting swelling and mitochondrial disruption may be TUNEL positive. This finding may explain why some researchers have found TUNEL positive cardiomyocytes in hearts subjected to ischemia and reperfusion. ${ }^{28-30}$ 
One of the reasons why the debate on apoptosis versus necrosis is still ongoing might be the lack of a method that is able to detect apoptosis in a rapid and accurate way. The current techniques, such as DNA laddering, TUNEL assay and EM analysis require specimens from the tissue of interest. This limits the temporal and spatial resolution of these techniques. Therefore, we do not know how rapidly the apoptotic program is activated following ischemia and reperfusion and how apoptosis proceeds once activation occurs. This information is needed to define the potential therapeutic window of anti-apoptotic compounds. Another key question is which fraction of dying cells undergo apoptosis and which fraction of dying cells undergo necrotic cell death. This information is needed to define the potential benefit of anti-apoptotic compounds, since these compounds, at least in theory, will not prevent classical necrotic cell death. A third critical question is the definition of the point of no return in the cell death program in cardiomyocytes following ischemia and reperfusion. One of the attractive concepts in apoptosis is that cells may have some activation of the cell death program, but will not die unless a critical point in the cell death program has been reached. This is the so-called point of no return. The point of no return probably relates to activation of key steps in the apoptotic program, such as the activation of executioner caspases, e.g. caspase-3. The passage of the point of no return is not yet defined in cardiomyocytes in vivo following ischemia and reperfusion. Insight into the regulation and kinetics of the cell death program will guide us to define the best possible anti-apoptotic strategy following ischemia and reperfusion of the heart.

In conclusion, the lack of knowledge on the kinetics and mechanisms of cell death in the heart, which is, at least in part, due the absence of a suitable detection method, hampers the implementation of cell death inhibiting strategies into clinical trials. In the next part of this chapter we will look at potential targets for inhibition of programmed cell death. In chapter 2, we will examine the different methods to detect programmed cell death and introduce the concept of Annexin-A5 as a method to detect programmed cell death.

\subsection{Apoptosis}

In contrast to necrosis or accidental cell death, apoptosis is defined by tightly regulated biochemical steps that finally result in activation of executioners of the cell death program, the caspases, ${ }^{27,31-37}$ In the last 10-15 years a large number of researchers have devoted their efforts to the elucidation of the regulation of apoptosis. One important consequence of this work is that we are overwhelmed with potential targets to intervene in the cell death program. The interventions may be pro-apoptotic in diseases such as cancer, or anti-apoptotic in diseases such as an acute myocardial infarction and 
stroke. ${ }^{38-44}$ A major challenge for translational scientists is to find the targets that will be of clinical benefit. ${ }^{45}$ This field of translational research in apoptosis will benefit from rapid methods to measure or to visualize programmed cell death in vivo. In the next paragraph we will first discuss the history of apoptosis research, the role of apoptosis in disease and the various morphological characteristics of programmed cell death. Then we will discuss our current understanding on how apoptosis is biochemically regulated and address the implications of these findings for cardiac apoptosis.

\subsubsection{HISTORY OF APOPTOSIS RESEARCH}

What we would today call true apoptosis, or programmed cell death, was first recognized by Carl Vogt in 1842 who saw dying cells in the neuronal system of developing toad embryos. ${ }^{46}$ However, it is thought that the very first cells described, those from cork, by Hooke in 1665, were from corpses that had died through the apoptotic pathway. ${ }^{47}$ After studies by Walther Flemming in 1885 and others, cell death remained a subject of some interest in insect physiology. For instance, llya Mechnikov won the Nobel prize in 1908 for his discovery of phagocytosis. In 1948 Saunders observed cell death in chick limbs and in 1949 Hamburger begins the exploration of the nerve growth factor. ${ }^{46}$ The morphological alterations in programmed cell death were described for the first time in 1964, in the review of Saunders named 'shrinkage necrosis', In 1972 Kerr first coined the term apoptosis to describe the process of programmed cell death. Based on the characteristic morphology, it was proposed in 1972 that death of normal but redundant cells (physioptosis), as well as some pathological ones (pathoptosis), are suicides, ${ }^{48}$ i.e. the cells activate an intracellular death program and kill themselves in a controlled way. From 1977, cell death genes have been studied extensively in the nematode worm Caenorhabditis elegans. From then on DNA-ladders were observed and apoptosis genes identified. ${ }^{46}$ Apoptotic cells shrink and are then rapidly eaten by neighboring cells, before there is any leakage of their contents. Their remnants, called apoptotic bodies or blebs, are eaten and digested so quickly by neighboring cells and phagocytes, that usually few dead cells are seen, even when large numbers of cells have died. This could be the reason why apoptosis was neglected for so long, ${ }^{49-52}$

\subsubsection{ROLE OF APOPTOSIS IN HEALTH AND DISEASE}

The insight that both normal and abnormal animal cells have a built-in death program was a crucial one, as programmed cell death is essential for normal development in morphogenesis, to control cell number, and as a defensive strategy to remove infected, mutated, or damaged cells. ${ }^{47,53}$ When a cell in an organism dies due to a process encoded by that organism for the purpose of killing its own cells, this mode of cell death can be considered to be a physiological process. The great majority of our cells are 
destined to die by just such a mechanism; relatively few die as a resu of injury or inability to sustain their own viability. ${ }^{54}$ In humans every second about undred thousand cells are reproduced by mitosis, and a similar number die by apoptors. Most of the cells reproduced during mammalian embryonic development undergoshysiological cell death before the end of the perinatal period. ${ }^{47,55,56}$ In this way cell leath helps to sculpt parts of the body, carving out cavities and separating digits. Durinģour life span, over $99.9 \%$ of our cells undergo the same fate. ${ }^{47}$ It is being increasingl realized that either excessive apoptosis or lack of appropriate apoptosis plays a ole in many diseases. In oncogenesis, loss of normal apoptosis results in excessive ced numbers. In heart failure, apoptosis is related to progressive loss of functioning myoytes while in autoimmune disorders diminished apoptosis permits immunologically cmpetent cells to survive and to continue damaging healthy organs. ${ }^{57-64}$

Deregulation of apoptosis is believed to be a major contributor to theetiology and pathology of cardiovascular diseases, congenital malformations, neurdegenerative diseases and cancer. ${ }^{41,65}$ Its general acceptance took another 20 yars after the discovery by Kerr. Studies in Caenorhabditis elegans identified genes dedicated to apoptosis and its control. ${ }^{66}$ With the discovery of similar genes in humans, the cell death field transformed radically. ${ }^{67,68}$

\subsubsection{DifFERENT MORPHOLOGIES OF PROGRAMMED CELL DEATH}

Current thinking indicates that apoptosis and necrosis constitute two extremes of a spectrum. ${ }^{34}$ Apoptosis is a genetically programmed and energy-requiring complex series of events that permits the cell to die without inducing an inflammatory response. The classical changes in apoptosis include cell shrinkage and formation of apoptotic bodies. ${ }^{33.69}$ The activation of endonucleases results in cleavage of chromatin into typical oligonucleosomal-length DNA fragments of $180-200$ basepairs and its multiple. The chromatin marginalizes in dense crescent shaped aggregates under the nuclear envelope as the nucleus becomes segmented. The sarcolemmal integrity is preserved but convolution of membrane subdivides the cell into clusters of membrane-bound sub-cellular organelles referred to as apoptotic bodies. Since cell swelling and sarcolemmal disintegration does not occur, cytoplasmic contents are not released into the extra-cellular space and inflammation is not provoked. The apoptotic bodies are eventually phagocytized and removed. ${ }^{50-52,70-74}$ Identification of such cells is feasible by histochemical characterization through biochemical markers (such as caspase activation and cytochrome $\mathrm{c}$ release from mitochondria) or morphologically by light and electron microscopic examination. ${ }^{75-81}$ in contrast, cells that die accidentally in response to an acute injury often do so by an uncontrolled process called necrosis. In 
necrosis, cells swell and burst, spilling their contents over their neighbors, eliciting a damaging inflammatory response. It is a disorderly process and results in local inflam. mation. ${ }^{34}$

Recent findings have shown that intermediate types of cell death exist, that may have characteristics of both apoptotic and necrotic cell death. 29, 14,82-86 Some researchers came up with unique terminology to describe these intermediate types of cell death ('necroptosis' or 'aponecrosis'). Another classification has defined these intermediate types of morphology as 'programmed cell death with apoptotic morphology' and 'programmed cell death with necrotic morphology', respectively. ${ }^{34}$ The latter type of cell death may be the most relevant in the ischemic heart, where mostly necrotic cardiomyocytes are found, but activation of the apoptotic program is also observed, as reflected by positive TUNEL assay and DNA laddering. ${ }^{14}$ The fact that activation of the apoptotic program occurs during cardiac ischemia suggests that at least part of the cells that are lost during ischemia may be saved through intervention in the cell death program. ${ }^{14}$ Post-mortem studies in patients with acute myocardial infarction have shown a high frequency of TUNEL positive cardiomyocytes suggesting substantial activation of the cell death program in the infarcted area. ${ }^{26}$ The apoptotic cells are predominantly seen in the infarct borderzone where the severity of ischemic insult is milder. However, upon reperfusion the infarct center shows an extensive mixture of apoptotic and necrotic cells as some of the doomed cells are rescued from necrosis but die by apoptosis. Furthermore, reperfusion injury may accelerate apoptosis in the cells in the center of the infarct. ${ }^{16,18,26,82}$ In the next paragraph we will discuss the potential targets for intervention in the cell death program.

\subsubsection{CELL DEATH PATHWAYS}

A lot of pioneering work in apoptosis signaling research has been done in the worm $\mathrm{C}$. elegans and the fruit fly Drosophila melanogaster. ${ }^{55,68,87-103}$ The first studies in C. elegans identified two genes, CED-3 and CED-4 (CED for cell death abnormal), required for apoptosis in the worm. If either gene is inactivated by mutation, the 131 cell deaths that normally happen during the development of the worm (which has 1090 cells when mature) fail to occur. ${ }^{66}$ Remarkably, the mutant worms with 131 extra cells have a normal life span. In contrast, more complex animals cannot survive without apoptosis: mutations that inhibit apoptosis in the fruit fly Drosophila melanogaster, for example, are lethal early in development ${ }^{88}$, as are some mutations in mice. ${ }^{104}$

The protein encoded by the CED-3 gene was found to be very similar to the human protein called interleukin-1-converting enzyme (ICE). ${ }^{35}$ The similarity between the CED-3 and ICE proteins was the first indication that the death program depends on 
protein cleavage (proteolysis). Soon new members of the CED-3/ICE family of proteases were identified, including more than ten in humans, many of which become activated in apoptosis. They are all cysteine aspartic acid specific proteases, and therefore called caspases. ${ }^{105}$ Each caspase is made as a large, inactive precursor or procaspase, which is activated, usually by another caspase. ${ }^{35}$ In apoptosis, caspases are activated in an amplifying proteolytic cascade, cleaving one another in sequence. ${ }^{81}$

The molecular biology and biochemistry of the apoptotic death machinery are far from being completely resolved. The apoptotic process shows great diversity in the signaling pathways by which it is induced in various cell types. Beyond this diversity, three functionally distinct phases of apoptosis, common to all cell types, can be distinguished. ${ }^{54,106}$ First, the initiation phase starts by death inducing signals, like Fas ligand and tumor necrosis factor $\alpha$ (TNF $\alpha$ ) ref.107 a lack of growth and/or survival signals, or DNA damage ${ }^{108}$, which may devise the cell to prepare for suicide. This preparation may proceed in a manner, which involves a subclass of proteases, the so-called upstream or decision caspases. ${ }^{36}$ The initiation phase results in the activation of the second more general decision phase, in which the cell is still able to make the decision to live. This phase is characterized, in most cases, by the involvement of the mitochondrion. ${ }^{78.109}$ This organelle provides the molecular links between the upstream initiation phase and the downstream execution phase, by releasing apoptosis inducing factor ${ }^{110}$, cytochrome $\mathrm{c}^{\mathrm{ref}} .79$, and procaspases-2, -3 and $-9 .^{111,112}$ When the cell is committed to die, and thus the point of no return has been passed, the third phase, the execution phase, is activated. This phase is characterized by the activation of the downstream or effector caspases ${ }^{36}$, which subsequently orchestrate a sequence of events by their hierarchical activation. ${ }^{80}$ These events include loss of cell junctions, loss of cell adhesion, cell shrinkage, chromatin condensation and margination, nuclear pyknosis and fragmentation, membrane blebbing, and disassembly of the cell into membrane-enclosed vesicles (apoptotic bodies). ${ }^{48}$ Several events have been identified on the biochemical level, including the degradation of DNA into fragments of multiples of -200 base pairs, the proteolytic cleavage of poly(ADP-ribose) polymerase (PARP) and cytoskeleton components, and the cell surface exposure of phosphatidylserine (PS). 113-121 Two distinct, but mutually not exclusive, pathways have been described in apoptotic cell death in mammalian cells, one occurring through death receptors (extrinsic pathway) and the other through the mitochondria (intrinsic pathway). $22,107,122$ 


\section{CELL DEATH RECEPTOR MEDIATED PROGRAMMED CELL. DEATH} (EXTRINSIC PATHWAY)

In the death receptor pathway soluble or cell surface death ligands, such as TNF $\alpha$ and Fas ligand bind to their corresponding receptors inducing the recruitment and activation of caspase- 8 or $-10^{\text {ref } 123}$, thereby activating the cell death machinery (Figure 1). Activation of caspase precursors is achieved by adaptor proteins. Caspase 8 is activated when death effector domains (DEDs) bind to the C-terminal DED in the adaptor FADD. ${ }^{124}$ These caspases activate other downstream caspases, such as caspase-3, -6 , and -7, either directly (by proteolytic processing), or indirectly by cleaving Bid, a BCl-2 family member. Bid also activates the mitochondrial pathway by permeabilizing the mitochondrial membrane. ${ }^{123}$ Once activated, the downstream of effector caspases fragment cellular proteins resulting in orderly deconstruction of the cell. The effector caspase-3 cleaves the inhibitory subunit of the endonuclease ICAD, which leads to activation of CAD and fragmentation of nuclear DNA. ${ }^{25,126}$

\section{MITOCHONDRIAL MEDIATED PROGRAMMED CELL DEATH (INTRINSIC PATHWAY)}

In the mitochondrial pathway, the central event is the translocation of cylochrome $c$, AIF, and endonuclease G from mitochondria to the cytoplasm (Figure 1). ${ }^{123}$ This pathway is initiated by death stimuli that include ischemia and reperfusion, oxidative stress, genotoxic stress, UV radiation, chemotherapeutic agents and calcium excess. Once in the cytoplasm, cytochrome c binds Apaf-1 stimulating its oligomerization and the subsequent recruitment of procaspase-9 into a large complex termed the apoptosome. Following its activation, caspase-9 activates downstream effector caspases. The death receptor pathway and mitochondrial pathway are linked by Bid, which is cleaved by caspase- 8 following death receptor activation. Subsequently, the carboxy fragment of Bid, termed $\mathrm{BBid}$, translocates to the mitochondria where it inserts into the outer mitochondrial membrane and stimulates cytochrome c release through its interactions with Bax and/or Bak, which are pro-apoptotic proteins. Bcl-2 and $\mathrm{BCl}-\mathrm{xL}$, anti-apoptotic proteins, which are also components of the outer mitochondrial membrane, inhibit cell death indirectly by competing with Bax and Bak for $\mathrm{Bid}$ and possibly through their direct interactions with Bax and Bak. ${ }^{127}$ Other inhibitors include ARC or FLIP (inhibitor of caspase- 8 activation), and XIAP or related proteins (inhibitors of caspases-3 and -9). When apoptosis is induced, in addition to cytochrome $C$, SMAC/Diablo is also released from the mitochondria and binds to XIAP precluding its inhibition of caspases. (Personal communications Dr. Richard Kitsis, Albert Einstein College of Medicine, New York, NY). 


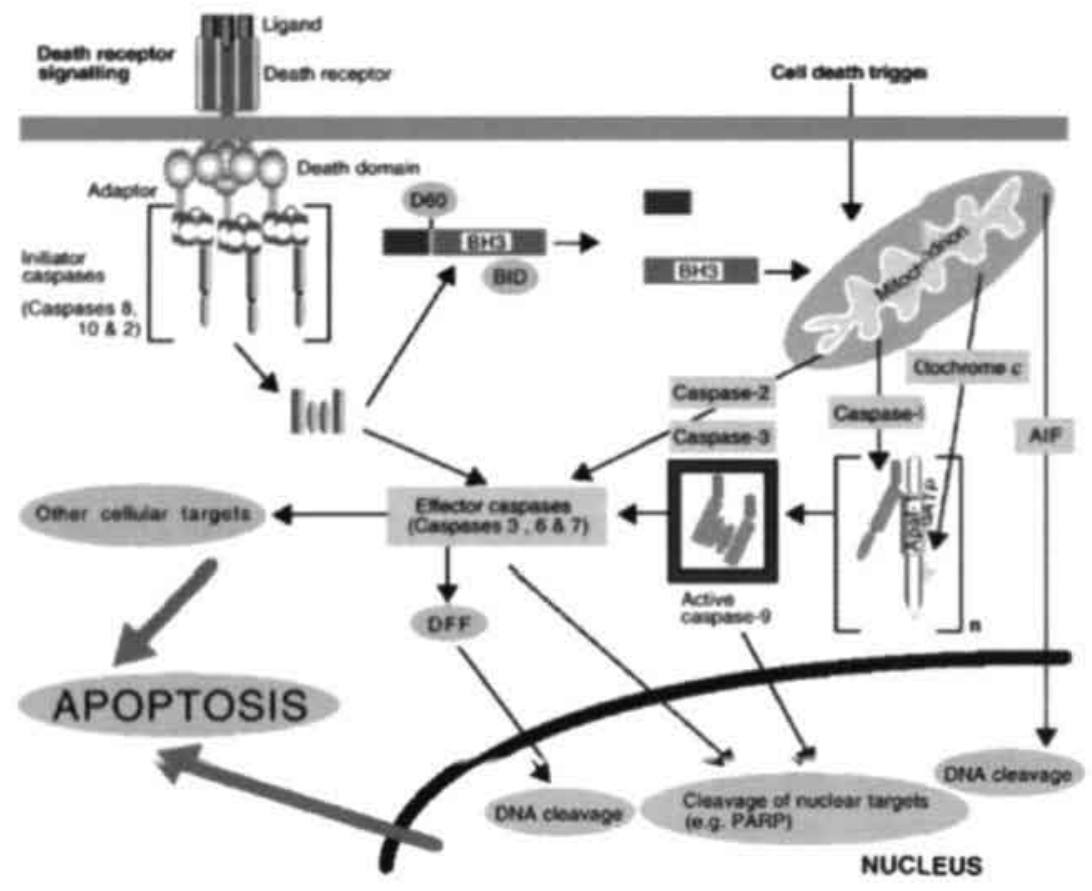

Figure 1 On the left side the extrinsic pathway is depicted, on the right side the intrinsic pathway of apoptosis induction is shown.

\section{STRATEGIES FOR INTERVENTION IN THE CELL DEATH PROGRAM}

Many viruses have developed strategies for blocking apoptosis, to prevent infected cells from committing suicide before the virus has had a chance to multiply. Some viruses produce proteins that bind to caspases and block their activity. ${ }^{128-131}$ Although these can be used experimentally to inhibit caspases, they are too large to enter cells, and one has either to inject them into the cell or to introduce the genes that encode them. A more convenient strategy is to synthesize modified small peptides that can enter cells and block the active site of caspases. ${ }^{35}$ Such inhibitors are now widely used by cell biologists: they not only block most forms of apoptosis in cultured cells, but also some forms of apoptosis in experimental animals. Whether they will be useful in human disease remains to be seen.

In neurodegenerative diseases, such as Parkinson's and Alzheimer disease, where nerve cell loss occurs slowly, it is still unclear if the affected cells die by apoptosis and, if they do, whether it would be helpful to keep them alive ${ }^{65,106,132-136}$ 
In cancer the goal is the opposite, that is, one would like drugs that will activate apoptosis in tumors. Most of the cell-killing anti-cancer drugs used today work at least. partly in this way. Unfortunately, they also affect normal cells, which is why they can have such severe side effects. The challenge is to find ways to kill cancer cells specifically. The death program is often regulated abnormally in cancer cells. For instance, $\mathrm{BCl}-2$ or other apoptosis inhibitors may be increased, or the p53 gene may be inactivated by mutation. However, the death program itself never seems to be completely inactivated in cancer cells. $38,42,44,106,137-143$

A major difficulty in the anti-apoptotic treatment of myocardial infarction may be that damage occurs very rapidly following reperfusion. ${ }^{144}$ Paradoxically, it has been observed that opening the infarct related artery is a major trigger for inducing cell death in the heart. The ideal drug to prevent myocardial cell loss during myocardial infarction, therefore, has to reach the myocardium rapidly following reperfusion and in a sufficiently high concentration. This is hampered by the fact that reperfusion is often incomplete, which prevents the build-up of sufficient concentration of the compound to prevent cell loss. ${ }^{7,15-17,144-145}$ Another concern is that compounds that inhibit the cell death program could theoretically facilitate the formation of tumor cells, since escape from cell death could provoke the development of a tumor cell. This issue is hard to study, since there may be a considerable delay between the formation of a pre-cancerous cell and the outbreak of cancer. Together, the ideal heart-salvaging drug should reach the injured myocardium rapidly and remain locally in a high enough concentration, minimizing the risk of developing cancer. 
CHAPTER 2

GENERAL INTRODUCTION:

DETECTION OF APOPTOSIS 
In this chapter, we discuss conventional techniques to detect apopsis, such as DNA laddering and the TUNEL assay. Next we will discuss the use of Anexin-A5 for the detection of apoptosis in vitro and introduce the possibility to ue Annexin-A5 for detection of apoptosis in vivo.

\section{1. DETECTION OF APOPTOSIS IN GENERA.}

The original techniques to measure apoptosis employed the erly definition of apoptosis based on morphology. During the last decade, techrques have been extended to biochemistry, molecular biology and immunology dueo our expanding knowledge about the molecular mechanisms of apoptosis. These techiques have been applied to detect apoptosis in a wide variety of diseases. Exampls of detection in cardiovascular disease are given in Table 1. Despite our increasing isight in the initiation and decision phases of apoptosis, most of these techniques arbased on what is happening during the execution phase. The mechanistic concepts ofhe various detec-

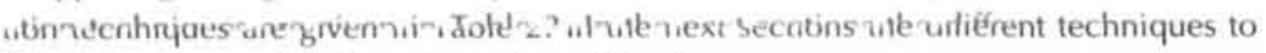
detect programmed cell death will be outlined.

\subsection{MORPHOLOGICAL CHANGES}

\subsubsection{LIGHT MICROSCOPY (LM)}

The first technique used to detect apoptosis was LM to study the morphology of the cell. Membrane blebbing, nuclear pyknosis and fragmentation, hallmarks of cells undergoing apoptosis, can thus be visualized on haematoxylin and eosin stained histological sections. A disadvantage of $\mathrm{LM}$, however, is its low sensitivity especially since apoptotic cells are rapidly removed from the tissues by phagocytosis, which can be completed within $30-60 \mathrm{~min}$ following the onset of apoptosis. In the myocardium, cells with apoptotic morphology have been observed incidentally. Hence, it is very well possible that L.M reveals the tip of the iceberg. ${ }^{29,48}$ Another disadvantage is that detailed kinetic studies on apoptosis are painstaking and cumbersome.

\subsubsection{ELECTRON MICROSCOPY (EM)}

EM has the great advantage of high specificity. Morphological changes can be detected on a subcellular level, thereby increasing sensitivity and specificity as compared to LM. The specific characteristics of apoptosis, such as shrinkage of cells, chromatin condensation, an intact cell membrane and normally shaped mitochondria can be visualized in 
Table 1 Examples of cardiovascular entities in which apoptosis has been reported

Cardiovascular entity

Method*

Vascular wall

Atherosclerosis

Diabetes

Hypertension

Vascular allograft rejection

Vascular development

Vascular remodeling

Vascular restenosis

Myocardium

Acromegalic cardiomyopathy

Arrhythmogenic right ventricular cardiomyo-

pathy

Cardiac allograft rejection

Cardiac development

Cardiac disease in Down Syndrome

Cardiac hibernation

Cardiac preconditioning

Cardiac remodeling

Cardiac reperfusion injury

Chagasic myocarditis

Congenital AV block

Dilated cardiomyopathy

Heart failure

Hypertensive heart disease

Myocardial infarction

Transplant coronary artery disease

Viral myocarditis

-Method: A: microscopy; B: cytoplasmic changes; C: DNA laddering; D: caspase activity; E:

membrane permeability; F: membrane changes; G: DNA strand break labeling.

great detail. The cumbersome workup of the material and the limited number of cells that can be studied, make it unsuitable for routine use. Therefore, EM is considered to be a valuable, specific and sensitive, but merely a qualitative methodology for the detection of apoptosis. ${ }^{184}$
C. $\mathrm{G}^{15 \pi}$

F $146, \mathrm{G}^{147+149}$

A, G 130

$\mathrm{C}^{127.151 ; \mathrm{G}^{151}}$

$F^{152} ; G^{160.132}$

$G^{153}$

C $^{154,155}, \mathrm{E}^{134} ; \mathrm{G}^{154-156}$

$\mathrm{A}^{157} ; \mathrm{G}^{\text {147-157 }}$

A, G 150,160

$A^{161} ; D^{162}, F^{163,164}, G^{161-164}$

D, F ${ }^{165}, \mathrm{C}^{165-167}$

$G^{168}$

$\mathrm{A}^{169}, \mathrm{C}^{170}, \mathrm{G}^{169,170}$

B, $\mathrm{G}^{171}$

C 172,173

A, C, G ${ }^{174}$

$A^{175}, B^{176}, G^{175,176}$

A 177

$G^{170}$

$B^{61}, C^{173,179}, G^{61.173 .179}$

$\mathrm{G}^{180}$

$\mathrm{A}^{30}, \mathrm{G}^{19,30}$

F, G 18

B, $D^{182}, G^{182,183}$ 
Table 2 Overview of techniques used to detect apoptosis

\section{Technique}

Specimen

Use

Morphological changes

Light microscopy

Electron microscopy

Flow cytometry

Cytoplasmic changes

Caspase activity

Calcium flux

Mitochondrial dysfunction

DNA fragmentation

DNA laddering

DNA content by flow cytometry

DNA strand break labeling

$\begin{array}{ll}\text { Fixed tissue } & \text { In vitro } \\ \text { Fixed tissue } & \text { In vitro }\end{array}$

In vitro

Fixed tissue In vitro

Lyzed cells

Intact celis

Intact cells

$\begin{array}{ll}\text { Lyzed cells } & \text { In vitro } \\ \text { Homogenized tissue } & \text { In vitro } \\ \text { Fixed cells } & \text { In vitro } \\ \text { Fixed tissue } & \text { In vitro }\end{array}$

Membrane alterations

Membrane permeability

Membrane changes

In vitro

In vivo

In vitro
Intact cells

Pro

Contra

Preservation of histological context

All phaser of apoptosis

Golden stundard

High specficity

Rapid anc quantitative analysis Low specificity

High specficity

Population based information

Early phas: of apoptosis

Low specificity

Low specificity

Late phase of apoptosis

Tedious procedure$$
\text { w specificity }
$$

Late phase of apoptosis

Population based information

Late phase of apoptosis

Late phase of apoptosis

Phagolysosomal staining

$\begin{array}{ll}\text { Intact cells } & \text { In vitro } \\ \text { Intact cells } & \text { In vitro } \\ \text { Intact tissue } & \text { In vivo }\end{array}$

Stains also necrotic . pllk.

Stains also necrotic cells

In vivo molecular imaging
Late phaseof apoptosis

Rapid andquantitative analysis

All phases of apoptosis 


\subsubsection{FLOW CYTOMETRY (FC)}

FC enables the analysis of a relatively large number of cells on a per cell basis in a short period of time. Assay-required manipulation of cells is in most cases restricted to a minimum. As the apoptotic cell shrinks (in contrast to the necrotic cell which shows swelling) and subsequently condenses, the forward scatter decreases and sideward scatter slightly increases. ${ }^{184} \mathrm{FC}$ can be performed on cultured non-adherent as well as adherent cells. In general, cells have to be in suspension for analysis. This feature limits its applicability as a routine technique. $\mathrm{FC}$ is therefore an excellent tool for in vitro studies but not suitable for the detection of apoptosis in tissues, since it lacks the histological context.

\subsection{CYTOPLASMIC CHANGES}

The apoptotic process causes a dramatic change in the biochemistry of the cytoplasm. Some cytoplasmic parameters have been found to be useful markers for the detection of the apoptotic process. These include the detection of key steps in the signalling of the apoptotic program such as activation of caspases, and "de novo" antigens, which arise from proteolytic action of caspases. In addition detection of biochemical changes such as an increase in $\mathrm{Ca}^{2+}$-ion concentration, and release of mitochondrial proteins into the cytosolic compartment are used as markers for the presence of apoptosis.

\subsubsection{CASPASE ACTIVITY}

Caspases constitute a family of cysteine proteases that cleave target proteins at an aspartate residue in a recognition sequence. ${ }^{36,185}$ Currently, various fluorogenic and chromogenic substrates are available for different active caspases. Most of these substrates are cell impermeable and require cell and tissue homogenization to measure the caspase activity. ${ }^{186}$ These substrates are in general not specific for individual caspases. This makes it difficult to attribute fluorogenic and chromogenic activity to one specific caspase. Caspase activity can also be measured by immunohistochemical techniques using antibodies against neoepitopes, which arise from proteolytic activation. ${ }^{187-189}$ Caspase activity can also be detected immunologically by using antibodies, which recognize only the cleaved substrates of caspases. Recently, antibodies were described that recognize caspase-cleaved cytokeratin $18 \mathrm{ref} .187$, actin ${ }^{188}$ and PARP. ${ }^{189}$ These immunological approaches require fixation of the specimen and are therefore not suitable for in vivo assessment. 


\subsubsection{CALCIUM FLUX}

Activation of the apoptotic pathways is in most cases associated with an increase in cytosolic $\mathrm{Ca}^{2+}$ concentration. Such an increase can be measured by using $\mathrm{Ca}^{2+}$ indicators like fura-2. ${ }^{190} \mathrm{~A}$ drawback of this technique is that the rise in cytosolic calcium is not exclusive for apoptosis and can also be associated with the activation of a variety of signaling pathways, which do not lead to the execution of apoptosis. ${ }^{191}$ Furthermore, a lack of sensitivity has been observed, because apoptosis may proceed in the absence of $\mathrm{Ca}^{2+}$ changes. ${ }^{192}$ Finally, it has to be said that the currently available indicators are only useful for in vitro assays.

\subsubsection{MITOCHONDRIAL DYSFUNCTION}

A decrease in mitochondrial membrane potential is an early feature of apoptotic cell death and is considered to be close to the point of no return in the apoptotic program. The mitochondrial potential can be measured by a variety of fluorescent probes, which accumulate in the mitochondrion, as a function of the membrane potential. Collapse of the mitochondrial membrane potential due to apoptosis, will result in a diminished ability of these fluorochromes to accumulate in the mitochondria. ${ }^{193}$ Moreover, the translocation of several mitochondrial proapoptotic proteins from the intermembrane space into the cytosol can be measured. These proteins include apoptosis inducing factor (AIF) ref.110, cytochrome $c$ ref.79, and procaspase-2, -3 and $-9 .{ }^{110,111}$ Translocation of these proteins can be visualized immunohistochemically, using specific antibodies. 194,195 The drawback of these approaches may be their low sensitivity, since certain death pathways recently described, circumvent the mitochondrion and activate the downstream executioner directly. ${ }^{194}$

\subsection{DNA FRAGMENTATION}

\subsubsection{DNA LADDERING}

Degradation of nuclear DNA is one of the key features of apoptosis. During apoptosis activated endonucleases cleave the DNA into fragments of multiples of 180-200 base pairs. These fragments appear as a DNA ladder on agarose gels. ${ }^{25}$ One limitation of this technique is the large quantities of degraded DNA required to visualize a ladder pattern. Selective amplification of DNA fragments by ligation-mediated polymerase chain reaction (PCR) reduces this need. ${ }^{196}$ A major disadvantage, however, is loss of tissue morphology, which renders the localization and identification of apoptotic cells impossible. In some cases apoptosis only generates high-molecular-weight DNA fragments, thereby lowering sensitivity of this technique. 110 


\subsubsection{DNA STRAND BREAK LABELING}

The presence of $3^{\prime}$ hydroxyl-termini at the DNA strand breaks, characteristic of endonuclease-cleaved DNA, can be detected by a labeling reaction with modified nucleotides, such as biotin;, or fluorescein-labeled dUTP. This reaction requires enzymes like terminal deoxynucleotidyltransferase (TdT) or DNA polymerase. The commonly used techniques are the in situ nick end labeling (ISEL) technique using DNA polymerase ${ }^{129}$ and the TdT-mediated X-dUTP nick end labeling (TUNEL) technique (Figure 1). ${ }^{197}$ Both techniques stain the nuclei of the cells and vesicles in the tissue. ${ }^{198}$ Recent improvements of the protocol, to exclude the nonspecific staining of $\mathrm{Ca}^{2+}$ filled vesicles and RNA splicing factors, provide more consistent staining results. ${ }^{148,199} \mathrm{~A}$ limitation is the fact that the TUNEL staining is only positive $>4$ hours after apoptosis initiation, which makes it not suitable for experiments of shorter duration.

\subsection{PLASMA MEMBRANE ALTERATIONS}

\subsubsection{MEMBRANE PERMEABILITY}

Apoptosis is marked by altered cell morphology while the plasma membrane excludes the uptake of dyes such as trypan blue and propidium iodide. This phenomenon has great advantages with respect to specificity, as it allows discrimination between apoptotic and necrotic cells. Especially, the combined analyses of morphological changes and nonpermanent dye uptake, due to altered membrane permeability, make flow cytometric analysis very useful. ${ }^{200}$ However, because of the toxicity of these dyes, this approach is less suitable for in vivo detection of apoptosis.

\subsubsection{MEMBRANE CHANGES}

Apoptotic cells express PS on their outer leaflet, which can be measured by derivatisation with fluorescamine and subsequent analysis of the derivatized, extracted membrane lipids by two-dimensional thin layer chromatography. ${ }^{113}$ Furthermore, incorporation of the hydrophobic dye merocyanine 540 into the cellular membrane shows a loosely packed membrane, characteristic of apoptotic cells. ${ }^{113}$ Both features indicate that the plasma membrane is altered due to the apoptotic process. It is obvious that the above-mentioned techniques are only suitable for in vitro analyses. 


\subsection{LIMITATIONS OF THE CURRENTLY AVILABLE TECHNIQUES}

The most important limitation of the techniques described above is hat these methods measure parameters of the late execution phase of apoptosis (Tabl 2). It is expected that cells in this phase are removed from the tissue by phagocytosis. Hence, measuring apoptosis in cardiovascular tissue by these techniques harbors therisk of underestimating this process. It will be of great advantage if techniques as available which measure parameters that are active at the transition from the decisic to the execution phase. Also, analysis of only one parameter will in most cases notesult in sufficient sensitivity and specificity. This can be improved by measuring mulple parameters. A general disadvantage of the current methods is that they are single ndpoint measurements, which do not provide information of the dynamics of the apptotic process in the tissues.

Most techniques can only be performed after fixation of the materiabr after lysis of the celís. Witri respect to cardiovascular researcti oniý the IUNEL/SEL' gives information on the localization of apoptosis in situ. LM and EM are time consuming because, especially in myocardium, where typical morphological changes are rare. FC requires cells in suspension whereas assessment of DNA laddering requires cell/tissue homogenates. ${ }^{201}$ Therefore, there is a need for new methods to gain more understanding of the role of apoptosis in physiology and pathology of the cardiovascular system, with a high specificity and sensitivity which can be used in in vitro and in in vivo models with high reproducibility.

\subsection{ANNEXIN-A5, A NEW MARKER FOR THE DETECTION OF APOPTOSIS}

In 1992, Fadok et al. established the fundamentals for a novel apoptosis detection methodology by showing that apoptotic cells expose phosphatidylserines (PS) at their cell surface. ${ }^{113}$ This observation triggered us to develop a novel technique to measure apoptosis using Annexin-A5. The basis of this technique is simple, yet elegant. Annexin-A5 is able to bind to PS-exposing membranes in a calcium dependent manner. ${ }^{202}$ Conjugation of Annexin-A5 to detectable prosthetic groups, like fluorescein and biotin, thus allows the detection of cells, which expose PS. ${ }^{116,120,203,204}$ The sensitivity and specificity of the Annexin-A5-based assay depends on the biological properties of PS, and the physicochemical property of Annexin-A5 to bind to PS. Below, these two aspects will be addressed in more detail. 


\subsubsection{PS LOCALIZATION AND (PATHO)PHYSIOLOGICAL SIGNIFICANCE}

The aminophospholipid PS localizes predominantly in membrane leaflets facing the cytosol as was first shown for erythrocytes and platelets and later for nucleated cells. ${ }^{121,205,206}$ This PS asymmetry of the plasma membrane is generated and maintained by an aminophospholipid translocase, which selectively transports aminophospholipids from the outer to the inner leaflet, thereby creating a situation in which PS is exclusively localized to the leaflets facing the cytosol. ${ }^{121,205,206}$

Blood platelets were the first cells in which it was demonstrated that a change of PS asymmetry could be caused by the action of agonists like thrombin and collagen. ${ }^{207}$ Stimulation of platelets results in a rise of cytosolic $\mathrm{Ca}^{2+}$, which on one hand inhibits the aminophospholipid translocase and on the other hand, activates a so-called scramblase, which scrambles the phospholipid species symmetrically over the two leaflets. ${ }^{208}$ Within minutes the architecture of the plasma membrane is changed such that the platelet exposes significant amounts of PS at its outer plasma membrane leaflet. Comparable mechanisms appear to operate during apoptosis giving rise to the cell surface exposure of PS (Figure 1). ${ }^{113,209}$

\subsubsection{FUNCTIONS OF PS IN APOPTOSIS}

Cell surface exposure of PS has a functional significance in the removal of senescent and dying cells from the tissue. The reticuloendothelial system recognizes PS by receptors and removes PS-exposing cells, like aged erythrocytes, from the circulation. ${ }^{210} \mathrm{~A}$ similar scavenging system appears to be operational in tissues, where phagocytes recognize and engulf PS-exposing cells through receptor mediated processes. ${ }^{209}$ Hence, surface-exposed PS appears to be one of the signals to communicate termination of existence to the environment, and fulfills a distinct role in the physiological process to remove unwanted and superiluous cells from the tissues. It is therefore not surprising that surface exposure of PS is an event that occurs while the plasma membrane integrity is not compromised.

\subsubsection{ANNEXIN-A5 AND ITS BINDING TO PS}

Annexin-A5 was originally isolated from the human umbilical cord artery by virtue of its anticoagulant activity ${ }^{211}$, which, in retrospect, can be explained by its binding to and shielding of negatively charged phospholipids. 202,212 In model systems, Annexin-A5 hardly associates with phosphatidylcholine and sphingomyelin $\left(a t<5 \mathrm{mM} \mathrm{Ca}^{2+}\right.$ ) ref.202, but it avidly binds to PS at $1 \mathrm{mMCa}^{2+}$. This may be explained by the presence of a putative binding pocket for the phosphoserine headgroup. ${ }^{213}$ Once bound to the 


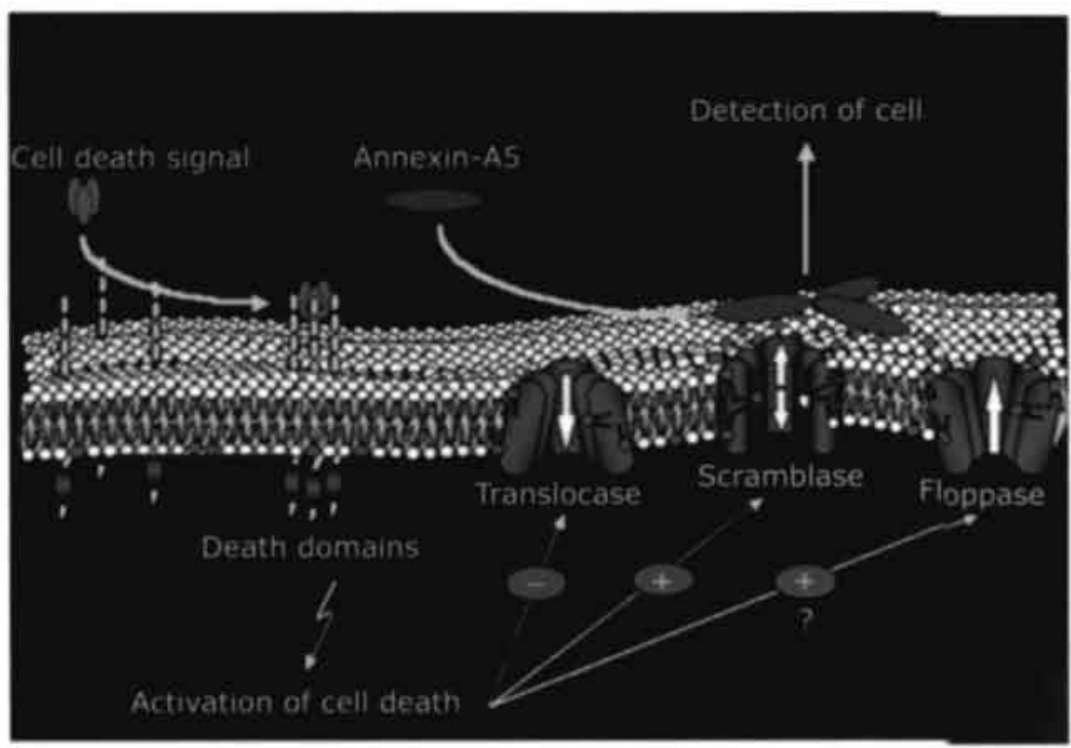

Figure 1 Mechanism of Annexin-A5 binding to Phosphatidylserine (red dots) during programmed cell death.

phospholipid surface, Annexin-A5 forms two-dimensional lattices, which are stabilized by protein-protein interactions. ${ }^{214,215}$ Binding of Annexin-A5 to phospholipid membranes is reversible when calcium ions are chelated. The rates of association and dissociation suggest that Annexin-A5 does not penetrate the membrane and behaves as an extrinsic membrane protein. 202,216 Altogether, these binding features make Annexin-A5 an excellent tool to detect cell surface-exposed PS in vitro as well as in vivo (Figure 1).

\subsection{ANNEXIN-A5 AND CELL SURFACE-EXPOSED PS, A REVEALING PAS DE DEUX OF APOPTOSIS}

Using leukocytes, it was demonstrated for the first time that Annexin-A5 discriminates between viable and apoptotic cells. $116,120,203$ Indeed, competition experiments, using PS containing phospholipid vesicles, demonstrated that the binding site for Annexin-A5 on the apoptotic cell comprises PS. ${ }^{204}$ In combination with the vital dye propidium iodide, it was shown that apoptotic cells expose PS while maintaining their plasma membrane integrity. ${ }^{116,120,203}$ The Annexin-A5-based assay was first developed for cells in suspension. Later it was shown that this assay could also be applied to adherent cell types and in tissues. 217 
The Annexin-A5-based assay 204 rapidly increased our knowledge about the function of PS exposure in the apoptotic process. The accumulated experimental data point towards a position at the transition from the decision to the execution phase, hence early in the execution phase ${ }^{218}$ before morphological changes of the nucleus can be detected. ${ }^{219}$ The exposure of PS does not depend on the involvement of the nucleus, but requires the activation of caspase- 3 and $\mathrm{A} \mathrm{Ca}^{2+}$ flux over the plasma membrane. 220 Next, it turned out that exposure of PS is under control of the Bcl-2 checkpoint, in case the mitochondrion participates in the death process. ${ }^{204}$ These insights were generated by in vitro experiments using cultured or isolated cells. It was demonstrated that the Annexin-A5 assay could be used in vivo by injecting Annexin-A5-biotin into the blood. stream of living mouse embryos. ${ }^{221}$ In vivo Annexin-A5-biotin stains cells in various phases of apoptosis ranging from the early phase in which no morphological changes of the nucleus are detected on the EM level, until the late phase with pyknotic nucleus and condensed cytoplasm. ${ }^{221}$ The combination of the Annexin-A5-based assay and the TUNEL method revealed the presence of three subpopulations of apoptotic cells in tissues. Firstly, Annexin-A5 positive/TUNEL negative cells which are in the early execution phase. Secondly, both TUNEL and Annexin-A5 positive cells, which are in the late stage of the execution phase, and third, Annexin-A5 negative/TUNEL positive cells, which are located in phagolysosomes. ${ }^{222}$ The latter subpopulation reflects cells, which started to execute apoptosis well before the time point of the experiment. This could range from hours to days. These data indicate that the Annexin-A5-based assay is the most sensitive technique to detect ongoing apoptosis.

\subsection{AIM OF THE THESIS: MOLECULAR IMAGING OF PROGRAMMED CELL DEATH USING ANNEXIN-A5}

Based on the fact that Annexin-A5 based imaging protocol is a sensitive an relatively easy method to detect programmed cell death, we hypothesized that Annexin-A5 might be valuable, sensitive and specific tool for molecular imaging of programmed cell death. The term molecular imaging can be defined as the in vivo characterization and measurement of biologic processes at the cellular and molecular level. In theory, labeling of Annexin-A5 with an imaging label, such as a fluorescent probe or technetium, may provide a method for molecular imaging of programmed cell death in living organisms. When we started the projects described in the thesis, only limited work was done in this field. Detection of apoptosis in the developing embryo was shown by direct injection of biotinylated Annexin-A5 in the heart, and subsequent harvesting of various tissues from the embryo. These data showed numerous Annexin-A5 positive cells in areas with a high occurrence of apoptosis. Furthermore, the Annexin-A5 positive cells 
exhibited other hallmarks of apoptosis, as shown by the TUNEL assay nd EM analysis. These data indicate that labeled Annexin-A5, when injected into the bloodstream is able to reach and bind to apoptotic cells in remote tissue in the deviloping embryo. Therefore, a first critical step in the establishment of Annexin-A5 as a milecular imaging probe was performed. However, for detection of apoptosis in embyos, it was still necessary to harvest tissue to identify apoptosis.

In this thesis we propose to further develop Annexin-A5 as a tool for mulecular imaging of programmed cell death in the heart in experimental models and in pitients. A second goal was to study unresolved questions in the field of apoptosis in myoardial ischemia, using the molecular imaging technology based on Annexin-A5. A firststep, as outlined in chapter 3, describes the use of biotinylated Annexin-A5 in the detetion of myocardial cell death in an ischemia and reperfusion model of the mouse hert in vivo. These data show that biotinylated Annexin-A5 is a relatively easy and rdiable detection method for programmed cell death in the ischemic heart in mice. Futhermore, these data showed that Annexin-A5 can be used as an endpoint to evaluate the efficacy of cell death inhibiting compounds to prevent injury mediated by cardiac ischemia and reperfusion. In the following study, described in chapter 4, a novel methodology is described to detect programmed cell death real-time, using optical imaging of the mouse heart in combination with fluorescently labelled Annexin-A5. These data show that binding of Annexin-A5 starts within minutes after the onset of reperfusion, and is completed within 20-30 minutes following the start of reperfusion. These findings suggest that the cell death program is activated within minutes after the start of reperfusion following an ischemic episode. In chapter 5 we have used detection of Annexin-A5 to study the relationship between the point of no return in the cell death program and the externalisation of PS. Using a brief cardiac ischemia protocol in vivo we observed that Annexin-A 5 binds to cells in the ischemic area, but that these cells do not die in the subsequent days. In addition, we observed that the binding of Annexin-V to these cells was associated with activation of caspase- 3 , which is thought to be one of the key executioners of the apoptotic program. Together, these data indicate that cardiomyocytes can recover from the initiation of apoptosis, if reperfusion is restored rapidly enough, which provides an entirely novel concept to resurrection of mammalian cells. These data challenge the conclusions of chapter 3 and 4 , where it was suggested that binding of Annexin-A5 indicates irreversible activation of the cell death program.

In chapters 6 and 7 , the final part of the thesis, we evaluated the use of technetium labelled Annexin-A5 and nuclear imaging in the detection of apoptosis in patients with cardiac disease. In chapter $\mathbf{6}$, we report the detection of apoptosis in patients with acute myocardial infarction. Enhanced uptake of technetium labelled Annexin-A5 was 
observed in the infarcted area on day one, which co-localized with a perfusion defect seen with perfusion imaging on day 3 . These data showed, for the first time, that in vivo imaging of programmed cell death is possible in patients. In addition, the binding of Annexin-A5 in the infarcted region suggests that a form of cell death is present in the infarcted region that may be amenable to anti-apoptotic intervention. The final study, presented in chapter 7 , describes a case study of the in vivo detection of apoptosis in an intra-cardiac tumour, using the Annexin-A5 image technology. Usually, intra-cardiac tumors present diagnostic and therapeutic problems, since no biopsies can be taken from the tumour. Nuclear imaging showed substantial uptake of technetium labelled Annexin-A5 in the intra-cardiac region, at the site of the tumour, indicating of enhanced programmed cell death. Since most malignant tumours, in contrast to most benign tumors, exhibit high apoptosis rates, we hypothesized that the tumour would be malignant. After surgical removal of the tumor, the immuno-histochemical diagnosis indicated a malignant sarcoma. We believe, from the few patients studied, that non-invasive detection of the biology of intra-cardiac masses may be of help to make the correct diagnosis and to guide therapy.

\section{REFERENCES}

1. Braunwald, E., Heart Disease (A Textbook Of Cardiovascular Medicine). 5th Ed ed. 1997: Harcourt Publishers Ltd, a subsidiary of Harcourt International L.td.

2. Kolodgie, F.D., et al., The thin-cap fibroatheroma: a type of vulnerable plaque: the major precursor lesion to acute coronary syndromes. Curr Opin Cardiol, 2001. 16(5); p. 285-92.

3. Kolodgie, F.D., et al., Localization of apoptotic macrophages at the site of plaque rupture in sudden coronary death. Am J Pathol, 2000. 157(4): p. 1259-68.

4. Kolodgie, F.D., et al., Apoptosis in atherosclerosis. Does it contribute to plaque instability? Cardiol Clin, 2001. 19(1): p. 127-39, ix.

5. Listenberger, L.L. and I.E. Schaffer, Mechanisms of lipoapoptosis. Implications for human heart disease. Trends Cardiovasc Med, 2002. 12(3): p. 134-8.

6. Association, A.H., Heart and Stroke Statistical Update. 1999.

7. Braunwald, E., Myocardial reperfusion, limitation of infarct size, reduction of left ventricular dysfunction, and improved survival. Should the paradigm be expanded? Circulation, 1989. 79(2): p. $441-4$.

8. Nadal-Ginard, B., et al., Myocyte death, growth, and regeneration in cardiac hypertrophy and failure. Circ Res, 2003. 92(2): p. 139-50.

9. Bremer, C., C.H. Tung, and R. Weissleder, In vivo molecular target assessment of matrix metalloproteinase inhibition. Nat Med, 2001. 7(6): p. 743-8.

10. Bremer, C., C.H. Tung, and R. Weissleder, Molecular imaging of MMP expression and therapeutic MMP inhibition. Acad Radiol, 2002. 9 Suppl 2; p. S314-5. 
11. Calvillo, L., et al., Recombinant human erythropoietin protects the nyocardium from ischemia-reperfusion injury and promotes beneficial remodeling. Proc Nil Acad Sci U S A, 2003. 100(8): p. 4802-6.

12. Huang, D.C., I. Tschopp, and A. Strasser, BCl-2 does not inhibit cell de.h induced by the physiological Fas ligand: implications for the existence of type I and typel cells. Cell Death Differ, 2000. 7(8): p. 754-5.

13. Korsmeyer, S.J., BCl.2: an antidote to programmed cell death. Cancer urv, 1992. 15: p. 105-18.

14. Dumont, E.A., et al., Cardiomyocyte death induced by myocardial ischem and reperfusion: measurement with recombinant human annexin- $V$ in a mouse model irculation, 2000. 102(13): p. 1564-8.

15. Fliss, H. and D. Gattinger, Apoptosis in ischemic and reperfused rat mycardium. Circ Res, 1996. 79(5): p. 949-56.

16. Freude, B., et al., Apoptosis is initiated by myocardial ischemia an executed during reperfusion. I Mol Cell Cardiol, 2000. 32(2): p. 197-208.

17. Fujio, Y.. et al. Akt promotes survival of cardiomyocytes in vitro art protects against ischemia-reperfusion injury in mouse heart. Circulation, 2000. 101(6): p660-7.

18. Gottlieb, R.A., et al., Reperfusion injury induces apoptosis in rabbit cariomyocytes, I Clin .lovest. 1994, 94/4;; D. 1621-8.

19. Anversa, P., et al., Apoptosis and myocardial infarction. Basic Res Cardiol, 1998, 93 Suppl 3: p. 8-12.

20. Yuan, I., Molecular control of life and death. Curr Opin Cell Biol, 1995. 7(2): p. 211-4.

21. Susin, S.A., et al., BCl-2 inhibits the mitochondrial release of an apoptogenic protease. J Exp Med, 1996. 184(4): p. 1331-41.

22. Scorrano, L., et al., $B A X$ and $B A K$ regulation of endoplasmic reticulum Ca2+: a control point for apoptosis. Science, 2003. 300(5616): p. 135-9.

23. Sax, I.K., et al., BID regulation by p53 contributes to chemosensitivity. Nat Cell Biol, 2002. 4(11): p. 842-9.

24. Kuwana, T., et al, Bid. Bax, and lipids cooperate to form supramolecular openings in the outer mitochondrial membrane. Cell, 2002. 111(3): p. 331-42.

25. Itoh, G, et al., DNA fragmentation of human infarcted myocardial cells demonstrated by the nick end labeling method and DNA agarose gel electrophoresis. Am I Pathol, 1995. 146(6): p. 1325-31.

26. Saraste, A., et al., Apoptosis in human acute myocardial infarction. Circulation, 1997. 95(2): p. 320-3.

27. Ekert, P.G., I. Silke, and D.L. Vaux, Caspase inhibitors. Cell Death Differ, 1999. 6(11): p. 1081-6.

28. Elsasser, A., et al., The role of apoptosis in myocardial ischemia: a critical appraisal. Basic Res Cardiol, 2001, 96(3): p. 219-26.

29. Majno, G. and I. Joris, Apoptosis, oncosis, and necrosis, An overview of cell death. Am J Pathol, 1995, 146(1): p. 3-15.

30. Ohno, M., et al.. "Apoptotic* myocytes in infarct area in rabbit hearts may be oncotic myocytes with DNA fragmentation: analysis by immunogold electron microscopy combined with In situ nick end-labeling. Circulation, 1998. 98(14): p. 1422-30. 
31. Green, D.R. and G.P. Amarante-Mendes, The point of no return: mitochondria, caspases, and the commitment to cell death. Results Probl Cell Differ, 1998. 24: p. 45-61.

32. Green, D.R., Apoptotic pathways: paper wraps stone blunts scissors. Cell, 2000, 102(1); p. $1-4$.

33. Hengartner, M.O., The biochemistry of apoptosis. Nature, 2000, 407(6805): p. 770-6.

34. Leist, $M$ and $M$. Jaattela, Four deaths and a funeral: from caspases to alternative mechanisms. Nat Rev Mol Cell Biol, 2001. 2(8): p. 589-98.

35. Nicholson, D.W. and N.A. Thomberry, Caspases: killer proteases. Trends Biochem Sci, 1997. 22(8): p. 299-306.

36. Thornberry, N.A and Y, Lazebnik, Caspases: enemies within. Science, 1998. 281(5381): p. $1312-6$.

37. Vaux, D.L., Caspases and apoptosis - biology and terminology. Cell Death Differ, 1999. 6(6): p. $493-4$.

38. Flores, E.R., et al., $p 63$ and $p 73$ are required for p53-dependent apoptosis in response to DNA damage. Nature, 2002. 416(6880): p. 560-4.

39. Green, D.R. and G.I. Evan, A matter of life and death. Cancer Cell, 2002. 1(1): p. 19-30.

40. Hopkins-Donaldson, S., et al., Loss of caspase-8 expression in highly malignant human neuroblastoma cells correlates with resistance to tumor necrosis factor-related apoptosis-inducing ligand-induced apoptosis. Cancer Res, 2000, 60(16): p. 4315-9.

41. Kerr, J.F., C.M. Winterford, and B.V. Harmon, Apoptosis. Its significance in cancer and cancer therapy. Cancer, 1994. 73(8): p. 2013-26.

42. Li, C. and C.B. Thompson, Cancer. DNA damage, deamidation, and death. Science, 2002. 298(5597): p. 1346-7.

43. Reed, J.C., Apoptosis-regulating proteins as targets for drug discovery. Trends Mol Med, 2001. 7(7): p. 314-9.

44. Wyllie, A.H., The biology of cell death in tumours. Anticancer Res, 1985. 5(1): p. 131-6.

45. Nicholson, D.W., From bench to clinic with apoptosis-based therapeutic agents. Nature, 2000. 407(6805): p. 810-6.

46. Lockshin, R.A. and Z. Zakeri, Programmed cell death and apoptosis: origins of the theory. Nat Rev Mol Cell Biol, 2001. 2(7): p. 545-50.

47. Vaux, D.L. and S.J, Korsmeyer, Cell death in development, Cell, 1999. 96(2): p. 245-54.

48. Kerr, J.F., A.H. Wyllie, and A.R. Currie, Apoptosis: a basic biological phenomenon with wide-ranging implications in tissue kinetics. Br J Cancer, 1972. 26(4): p. 239-57.

49. Fadok, V.A., et al., The role of phosphatidylserine in recognition of apoptotic cells by phagocytes. Cell Death Differ, 1998. 5(7). p. 551-62.

50. Fadok, V.A., D.L. Bratton, and P.M. Henson, Phagocyte receptors for apoptotic cells: recognition, uptake, and consequences. I Clin Invest, 2001. 108(7): p. 957-62.

51. Fadok, V.A., et al., A receptor for phosphatidylserine-specific clearance of apoptotic cells. Nature, 2000. 405(6782): p. 85-90.

52. Fadok, V.A. and G. Chimini, The phagocytosis of apoptotic ce/ls. Semin Immunol, 2001. 13(6): p. 365-72.

53. laattela, M., et al., BCl-x and BCl-2 inhibit TNF and Fas-induced apoptosis and activation of phospholipase A2 in breast carcinoma cells. Oncogene, 1995. 10(12): p. 2297-305.

54. Kroemer, G., et al., The biochemistry of programmed cell death. Faseb J, 1995. 9(13): p. $1277-87$ 
55. Meier, P., A. Finch, and G. Evan, Apoptosis in development. Nature, 2000. 407(6805): p. 796-801.

56. Zakeri, Z. and R.A. Lockshin, Cell death during development. J Immunol Methods, 2002. 265(1-2): p. 3-20.

57. Anversa, P., J. Kajstura, and G. Olivetti, Myocyte death in heart failure. Curr Opin Cardiol, 1996. 11(3): p. 245-51.

58. Anversa, P., et al., Myocyte growth and cardiac repair. I Mol Cell Cardiol, 2002, 34(2): p. 91-105.

59. Chien, K.R., Stress pathways and heart failure. Cell, 1999. 98(5): p. 555-8.

60. Kang, P.M. and S. Izumo, Apoptosis and heart failure: $A$ critical review of the literature, Circ Res, 2000. 86(11): p. 1107-13.

61. Saraste, A., et al., Cardiomyocyte apoptosis and progression of heart failure to transplantation. Eur I Clin Invest, 1999. 29(5): p. 380-6.

62. Schaper, J., S. Lorenz-Meyer, and K. Suzuki, The role of apoptosis in dilated cardiomyopathy. Herz, 1999, 24(3): p. 219-24.

63. Schaper, J., A. Elsasser, and S. Kostin, The role of cell death in heart failure Circ Res, 1999. 85(9): p. 867-9.

64. Towbin, I.A and N.E. Bowles, The failing heart. Nature, 2002, 415(6868): p. 227-33.

65. Mattson, M.P., Apoptosis in neurodegenerative disorders. Nat Rev Mol Cell Biol, 2000, 1(2): p. 120-9.

66. Ellis, R.E., I.Y. Yuan, and H.R. Horvitz, Mechanisms and functions of cell death. Annu Rev Cell Biol, 1991. 7: p. 663-98.

67. Hengartner, M.O. and H.R. Horvitz, C. elegans cell survival gene ced-9 encodes a functional homolog of the mammalian proto-oncogene bct-2. Cell, 1994. 76(4): p. 665-76.

68. Yuan, J., et al., The C elegans cell death gene ced-3 encodes a protein similar to mammalian interleukin-1 beta-converting enzyme. Cell, 1993. 75(4): p. 641-52.

69. Hirsch, G.M., et al., Medial smooth muscle cell loss in arterial allografts occurs by cytolytic cell induced apoptosis. Eur I Cardiothorac Surg, 1998. 14(1): p. 89-96; discussion 96-7.

70. Geske, F.J., et al., The role of the macrophage in apoptosis: hunter, gatherer, and regulator. Int J Hematol, 2002, 76(1): p. 16-26.

71. Fadok, V.A., Clearance: the last and often forgotten stage of apoptosis, I Mammary Gland Biol Neoplasia, 1999. 4(2): p. 203-11.

72. Savill, I., et al., Phagocyte recognition of cells undergoing apoptosis. Immunol Today, 1993. 14(3): p. 131-6.

73. Savill, I. and V. Fadok, Corpse clearance defines the meaning of cell death. Nature, 2000. 407(6805): p. 784-8.

74. Taylor, P.R., et al., A hierarchical role for classical pathway complement proteins in the clearance of apoptotic cells in vivo. I Exp Med, 2000. 192(3): p. 359-66.

75. Bossy-Wetzel, E. and D.R. Green, Caspases induce cytochrome c release from mitochondria by activating cytosolic factors. I Biol Chem, 1999. 274(25): p. 17484-90.

76. Goldstein, I.C., et al., The coordinate release of cytochrome $c$ during apoptosis is rapid, complete and kinetically invariant. Nat Cell Biol, 2000. 2(3): p. 156-62.

77. Gottlieb, R.A., Role of mitochondria in apoptosis. Crit Rev Eukaryot Gene Expr, 2000. $10(3-4):$ p. $231-9$. 
78. Green, D.R. and I.C. Reed, Mitochondria and apoptosis. Science, 1998. 281(5381): p. 1309-12.

79. Kluck, R.M., et al., The release of cytochrome c from mitochondria: a primary site for BCl-2 regulation of apoptosis. Science, 1997, 275(5303): p. 1132-6.

80. Slee, E.A., et al., Ordering the cytochrome c-initiated caspase cascade: hierarchical activation of caspases-2, $-3,-6,-7,-8$, and -10 in a caspase-9-dependent manner. I Cell Biol, 1999. 144(2): p. 281-92.

81. Zimmermann, K.C., C. Bonzon, and D.R. Green, The machinery of programmed cell desth. Pharmacol Ther, 2001. 92(1): p. 57-70.

82. Kajstura, J., et al,, Apoptotic and necrotic myocyte cell deaths are independent contributing variables of infarct size in rats. Lab Invest, 1996. 74(1): p. 86-107.

83. Leist, M. and P. Nicotera, Apoptosis versus necrosis; the shape of neuronal cell death. Results Probl Cell Differ, 1998. 24: p. 105-35.

84. Nicotera, P., M. Leist, and E. Ferrando-May, Apoptosis and necrosis: different execution of the same death. Biochem Soc Symp, 1999, 66: p. 69-73.

85. Saraste, A. and K. Pulkki, Morphologic and biochemical hallmarks of apoptosis, Cardiovasc Res, 2000. 45(3): p. 528-37.

86. Vermes, I., et al. Apoptosis and secondary necrosis of lymphocytes in culture. Acta Haematol, 1997. 98(1): p. 8-13.

87. Tzur, Y.B., et al., Fate of the nuclear lamina during Caenorhabditis elegans apoptosis. I Struct Biol, 2002. 137(1-2): p. 146-53.

88. White, K., et al., Genetic control of programmed cell death in Drosophila. Science, 1994. 264(5159): p, 677-83.

89. Wu, Y.C. and H.R. Horvitz, C. elegans phagocytosis and cell-migration protein CED-5 is similar to human DOCK180. Nature, 1998. 392(6675): p. 501-4.

90. Crackower, M.A., et al., Angiotensin-converting enzyme 2 is an essential regulator of heart function. Nature, 2002, 417(6891): p. 822-8.

91. Cameron, S., et al., PAG-3, a Zn-finger transcription factor, determines neuroblast fate in $C$. elegans. Development, 2002. 129(7): p. 1763-74.

92. Hengartner, M.O. and H.R. Horvitz, Programmed cell death in Caenorhabditis elegans. Curr Opin Genet Dev, 1994. 4(4): p. 581-6.

93. Hengartner, M.O. and H.R. Horvitz, Activation of C. elegans cell death protein CED-9 by an amino-acid substitution in a domain conserved in BCl-2. Nature, 1994. 369(6478): p. 318-20.

94. Hoeppner, D.J., M.O. Hengartner, and R. Schnabel, Engulfment genes cooperate with ced-3 to promote cell death in Caenorhabditis elegans. Nature, 2001 -412(6843): p. 202-6.

95. Horvitz, H.R., S. Shaham, and M.O. Hengartner, The genetics of programmed cell death in the nematode Caenorhabditis elegans. Cold Spring Harb Symp Quant Biol, 1994. 59: p. 377-85.

96. Horvitz, H.R., Genetic control of programmed cell death in the nematode Caenorhabditis elegans. Cancer Res, 1999. 59(7 Suppl): p. 1701s-1706s.

97. Metzstein, M.M., G.M. Stanfield, and H.R. Horvitz, Genetics of programmed cell death in C. elegans: past, present and future. Trends Genet, 1998. 14(10): p. 410-6.

98. Reddien, P.W., S. Cameron, and H.R. Horvitz, Phagocytosis promotes programmed cell death in C. elegans. Nature, 2001. 412(6843): p. 198-202. 
99. Shaham, S. and H.R. Horvitz, Developing Caenorhabditis elegans neurons may contain both cell-death protective and killer activities. Genes Dev, 1996. 10(5): p. 578-91.

100. Stanfield, G.M. and H.R. Horvitz, The ced-8 gene controls the timing of programmed cell deaths in C. elegans. Mol Cell, 2000. 5(3): p. 423-33.

101. Wu, Y.C, and H.R. Horvitz, The C. elegans cell corpse engulfiment gene ced-7 encodes a protein similar to $A B C$ transporters. Cell, 1998, 93(6): p. 951-60.

102. Xue, D., S. Shaham, and H.R. Horvitz, The Caenorhabditis elegans cell-death protein CED-3 is a cysteine protease with substrate specificities similar to those of the human CPP32 protease Genes Dev, 1996. 10(9): p. 1073-83.

103. Zhou, Z, E. Hartwieg, and H.R. Horvitz, CED-1 is a transmembrane receptor that mediates cell corpse engulfment in C. elegans. Cell, 2001. 104(1): p. 43-56.

104. Kuida, K., et al., Decreased apoptosis in the brain and premature lethality in CPP32- defi. cient mice. Nature, 1996. 384(6607): p. 368-72.

105. Alnemri, E.S., et al., Human ICE/CED-3 protease nomenclature. Cell, 1996. 87(2): p. 171.

106. Thompson, C.B., Apoptosis in the pathogenesis and treatment of disease. Science, 1995. 267(5203): p. 1456-62.

107. Ashkenazi, A and V.M. Dixit, Death receptors: signaling and modulation. Science, 1998. 281(5381): p. 1305-8.

108. Evan, G. and T. Littlewood, A matter of life and cell death. Science, 1998, 281 (5381): p. $1317-22$.

109. Susin, S.A., et al., The central executioner of apoptosis: multiple connections between protease activation and mitochondria in Fas/APO-1/CD95. and ceramide- induced apoptosis. J Exp Med, 1997. 186(1): p. 25-37.

110. Susin, S.A., et al., Molecular characterization of mitochondrial apoptosis-inducing factor. Nature, 1999, 397(6718): p. 441-6.

111. Mancini, M., et al., The caspase-3 precursor has a cytosolic and mitochondrial distribution: implications for apoptotic signaling. J Cell Biol, 1998. 140(6): p. 1485-95.

112. Susin, S.A., et al., Mitochondrial release of caspase-2 and -9 during the apoptotic process. I Exp Med, 1999. 189(2): p. 381-94.

113. Fadok, V.A., et al., Exposure of phosphatidy/serine on the surface of apoptotic lymphocytes triggers specific recognition and removal by macrophages. I Immunol, 1992. 148(7): p. 2207-16.

114. Hanayama, R., et al., Identification of a factor that links apoptotic cells to phagocytes. Nature, 2002. 417(6885): p. 182-7.

115. Huynh, M.L., V.A. Fadok, and P.M. Henson, Phosphatidylserine-dependent ingestion of apoptotic cells promotes TCF-betal secretion and the resolution of inflammation. I Clin Invest, 2002, 109(1): p. 41-50.

116. Koopman, G., et al., Annexin V for flow cytometric detection of phosphatidylserine expression on B cells undergoing apoptosis, Blood, 1994. 84(5): p. 1415-20.

117. Reutelingsperger, C.P., Annexins: key regulators of haemostasis, thrombosis, and apoptosis. Thromb Haemost, 2001, 86(1): p. 413-9.

118. van Engeland, $M$., et al., Annexin V-affinity assay: a review on an apoptosis detection system based on phosphatidylserine exposure. Cytometry, 1998. 31(1): p. 1-9.

119. van Engeland, M., et al., Plasma membrane alterations and cytoskeletal changes in apoptosis, Exp Cell Res, 1997. 235(2): p. 421-30. 
120. Vermes, I., et al., A novel assay for apoptosis. Flow cytometric detection of phosphatidylserine expression on early apoptotic cells using fluorescein labelled Annexin V. J Immunol Methods, 1995. 184(1): p. 39-51.

121. Zwaal, R.F. and A.J. Schroit. Pathophysiologic implications of membrane phospholipid asymmetry in blood cells. Blood, 1997. 89(4): p. 1121-32.

122. van Heerde, W.L., et al., Binding of recombinant annexin V to endothelial cells: effect of annexin V binding on endothelial-cell-mediated thrombin formation. Biochem I, 1994. 302 ( Pt 1): p. 305-12.

123. Lassus, P., X. Opitz-Araya, and Y. Lazebnik, Requirement for caspase-2 in stress-induced apoptosis before mitochondrial permeabilization. Science, 2002, 297(5585): p. 1352-4.

124. Muzio, M., et al., FLICE, a novel FADD-homologous ICE/CED-3-like protease, is recruited to the CD95 (Fas/APO-1) death-inducing signaling complex. Cell, 1996, 85(6): p, 817-27.

125. Liu, Y, and R.N. Kitsis, Induction of DNA synthesis and apoptosis in cardiac myocytes by EIA oncoprotein. I Cell Biol, 1996. 133(2): p. 325-34.

126. Sakahira, H., M. Enari, and S. Nagata, Cleavage of CAD inhibitor in $C A D$ activation and DNA degradation during apoptosis. Nature, 1998. $391(6662)$; p. 96-9.

127. deBlois, D., et al. Smooth muscle apoptosis during vascular regression in spontaneously hypertensive rats. Hypertension, 1997. 29(1 Pt 2): p. 340-9.

128. Kyto, V., et al., Cardiomyocyte apoptosis after antiviral WIN 54954 treatment in murine coxsackievirus B3 myocarditis. Scand Cardiovasc I, 2002. 36(3): p. 187-92.

129. Meyaard, L., et al., Programmed death of T cells in HIV-I infection. Science, 1992. 257(5067): p. 217-9.

130. Tewari, M. and V.M. Dixit, Fas-and tumor necrosis factor-induced apoptosis is inhibited by the poxvirus crmA gene product. J Biol Chem, 1995. 270(7): p. 3255-60.

131. Thome, M., et al., Viral FLICE-inhibitory proteins (FLIPs) prevent apoptosis induced by death receptors. Nature, 1997. 386(6624): p. 517-21.

132. Yuan, J. and B.A. Yankner, Apoptosis in the nervous system. Nature, 2000. 407(6805): p. 802-9.

133. Nicotera, P., M. Leist, and L. Manzo, Neuronal cell death: a demise with different shapes. Trends Pharmacol Sci, 1999. 20(2): p. 46-51.

134. Pellegrini, M. and A. Strasser, A portrait of the BCl-2 protein family: life, death, and the whole picture. I Clin Immunol, 1999. 19(6): p. 365-77.

135. Friedlander, R.M. and J. Yuan, ICE, neuronal apoptosis and neurodegeneration. Cell Death Differ, 1998. 5(10): p. 823-31.

136. Cregan, S.P., et al., Apoptosis-inducing factor is involved in the regulation of caspase-independent neuronal cell death. I Cell Biol, 2002. 158(3): p. 507-17.

137. Belzacq, A.S., et al., BCl-2 and Bax modulate adenine nucleotide translocase activity. Cancer Res, 2003, 63(2): p. 541-6.

138. Coultas, L. and A. Strasser, The role of the BCl-2 protein family in cancer. Semin Cancer Biol, 2003. 13(2): p. 115-23.

139. Gozani, O., et al., Life and death in paradise. Nat Cell Biol, 2002, 4(6): p. E159-62.

140. Guchelaar, H.l., et al., Apoptosis- and necrosis-inducing potential of cladribine, cytarabine, cisplatin, and 5-fluorouracil in vitro: a quantitative pharmacodynamic model. Cancer Chemother Pharmacol, 1998. 42(1): p. 77-83. 
141. Hahne, M., et al., Melanoma cell expression of Fas(Apo-1/CD95) lignd: implications for tumor immune escape. Science, 1996. 274(5291): p. 1363-6.

142. Kandasamy, K., et al., Involvement of Proapoptotic Molecules Baand Bak in Tumor Necrosis Factor-related Apoptosis-inducing Ligand (TRAIL)-induced Ntochondrial Disruption and Apoptosis: Differential Regulation of Cytochrome $\mathrm{c}$ and Snc/DIABLO Release. Cancer Res, 2003. 63(7): p. 1712-21.

143. LeBlanc, $\mathrm{H}$, et al., Tumor-cell resistance to death receptor-induct apoptosis through mutational inactivation of the proapoptotic Bct-2 homolog Bax. NaMed, 2002. 8(3): p. 274-81.

144. Dumont, E.A., et al., Real-time imaging of apoptotic cell-membne changes at the single-cell level in the beating murine heart. Nat Med, 2001. 7(12): p.352-5.

145. Ikeda, $\mathrm{H}$., et al., Apoptosis is a major mode of cell death cause by ischaemia and ischaemia/reperfusion injury to the rat intestinal epithelium. Gut, 199, 42(4): p. 530-7.

146. Mallat, Z., et al., Shed membrane microparticles with procoagulanpotential in human atherosclerotic plaques: a role for apoptosis in plaque thrombogenicr. Circulation, 1999. 99(3): p. 348-53.

147. Kockx, M.M., et al., Cell composition, replication, and apoptosis in aerosclerotic plaques after 6 months of cholesterol withdrawal. Circ Res, 1998. 83(4): p. 32-87.

148. Lutgens, E., et al., Atherosclerosis in APOE*3-Leiden transgenic micefrom proliferative to atheromatous stage. Circulation, 1999. 99(2): p. 276-83.

149. Shindo, J., et al., Granulocyte-macrophage colony-stimulating factor prevents the progression of atherosclerosis via changes in the cellular and extracellular composition of atherosclerotic lesions in watanabe heritable hyperlipidemic rabbits. Circulation, 1999. 99(16): p. 2150-6.

150. Fukumoto, H., et al., Immunohistochemical and morphometric evaluations of coronary atherosclerotic plaques associated with myocardial infarction and diabetes mellitus. I Atheroscler Thromb, 1998.5(1): p. 29-35.

151. Hamet, P., et al., The time window of apoptosis: a new component in the therapeutic strategy for cardiovascular remodeling. I Hypertens Suppl, 1996. 14(5): p. S65-70.

152. Akyurek, L.M., et al., Tolerance induction ameliorates allograft vasculopathy in rat aortic transplants. Influence of Fas-mediated apoptosis. J Clin Invest, 1998. 101(12); p. 2889-99.

153. Slomp, I., et al., Differentiation, dedifferentiation, and apoptosis of smooth muscle cells during the development of the human ductus arteriosus. Arterioscler Thromb Vasc Biol, 1997. 17(5): p. 1003-9.

154. Lizard, G., et al., Characterization and comparison of the mode of cell death, apoptosis versus necrosis, induced by 7 beta-hydroxycholesterol and 7 -ketocholesterol in the cells of the vascular wall. Arterioscler Thromb Vasc Biol, 1999. 19(5): p. 1190-200.

155. Langille, B.L., Arterial remodeling: relation to hemodynamics. Can J Physiol Pharmacol, 1996. 74(7): p. 83441 .

156. Cho, A., D.W. Courtman, and B.L. Langille, Apoptosis (programmed cell death) in arteries of the neonatal lamb. Circ Res, 1995. 76(2): p. 168-75.

157. Bauriedel, G., et al., Apoptosis in restenosis versus stable-angina atherosclerosis: implications for the pathogenesis of restenosis. Arterioscler Thromb Vasc Biol, 1998. 18(7): p. 1132-9. 
158. Frustaci, A., et al., Cell death in acromegalic cardiomyopathy. Circulation, 1999, 99(11): p. 1426-34.

159. Valente, M., et al., In vivo evidence of apoptosis in arrhythmogenic right ventricular cardiomyopathy. Am J Pathol, 1998. 152(2): p. 479-84.

160. Fontaliran, $\mathrm{F}$., et al., /Arrhythmogenic right ventricular dysplasia and cardiomyopathy. Clinical and anatomic-pathologic aspects, nosologic approachl. Arch Anat Cytol Pathol, 1998. 46(3): p. 171-7.

161. Kageyama, $Y$., et al., Apoptosis is involved in acute cardiac allograft rejection in rats. Ann Thorac Surg, 1998. 65(6): p. 1604-9.

162. Koglin, J, and M.E. Russell, Alloimmune-mediated apoptosis: comparison in mouse models of acute and chronic cardiac rejection. Transplantation, 1999. 67(6): p. 904-9.

163. Vriens, P.W., et al., The use of technetium Tc $99 \mathrm{~m}$ annexin $V$ for in vivo imaging of apoptosis during cardiac allograft rejection. I Thorac Cardiovasc Surg, 1998, 116(5): p. 844-53.

164. Blankenberg, F.G., et al., In vivo detection and imaging of phosphatidy/serine expression during programmed cell death. Proc Natl Acad Sci U S A. 1998. 95(11): p. 6349-54.

165. Watanabe, M., et al., Developmental remodeling and shortening of the cardiac outflow tract involves myocyte programmed cell death. Development, 1998. 125(19): p. 3809-20.

166. Takeda, K., et al., Apoptosis and DNA fragmentation in the bulbus cordis of the developing rat heart. J Mol Cell Cardiol, 1996. 28(1): p. 209-15.

167. Poelmann, R.E., T. Mikawa, and A.C. Gittenberger-de Groot, Neural crest cells in outflow tract septation of the embryonic chicken heart: differentiation and apoptosis. Dev Dyn, 1998. 212(3): p. 373-84.

168. Saphier, C.J. and J. Yeh, Altered apoptosis levels in hearts of human fetuses with Down syndrome. Am J Obstet Gynecol, 1998. 179(4): p. 962-5.

169. Elsasser, A., et al., Hibernating myocardium: an incomplete adaptation to ischemia. Circulation, 1997. 96(9): p. 2920-31.

170. Chen, C., et al., Myocardial cell death and apoptosis in hibernating myocardium. I Am Coll Cardiol, 1997. 30(5): p. 1407-12.

171. Baghelai, K., et al., Delayed myocardial preconditioning by alpha 1 -adrenoceptors involves inhibition of apoptosis. J Thorac Cardiovasc Surg, 1999. 117(5): p. 980-6.

172. Swynghedauw, B., Molecular mechanisms of myocardial remodeling. Physiol Rev, 1999. 79(1): p. 215-62.

173. Narula, J., R.J. Hajjar, and G.W. Dec, Apoptosis in the failing heart. Cardiol Clin, 1998. 16(4): p. 691-710, ix.

174. Freude, B., et al., Cardiomyocyte apoptosis in acute and chronic conditions, Basic Res Cardiol, 1998. 93(2):p. 85-9.

175. Zhang, J., et al., Apoptosis in a canine model of acute Chagasic myocarditis. I Mol Cell Cardiol, 1999. 31(3): p. 581-96.

176. Rossi, M.A. and A.C. Souza, Is apoptosis a mechanism of cell death of cardiomyocytes in chronic chagasic myocarditis? Int J Cardiol, 1999. 68(3): p. 325-31.

177. James, T.N., et al.. Apoptosis as a possible cause of gradual development of complete heart block and fatal arrhythmias associated with absence of the AV node, sinus node, and internodal pathways. Circulation, 1996. 93(7): p. 1424-38. 
178. Seki, Y., et al., Myocardial DNA strand breaks are detected in biopsy ssues from patients with dilated cardiomyopathy. Clin Cardiol, 1998. 21(8): p. 591-6.

179. Feuerstein, G., et al., Novel mechanisms in the treatment of heart ulure: inhibition of oxygen radicals and apoptosis by carvedilol. Prog Cardiovasc Dis, 198. 41(1 Suppl 1): p. $17-24$.

180. Diez, J., et al., Cardiomyocyte apoptosis and cardiac angiotensin-civerting enzyme in spontaneously hypertensive rats. Hypertension, 1997. 30(5): p. 1029:4.

181. Dong, C., et al., Human transplant coronary artery disease: pathogical evidence for Fas-mediated apoptotic cytotoxicity in allograft arteriopathy. Lab Inest, 1996, 74(5): p. 921-31.

182. Colston, I.T., B. Chandrasekar, and G.L. Freeman, Expression of apopsis-related proteins in experimental coxsackievirus myocarditis. Cardiovasc Res, 1998. 38): p. 158-68.

183. Gebhard, I.R., et al., Coxsackievirus B3-induced myocarditis: perforinexacerbates disease, but plays no detectable role in virus clearance. Am I Pathol, 1998, 15(2): p. 417-28.

184. Darzynkiewicz, Z., et al., Features of apoptotic cells measured by flow cytometry. Cytometry, 1992, 13(8): p. 795-808.

185. Nagata, S., Apoptosis by death factor. Cell, 1997. 88(3): p. 355-65.

186. Gurtu, V., S.R. Kain, and G. Zhang. Fluorometric and colorimetricletection of caspase uoctiogivassociated with ropontosis Anal Biochem, 1997. 251(1): p. 9-102.

187. Leers, M.P., et al., Immunocytochemical detection and mapping of a cytokeratin 18 neoepitope exposed during early apoptosis. I Pathol, 1999. 187(5); p. 567-72.

188. Yang, F., et al., Antibody to caspase-cleaved actin detects apoptosis in differentiated neuroblastoma and plaque-associated neurons and microglia in Alzheimer's disease. Am J Pathol, 1998, 152(2): p. 379-89.

189. Sallmann, F.R., et al., Characterization of antibodies specific for the caspase cleavage site on poly(ADP-ribose) polymerase: specific detection of apoptotic fragments and mapping of the necrotic fragments of poly(ADP-ribose) polymerase. Biochem Cell Biol, 1997. 75(4): p. 451-6.

190. McConkey, calcium flux measurement in cell death. Techniques in apoptosis, ed. M.S. Cotter TG. 1996, London: Portland Press. 133-148.

191. Berridge, M., P. Lipp, and M. Bootman, Calcium signalling. Curr Biol, 1999. 9(5): p. R157-9.

192. Whyte, M.K., et al., Transient elevations of cytosolic free calcium retard subsequent apoptosis in neutrophils in vitro. I Clin Invest, 1993. 92(1): p. 446-55.

193. Metivier, D., et al., Cytofluorometric detection of mitochondrial alterations in early CD95/Fas/APO-1-triggered apoptosis of Jurkat $T$ lymphoma cells. Comparison of seven mitochondrion-specific fluorochromes, Immunol Lett, 1998. 61(2-3): p. 157-63.

194. Bossy-Wetzel, E., D.D. Newmeyer, and D.R. Green, Mitochondrial cytochrome c release in apoptosis occurs upstream of DEVD-specific caspase activation and independently of mitochondrial transmembrane depolarization. Embo J. 1998. 17(1): p. 37-49.

195. Krajewski, S., et al., Release of caspase-9 from mitochondria during neuronal apoptosis and cerebral ischemia. Proc Natl Acad Sci U S A, 1999. 96(10); p. 5752-7.

196. Staley K, B.A. Chun I. Apoptotic DNA fragmentation is detected by a semiquantitative ligation mediated PCR of blunt DNA ends. Cell Death Differ, 1997. 4: p. 66-75. 
197. Gavrieli, Y., Y. Sherman, and S.A. Ben-Sasson, Identification of programmed cell death in situ via specific labeling of nuclear DNA tragmentation. I Cell Biol, 1992. 119(3): p. 493-501.

198. Kockx, M.M., et al., Biotin- or digoxigenin-conjugated nucleotides bind to matrix vesicles in atherosclerotic plaques. Am I Pathol, 1996, 148(6): p. 1771-7.

199. Kockx, M.M., et al., RNA synthesis and splicing interferes with DNA in situ end labeling techniques used to detect apoptosis. Am I Pathol, 1998, 152(4): p. 885-8.

200. Darzynkiewicz. Z., Measurements of cell death by flowcytometry. Techniques in apoptosis, ed. M.S. Cotter TG. 1996, London: Portland Press. 71-106.

201. van Heerde, W.L., et al., Markers of apoptosis in cardiovascular tissues: focus on Annexin V. Cardiovasc Res, 2000, 45(3): p. 549-59.

202. Andree, H.A., et al., Binding of vascular anticoagulant alpha (VAC alpha) to planar phospholipid bilayers. I Biol Chem, 1990. 265(9): p. 4923-8.

203. Homburg, C.H., et al., Human neutrophils lose their surface $\mathrm{Fc}_{\mathrm{C}}$ gamma RIII and acquire Annexin V binding sites during apoptosis in vitro. Blood, 1995. 85(2): p. 532-40.

204. Martin, S.l., et al., Early redistribution of plasma membrane phosphatidylserine is a general feature of apoptosis regardless of the initiating stimulus: inhibition by overexpression of $B C l \cdot 2$ and $A b l$ I Exp Med, 1995. 182(5): p. 1545-56.

205. Seigneuret, M and P.F. Devaux, ATP-dependent asymmetric distribution of spin-labeled phospholipids in the erythrocyte membrane: relation to shape changes. Proc Natl Acad Sci US A, 1984. 81(12): p. 3751-5.

206. Diaz, C. and A.J. Schroit, Role of translocases in the generation of phosphatidylserine asymmetry. J Membr Biol, 1996. 151(1): p. 1-9.

207. Bevers, E.M., et al., Generation of prothrombin-converting activity and the exposure of phosphatidylserine at the outer surface of platelets. Eur I Biochem, 1982. 122(2): p. 429-36.

208. Williamson, P., et al., Continuous analysis of the mechanism of activated transbilayer lipid movement in platelets. Biochemistry, 1995. 34(33): p. 10448-55.

209. Verhoven, B., R.A. Schlegel, and P. Williamson, Mechanisms of phosphatidylserine exposure, a phagocyte recognition signal, on apoptotic Tlymphocytes. J Exp Med, 1995. 182(5): p. 1597-601.

210. Schroit, A.J., J.W. Madsen, and Y. Tanaka, In vivo recognition and clearance of red blood cells containing phosphatidy/serine in their plasma membranes. J Biol Chem, 1985. 260(8): p. 5131-8.

211. Reutelingsperger, C.P., G. Hornstra, and H.C. Hemker, Isolation and partial purification of a novel anticoagulant from arteries of human umbilical cord. Eur J Biochem, 1985. 151(3): p. 625-9.

212. Tait, J.F., D. Gibson, and K. Fujikawa, Phospholipid binding properties of human placental anticoagulant protein-1, a member of the lipocortin family. I Biol Chem, 1989. 264(14): p. 7944-9.

213. Swairjo, M.A., et al., Cal2+)-bridging mechanism and phospholipid head group recognition in the membrane-binding protein annexin V. Nat Struct Biol, 1995, 2(11): p. 968-74.

214. Mosser, G., et al., Sub-domain structure of lipid-bound annexin-V resolved by electron image analysis. I Mol Biol, 1991. 217(2): p. 241-5.

215. Andree, H.A., et al., Clustering of lipid-bound annexin V may explain its anticoagulant effect. J Biol Chem, 1992. 267(25): p. 17907-12. 
216. Meers, P. and T. Mealy, Calcium-dependent annexin $V$ bindingto phospholipids: stoichiometry, specificity, and the role of negative charge. Biochemist, 1993. 32(43): p. 11711-21.

217. van Engeland, M., et al., A novel assay to measure loss of plasma menbrane asymmetry during apoptosis of adherent cells in culture. Cytometry, 1996. 24(2): p131-9.

218. Castedo, M., et al., Sequential acquisition of mitochondrial and plasna membrane alterations during early lymphocyte apoptosis. J Immunol, 1996. 157(2): p. 12-21.

219. Stuart, M.C., et al., Surface exposure of phosphatidylserine durin apoptosis of rat thymocytes precedes nuclear changes. Eur J Cell Biol, 1998. 76(1): p. 7-83.

220. Bratton, D.L., et al., Appearance of phosphatidylserine on apoptotic ces requires calciummediated nonspecific flip-flop and is enhanced by loss of the minophospholipid translocase. J Biol Chem, 1997. 272(42): p. 26159-65.

221. Eijnde van den SM, B.L., Reutelingsperger CPM, De Zeeuw CI Vermeij-Keers C, Phosphatidylserine plasma membrane assymetry in vivo: a pancellular penomenon which alters during apoptosis. Cell Death Differ, 1997. 4: p. 311-316.

222. van den Eijnde, S.M., et al., In situ detection of apoptosis during enbryogenesis with annexin V: from whole mount to ultrastructure. Cytometry, 1997. 29/4 p. 313-20. 


\section{CARDIOMYOCYTE DEATH INDUCED BY MYOCARDIAL ISCHEMIA AND REPERFUSION \\ MEASUREMENT WITH RECOMBINANT HUMAN ANNEXIN-V IN A MOUSE MODEL}

Ewald A.W.J. Dumont, MD; Leo Hofstra, MD, PhD; Waander L. van Heerde, PhD, MD; Stephan van den Eijnde, PhD; Pieter A.F. Doevendans, MD, PhD; Ebo DeMuinck, MD, PhD; Marc A.R.C. Daemen, MD; Jos F.M. Smits, MD, PhD; Peter Frederik, PhD; Hein J.J. Wellens, MD, PhD; Mat J.A.P. Daemen, MD, PhD; Chris P.M. Reutelingsperger, PhD 


\section{ABSTRACT}

Introduction: Phosphatidylserine (PS) externalization is regarded as one of the earliest hallmarks of cells undergoing programmed cell death. We studied the use of labeled human recombinant annexin- $V$, a protein selectively binding to PS, to detect cardiomyocyte death in an in vivo mouse model of cardiac ischemia and reperfusion (I/R).

Methods and Results: I/R was induced in mouse hearts by ligation and subsequent release of a suture around the left anterior descending coronary artery. Annexin- $\mathrm{V}$ (25 $\mathrm{mg} / \mathrm{kg}$ ) fused to a marker molecule was injected intra-arterially 30 minutes before euthanasia. After 15 minutes of ischemia followed by 30 minutes of reperfusion, $1.4 \pm 1.2 \%$ (mean $\pm \mathrm{SD}$ ) of the cardiomyocytes in the area at risk were annexin-V positive $(\mathrm{n}=6)$. This increased to $11.4 \pm 1.9 \%$ after 15 minutes of ischemia followed by 90 minutes of reperfusion $(n=7)$ and to $20.2 \pm 3.3 \%$ after 30 minutes of ischemia followed by 90 minutes of reperfusion $(n=7)$. In control mice, including those injected with annexin- $V$ at the binding site of PS, no annexin- $V$-positive cells were observed. DNA gel electrophoresis showed typical laddering starting after 15 minutes of ischemia followed by 30 minutes of reperfusion, suggesting activation of the cell death program. Intervention in the cell death program by pretreatment with a novel $\mathrm{Na}^{+} / \mathrm{H}^{+}$exchange inhibitor substantially decreased annexin-V-positive cardiomyocytes from $20.2 \%$ to $2.2 \%$ in mice after 30 minutes of ischemia followed by 90 minutes of reperfusion.

Conclusions: These data suggest that labeled annexin- $V$ is useful for in situ detection of cell death in an in vivo model of $I / R$ in the heart and for the evaluation of cell death-blocking strategies, (Circulation. 2000;102:1564-1568.)

Key Words: apoptosis, cells, myocardial infarction, reperfusion, proteins

Received March 27, 2000; revision received May 2, 2000; accepted May 2, 2000.

From the Departments of Cardiology (E.A.W.J.D., L.H., P.A.F.D., E.D, H.J.J.W.), Biochemistry (W.L.v.H., S.V.D.E., C.P.M.R), Surgery (M.A.R.C.D.), Pharmacology (J.F.M.S.), Electron Microscopy (P.F.), and Pathology (M.J.A.P.D.), Cardiovascular Research Institute, Maastricht, the Netherlands.

Presented in part at the Keystone Conference (Apoptosis and Programmed Cell Death), Breckenridge, Colo, April 6-11, 1999, and at The Lancet Conference (The Challenge of Acute Coronary Syndromes), Copenhagen, Denmark, June 9-11, 1999. 


\section{INTRODUCTION}

To define the therapeutic window of cell death-blocking strategies after ischemia and reperfusion (I/R) of the heart, detailed information on the time frame of cell death is needed. Most of the studies evaluating cell death in the heart after $1 / R$ used detection methods based on the occurrence of DNA fragmentation, such as the terminal deoxynucleotidyl transferase (TdT)-mediated dUTP nick end-labeling (TUNEL) assay and DNA laddering. ${ }^{1-4}$ However, because TUNEL and DNA laddering do not detect the early stages of cell death, these techniques are not ideal to assess the time frame of cell death in the heart after $\mathrm{I} / \mathrm{R} .{ }^{4}$ In addition, in vivo detection of cell death is not possible with TUNEL and/or DNA gel electrophoresis. One of the earliest events after the triggering of cell death is the externalization of phosphatidylserine (PS) to the outer leaflet of the plasma membrane of the cell. ${ }^{5-8}$ In a viable cell, PS is expressed only on the inner leaflet of the cell membrane because of the active transport of PS from the outer to the inner cell membrane by an aminophospholipid translocase. ${ }^{7}$ However, after activation of the cell death program, PS is externalized rapidly to the outer leaflet of the cell membrane. ${ }^{10}$ PS externalization is considered to be in close relation to the activation of key players in the cell death program and can be induced by a variety of cell death triggers. ${ }^{5-7,11-15}$ Detection of PS exposure can be easily achieved by the phospholipid binding protein annexin- $V .{ }^{5-7}$ We have demonstrated in a number of in vitro and in vivo studies that annexin- $V$ is a specific marker for the early and late stages of cells undergoing programmed cell death and that annexin- $V$ is also suitable for the in situ detection of cell death. ${ }^{5-8,16}$ Therefore, labeled annexin-V provides a tool for in situ detection of cell death in vivo in animals and also, at least potentially, in the clinical setting. In the present study, we evaluated the potential of labeled annexin- $V$ to detect cell death in situ induced by $\mathrm{L} / \mathrm{R}$ in the murine heart. Furthermore, we determined the time frame of cell death induction in the early phase of $\mathrm{I} / \mathrm{R}$ of the heart. In addition, we tested whether labeled annexin- $V$ is useful in evaluating the effect of cell death-blocking strategies after $\mathrm{l} / \mathrm{R}$.

\section{METHODS}

\section{I/R OF THE MURINE HEART IN VIVO}

Two-month-old male Swiss mice were anesthetized with pentobarbital (100 mg/kg IP), and the trachea was intubated perorally with a stainless-steel tube. The animals were mechanically ventilated with room air. After left thoracotomy and exposure of the heart, the left anterior descending coronary artery (LAD) was ligated with 6-0 polypropylene just proximal to its main branching point. The suture was tied over a 1 -mm polyethylene 
tube (PE-10) that was left in place during the planned period of ischemia (15 or 30 minutes). Blood flow was then reestablished by removal of the tube. he occurrence of reperfusion could be assessed by the observation of blood flow in epicardial coronary arteries through the operation microscope. For the delineation of the area at risk (AR), colloidal ink ( $1 \mathrm{~mL}$ ) was injected just before euthanasia of the anima after the planned reperfusion time ( 30 to 90 minutes) after reinsertion of the tube inder the ligature around the LAD. Then the heart was removed for analysis. For each condition, at least 6 successfully operated animals were used. Sham procedures were dentical, with the exception of the actual tying of the polypropylene suture. A subgrou of animals $(n=7)$ received a single intra-arterial bolus of a $\mathrm{Na}^{+} / \mathrm{H}^{+}$inhibitor (Eniporide, $3 \mathrm{mg} / \mathrm{kg}, \mathrm{E}$. Merck) before ischemia.

\section{DETECTION OF CARDIOMYOCYTE DEATH WITH LABELEDANNEXIN-V}

Biotinylated annexin- $\mathrm{V}$ (Apoptest-Biotin) and annexin-y-Oregon green (Apoptest-Oregon-Green) were provided by NeXins Research Bv (Kattendijke, the Netherlands). Biotinylated annexin- $V(25 \mathrm{mg} / \mathrm{kg})$ was injected into the carotid artery 30 minutes before excision of the heart. Annexin- $v$ was always injected during reperfusion. Biotinylated annexin- $V$ was used for quantification studies. After excision of the heart and fixation in HEPES-buffered formalin with $2 \mathrm{mmol} / \mathrm{L} \mathrm{Ca}{ }^{2+}$ added, routine processing, and paraffin-embedding, 4- $\mu \mathrm{m}$-thick sections were cut perpendicular to the long axis of the heart. This was followed by staining with a standard avidin-biotin complex kit (ABC kit, Vector Laboratories). Diamino-benzidine was used as the chromogen. Sections were counterstained with hematoxylin. Control experiments were performed with the use of biotinylated annexin- $\mathrm{V}$ mutated for its binding site to PS in mice after 30 minutes of ischemia followed by 90 minutes of reperfusion (I/R 30/90 mice, $n=6$ ). The kidney was used as a positive control, because annexin- $V$ is cleared by the kidney and always shows labeling in successfully injected animals. The total area of annexin-V-positive cardiomyocytes was determined by computerized mor-phometry (Leica Quantimet 570). Quantitative data are expressed as the percentage (mean \pm SD) of the AR staining positive for annexin-V (annexin-V/ARx100\%). In a subset of I/R 30/90 animals $(n=6)$, Oregon-green-labeled annexin- $V$ was used for the detection of cardiomyocyte death by fluorescence microscopy according to a protocol similar to biotinylated annexin- $V$ injection.

\section{TUNEL ASSAY}

The TUNEL assay (Boehringer-Mannheim) was used for detection of DNA strand breaks in the hearts. Paraffin-fixed sections were pretreated with $3 \% \mathrm{H}_{2} \mathrm{O}_{2}$, and end-labeling was performed with TdT $(0.06 \mathrm{U} / \mathrm{mL})$ in TdT buffer containing $40 \mathrm{mmol}$ dig-11-dUTP for 1 hour. Staining with a standard $A B C$ kit was followed by incubation with 
diaminobenzidine. Nuclei were considered apoptotic by the presence of dark brown staining. As a positive control, we used mouse intestine.

\section{DNA GEL ELECTROPHORESIS}

The presence of nucleosomal laddering in hearts was investigated with a commercial ligase-mediated polymerase chain reaction assay kit (Apoalert, Clontech). Briefly, DNA was isolated from tissue samples previously frozen at $270^{\circ} \mathrm{C}$ by using a commercial DNA purification kit (Wizard, Promega) according to the manufacturer's instructions. DNA purity and concentration were determined by electrophoresis through an $0.8 \%$ agarose gel containing ethidium bromide, followed by visualization under UV illumination as well as by measuring absorbance at $260 / 280 \mathrm{~nm}$. Dephosphorylated adapters were ligated to $5^{\prime}$ phosphorylated blunt ends with T4 DNA ligase (during 16 hours at $16^{\circ} \mathrm{C}$ ) and served as primers in a ligase-mediated polymerase chain reaction under the following conditions: hot start $\left(72^{\circ} \mathrm{C}\right.$ for 8 minutes), 25 cycles $\left(94^{\circ} \mathrm{C}\right.$ for 60 seconds and $72^{\circ} \mathrm{C}$ for 180 seconds), and postcycling $\left(72^{\circ} \mathrm{C}\right.$ for 15 minutes). To confirm that equal amounts of DNA were used for polymerase chain reaction, an internal control using En-2 primer pairs was performed. Amplified DNA was subjected to gel electrophoresis on a $1.2 \%$ agarose gel containing ethidium bromide.

\section{IMMUNOSTAINING FOR INTRACYTOPLASMIC IGG}

Immunostaining for $\lg \mathrm{G}$ was performed to investigate the presence of plasma cell membrane leakage. ${ }^{17,18}$ The hearts were removed and processed as described for annexin-V-biotin detection. Incubation with a rabbit anti-mouse $\lg \mathrm{G}$ antibody $(1: 100)$ was followed by incubation with biotinylated goat anti-rabbit as the secondary antibody. Routine staining with a standard $A B C$ kit was followed by incubation with diaminobenzidine. As a positive control, mouse hearts subjected to 24 hours of ischemia were used. Quantitative data are expressed as the percentage of AR staining positive for $\operatorname{lgG}(\operatorname{lgG} / \mathrm{AR} \times 100 \%)$.

\section{IMMUNOELECTRON MICROSCOPY}

For analysis by electron microscopy, murine hearts from I/R 30/90 mice were used $(n=3)$. The hearts were fixed after annexin-V-biotin labeling of the heart with $2 \%$ paraformaldehyde and $0.2 \%$ glutaraldehyde in Apoptest binding buffer. After sectioning, the samples were sucrose-infiltrated as follows: $1 \mathrm{~mol} / \mathrm{L}$ sucrose in $0.1 \mathrm{~mol} / \mathrm{L}$. sodium phosphate buffer for several hours, followed by $2 \mathrm{~mol} / \mathrm{L}$ sucrose with $15 \%$ polyvinylpyrrolidone (molecular weight 25000 ) in $0.1 \mathrm{~mol} / \mathrm{L}$ sodium phosphate buffer for at least 24 hours. The sucrose-infiltrated samples were vitrified in liquid nitrogen. The vitrified samples were transferred to Eppendorf cups containing methanol with 


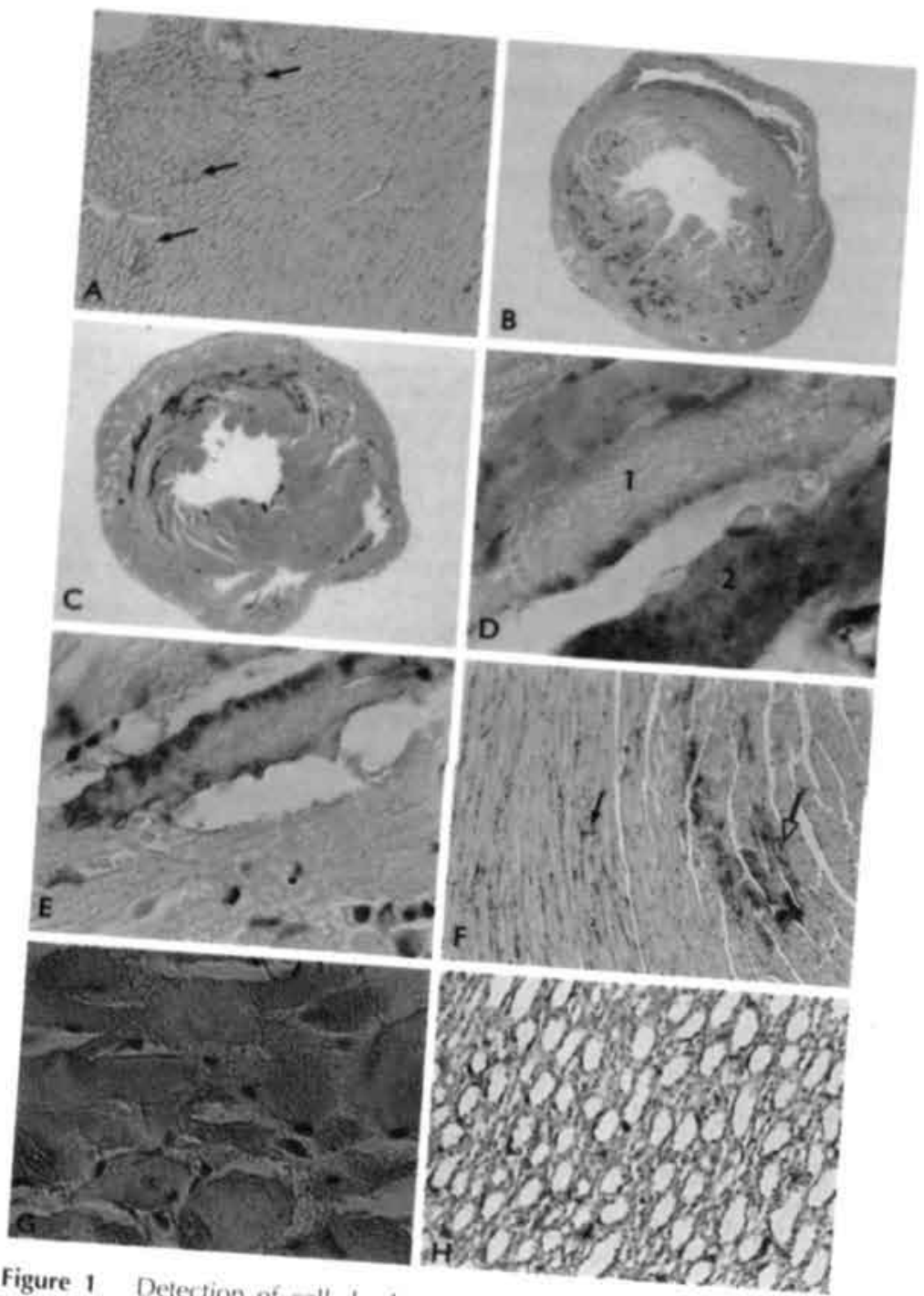

Figure 1 Detection of cell death

numbers of cardiomyocytes become annexin-V poxitive after 15 -biotin and light microscopy. A, Small reperfusion (brown staining of cardiomyocytes, arrows). B large 15 minutes of ischemia and 30 minutes of tive for annexin-V-biotin after 15 minutes of ischemia and 90 , Large numbers of cardiomyocyles stain posi. Large area of annexin-V-positive cardiomyucyes after 90 minutes of reperfusion (brown staining). C. reperfusion (brown staining) is shown. D. Higher magnifiction show ischemia and 90 minutes of annexin. $V$ staining. In some cardiomvocytes, Higher magnification shows variation in the intensity of others exhibit intense staining of plasma mes, only faint membrane staining can be seen (celt intensity of Shrinkage of an annexin-V. por plasma membrane and possibly also intracytopla seen (cell 1), whereas found only in areas withour coltive cardiomyocyte is shown. F. Annexin. which shows colloidat colloidal ink larea per-fused by the LAD. open arrowitive cardiomyocytes were Cardiomyocyte containing ink dots), annexin-V-positive cardiomyocytes were, In AR (closed arrow, brown staining of tubular cells is shown.
. 


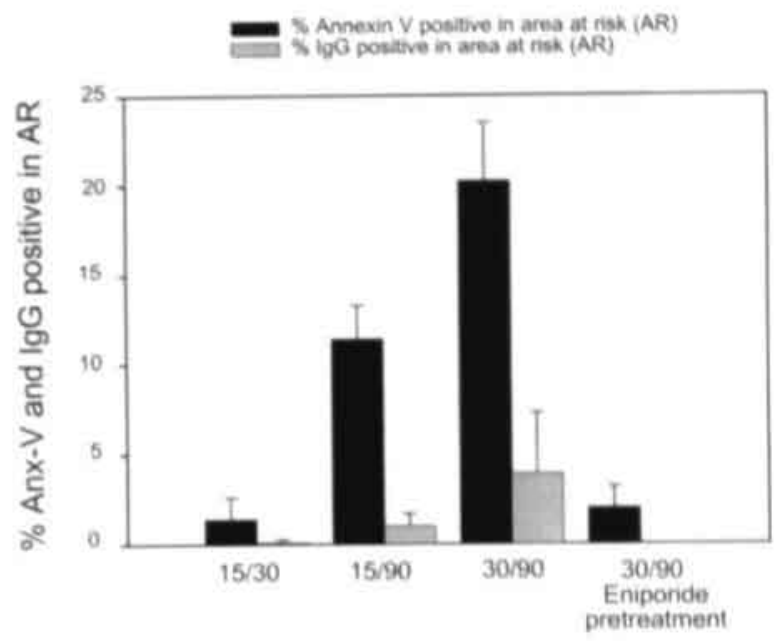

Duration of ischemia and reperfusion (1/R)

Figure 2 Time course of annexin-V (Anx-V)-positive and IgG-positive cardiomyocytes after $1 / R$ in murine heart. Time-related increase of Anx-V-positive and IgG-positive cardiomyocytes can be observed, which can be inhibited by Eniporide $(3 \mathrm{mg} / \mathrm{kg}$ ).
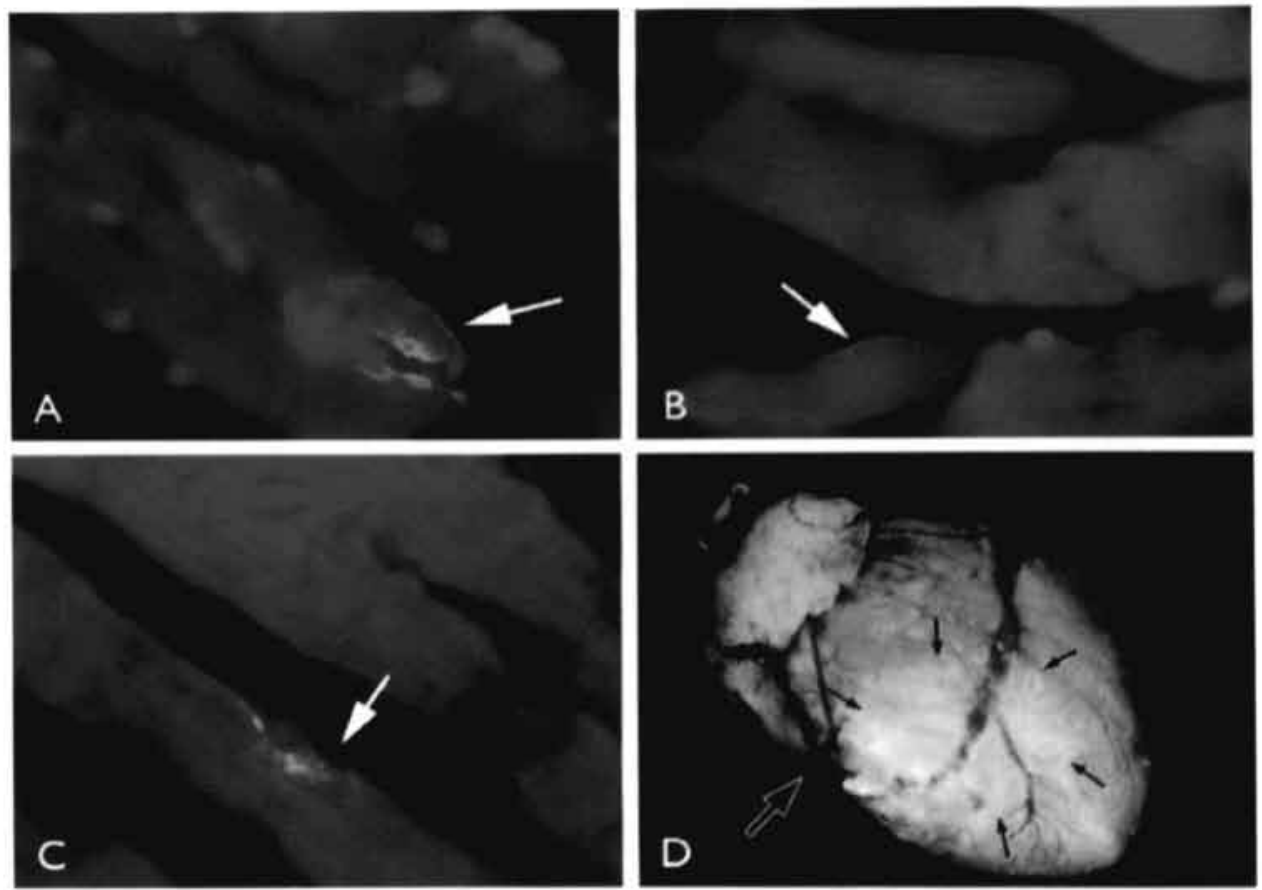

Figure 3 A through C, Cell death is detected by fluorescently labeled annexin-V. Detailed picture of $1 / R=30 / 90$ mouse heart shows specific staining of cell membrane of cardiomyocytes (arrows). D, Just after euthanasia, whole-heart specimen ex vivo shows uptake of fluorescently labeled annexin-V in AR ismall arrows). Ligature on LAD is still visible (large arrowi). 


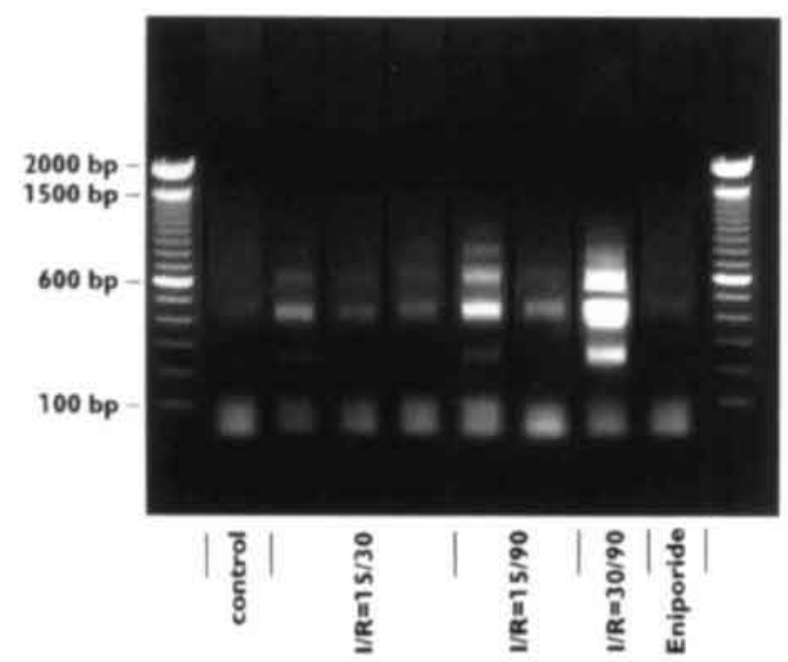

Figure 4 DNA gel electrophoresis. DNA laddering showing bands at multiples of 180 to 200 bp in hearts subjected to I/R. Intensity of bands increases with more extensive periods of $\mathrm{L} R$.

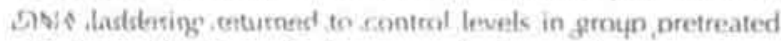
with Eniporide. Controls show some background.
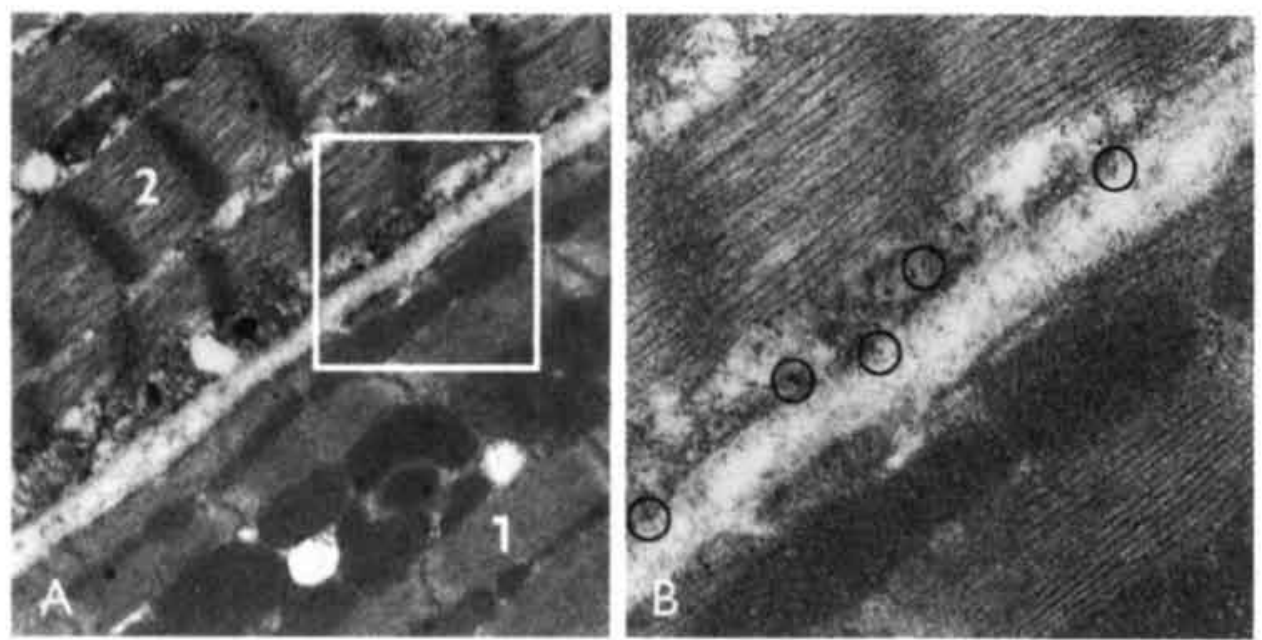

Figure 5 Electron microscopy of $1 / R 30 / 90$ mice hearts. A, Annexin-V immunogold staining. B, Enlargement of box in panel A. Clear staining of intact plasma membrane can be seen in cardiomyocyte with oncotic morphology (circles) (2). Neighboring cardiomyocyte has normal morphology (1). 
$0.5 \%$ uranyl acetate at $-90^{\circ} \mathrm{C}$. After freeze substitution at several temperature steps $\left(-90^{\circ} \mathrm{C},-70^{\circ} \mathrm{C},-50^{\circ} \mathrm{C}\right.$, and $-30^{\circ} \mathrm{C}$; each step for at least 8 hours), the samples were embedded in Lowicryl HM20 (Electron Microscopy Sciences) and polymerized at $-30^{\circ} \mathrm{C}$ under indirect UV light for 24 hours, followed by direct UV light at ambient temperature for 48 hours. The samples were cut into ultrathin sections $(-70 \mathrm{~nm})$ by using a Reichert-Jung Ultracut, followed by immunolabeling (at ambient temperature) as follows: grids were placed on drops of PBS with $50 \mathrm{mmol} / \mathrm{L}$ glycine for 15 minutes, transferred to blocking buffer (PBS containing 5\% [wt/vol] BSA, 10\% [vol/vol] newborn calf serum, $0.1 \%$ [vol/vol] cold water fish skin (CWFS) gelatin (Sigma) and $1 \%$ [vol/vol] goat normal serum) for 30 minutes, washed 3 times on drops of labeling buffer (PBS containing $0.1 \%$ [wt/vol] BSA and $0.2 \%$ [wt/vol] BSA-c), incubated with rabbit anti-biotin IgG (Chemicon International) for 60 minutes, washed 6 times for 5 minutes on drops of labeling buffer, incubated with goat anti-rabbit IgG (Aurion) conjugated with $10 \mathrm{~nm}$ gold diluted at 1:20 for 60 minutes, washed 6 times for 5 minutes on drops of labeling buffer, washed 5 times for 5 minutes on drops of plain PBS, postfixed for 5 minutes on drops of PBS containing 2.5\% glutaraldehyde, washed once with PBS for 5 minutes, washed 5 times for 2 minutes on drops of Milli Q water (Millipore) and contrasted with 15\% uranyl acetate in $50 \%$ ethanol for 10 minutes, followed by a 5 -minute lead citrate staining. The labeled sections were air-dried and examined in a Philips CM 10 microscope at $80 \mathrm{keV}$.

\section{DATA ANALYSIS}

Data are presented as mean \pm SD. To compare differences between groups, the Student $t$ test (Bonferroni correction) was performed by using SPSS software.

\section{RESULTS}

\section{DETECTION OF CELL DEATH WITH BIOTINYLATED ANNEXIN-V}

In hearts from mice subjected to 15 minutes of ischemia and 30 minutes of reperfusion $(\mathrm{I} / \mathrm{R}=15 / 30 \mathrm{mice}), 1.4 \pm 1.2 \% \quad(n=6)$ of the cardiomyocytes were annexin- $\mathrm{V}$ positive (Figure $1 \mathrm{~A}$ and Figure 2). The percentage of annexin- $\mathrm{V}$-positive cardiomyocytes in the AR increased to $11.4 \pm 1.9 \%$ for mice subjected to 15 minutes of ischemia and 90 minutes of reperfusion ( $\mathrm{l} / \mathrm{R}=15 / 90$ mice) and to $20.2 \pm 3.3 \%$ for $\mathrm{V} / \mathrm{R}=30 / 90$ mice (Figure $1 \mathrm{~B}$ and $1 \mathrm{C}$ and Figure 2 ). Intervention in the cell death program by pretreatment of the mice with the novel $\mathrm{Na}^{+} / \mathrm{H}^{+}$exchange inhibitor Eniporide resulted in a substantial decrease of annexin- $V$-positive cardiomyocytes in the $1 / R=30 / 90$ group from $20.2 \%$ to $2.2 \% \quad(\mathrm{P}<0.01$, Figure 2$)$. Annexin- $\mathrm{V}$-positive cells could easily be identified as 
cardiomyocytes by their characteristic morphology. Annexin-V-poitive cardiomyocytes exhibited selective staining at the cell membrane (Figure $1 \mathrm{D}$ cell $1 \mathrm{I}$ and IE and Figure $3 \mathrm{~A}$ through $3 \mathrm{C}$ ). Some punctuated staining could also be oberved, which likely reflects the staining of the T-tubules (Figure 1D [cell 2]). Annexin- $V$ staining ranged from staining limited to the cell membrane (Figure 1D [cell 1]) to intense staining (Figure 1D [cell 2]), probably reflecting varying stages of cell death. The injection of colloidal ink after reocclusion of the LAD enabled us to determint the perfusion area of the LAD (the AR). Annexin-V-positive cardiomyocytes were found only in the ischemic area, devoid of ink (Figure $1 \mathrm{~F}$, open arrow). In areas that stined with ink (Figure $1 \mathrm{~F}$, closed arrow), positive cardiomyocytes were never observed total of $n=20$ ). In control experiments, including sham-operated controls $(n=12)$ and $I R \quad 30 / 90$ mice injected with biotinylated annexin- $V$ mutated for its binding site to PS ( $n=6$ ), no positive cardiomyocytes were found. In the kidney, used as a positive control, clear annexin- $\mathrm{V}$-positive tubular epithelial cells were observed (Figure $1 \mathrm{H}$ ). "o quantify the extent of cells with plasma membrane leakage in relation to the exten of annexin- $V$ binding, we used IgG immunostaining (Figure 1G). The percentage if IgG-positive cardiomyocytes in the $A R$ was $0.1 \pm 0.2 \%$ for $\mathrm{V} / \mathrm{R}=15 / 30$ mice, $1.0 \pm 0.7 \%$ for $\mathrm{V} R=15 / 90$ mice, and $3.9 \pm 3.4 \%$ for $\mathrm{I} / \mathrm{R} 30 / 90$ mice (Figure 2). In mice pretreated with the $\mathrm{Na}^{+} / \mathrm{H}^{+}$ exchange inhibitor, no $\lg \mathrm{G}$ staining could be ob-served for $\mathrm{l} / \mathrm{R}=30 / 90$ mice (Figure 2 ).

\section{DETECTION OF CELL DEATH WITH ANNEXIN-V-OREGON GREEN}

Detection of cell death with annexin-V-Oregon green was tested in $\mathrm{V} / \mathrm{R}=30 / 90$ mice. Evaluation with fluorescence microscopy showed binding of the annexin-V-Oregon green complex to the membranes of cardiomyocytes in the AR (Figure 3A through 3C).

\section{DETECTION OF DNA FRAGMENTATION}

In cardiac specimens obtained from I/R 15/30 mice, some laddering of DNA could be observed (Figure 4). Clear DNA laddering could be observed in cardiac specimens obtained from I/R 15/90 mice and I/R 30/90 mice. DNA laddering decreased to control levels in cardiac specimens obtained from $1 / R$ 30/90 mice that were pretreated with Eniporide. Some background laddering was observed in cardiac tissue obtained from sham-operated animals (controls). Detection of DNA fragmentation in situ with TUNEL showed no staining of cardiomyocyte nuclei.

\section{ANNEXIN-V-BIOTIN: ELECTRON MICROSCOPY}

For electron microscopic analysis of cell death in L/R 30/90 mouse hearts $(n=3)$, we used small tissue sections obtained from the AR. Sampling of these tissue specimens was 
guided by biotinylated annexin- $V$-stained sections from serial sections of the same heart that were analyzed by light microscopy, Immunogold staining with an antibody against biotin demonstrated specific staining of the cell membranes of cardiomyocytes with an oncotic morphology, which had bound annexin-V-biotin during the experiment (Figure $5 \mathrm{~A}$ and $5 \mathrm{~B}$, circles).

\section{DISCUSSION}

The present study demonstrates that labeled annexin- $V$ provides an alternative method to detect cell death in situ in an V/R model of the heart in mice. In addition, these data suggest that annexin- $V$ may be a useful tool to evaluate cell death-blocking strategies to prevent $\mathrm{L} / \mathrm{R}$-induced injury in the heart. After 15 minutes of ischemia followed by 30 minutes of reperfusion, annexin-V-positive cardiomyocytes could already be observed in the AR. Because PS expression and subsequent binding of annexin- $V$ are, at least in vitro, downstream from the activation of executioner caspases, such as caspase 3 (YAMAVCPP32), our data suggest that activation of the cell death program beyond the point of no return may already have occurred in these cells, ${ }^{12,13}$ Extending the reperfusion time to 90 minutes resulted in a marked increase in annexin- $V$-positive cardiomyocytes. Further extension of the ischemic period to 30 minutes increased the percentage of annexin- $\mathrm{V}$-positive cardiomyocytes in the AR to $20.2 \%$. Intervention in the cell death pathway by a novel $\mathrm{Na}^{+} / \mathrm{H}^{+}$exchange inhibitor, Eniporide, decreased the number of annexin-V-positive cardiomyocytes substantially. These data suggest that labeled annexin- $V$ detects cells that have turned on an active cell death program, which can be inhibited. Activation of the cell death program within cardiomyocytes is also indicated by fragmentation of DNA in multiples of 200 bp, as shown with DNA gel electrophoresis. However, electron microscopic analysis never revealed cells with the classic apoptotic morphology as originally described for thymocytes. ${ }^{19}$ The annexin-V-positive cardiomyocytes appeared to have an oncotic morphology. Immunostaining for intracellular IgG, indicative of plasma cell membrane leakage, showed substantially lower values than the values found with annexin- $V$ staining. ${ }^{17}$ Pretreatment of $\mathrm{I} / \mathrm{R}=30 / 90$ mice with Eniporide resulted in the complete absence of IgG-positive cells, which suggests that the cardiomyocytes with extensive cell membrane leakage are a result of an active cell death program. Taken together, our data suggest that rapid and massive cell death occurs in the heart after $\mathrm{I} / \mathrm{R}$, which is the result of an active cell death program, despite the absence of cardiomyocytes with the classic apoptotic morphology. Therefore, our data support the findings of Buja and Entmann ${ }^{18}$ and Ohno et al, ${ }^{20}$ who found TUNEL-positive cardiomyocytes and DNA laddering, indicative of an active cell death program, in the absence of cardiomyocytes with the classic apoptotic morphology. The present study supports the concept that apoptotic 
and oncotic mechanisms proceed at the same time within cardiomyocytes after $\mathrm{V} / \mathrm{R}$. A point of debate is the exclusive use of morphological criteria and internucleosomal fragmentation of DNA to study apoptosis in in vivo models of cardiac injury. Possibly, the morphology of programmed cell death in relative large cells, such as cardiomyocytes and neurons, may differ from the classic morphological appearance of smaller and rapidly dividing cells, such as Jurkat cells. ${ }^{21}$ The limitation of using morphological criteria is also suggested from in vitro studies, which showed a change from Bax-induced apoptotic cell death to membrane-permeability cell death, when caspase activation blockers are used. ${ }^{22}$ In addition, necrotic cell death and apoptotic cell death may share common biological pathways. ${ }^{23}$ Therefore, for development of cell death-blocking strategies in the heart, it may be more efficient to focus on the understanding of biochemical pathways of cell death rather than to study the morphology of dying cells.

In conclusion, our data show that labeled annexin- $V$ is a valuable marker for the in situ detection of cell death induced by $1 / R$ of the mouse heart and is useful in the evaluation of cell death-blocking strategies. Our data obtained with annexin-V-Oregon green support the idea that in vivo imaging with labeled annexin- $V$ is possible. In a limited number of mice, detection of fluorescent annexin- $V$ was performed in vivo, with the use of an operation microscope with fluorescence equipment. Annexin-V-positive areas were observed in the AR (Figure 3D). The specific and massive annexin- $V$ staining of cardiomyocytes in the AR of the mouse hearts subjected to $1 / R$ suggests that in vivo detection of cell death with labeled annexin- $V$ in patients suffering from an acute myocardial infarction may be possible. An interesting option may be the use of technetium-labeled annexin- $V$ and detection with nuclear imaging. The data in the present study provide essential information as to the time of injection of labeled annexin- $V$ and the time course of binding of annexin- $V$ to PS in the acute phase of myocardial I/R. Preliminary data on cell death detection with technetium-labeled annexin- $V$ have shown promising results. ${ }^{24}$

\section{ACKNOWLEDGMENTS}

This study was supported by grants from the Dutch Heart Foundation (NHS 98.195 and NHS D96.025). We would like to thank P. Lux, N. Bitsch, and R. van Gool for their excellent assistance and invaluable technical support. We thank $M$. Borgers for his valuable discussion of the data. 


\section{REFERENCES}

1. Gottlieb RA, Burleson KO, Kloner RA, et al. Reperfusion injury induces apoptosis in rabbit cardiomyocytes. / Clin Invest. 1994;94:1621-1628.

2. Kajstura I, Cheng W, Reiss K, et al. Apoptotic and necrotic myocyte cell deaths are independent contributing variables of infarct size in rats. Lablnvest. 1996;74:86-107.

3. Fliss $\mathrm{H}$, Gattinger D. Apoptosis in ischemic and reperfused rat myocar-dium. Circ Res. 1996;79:949-956.

4. Bialik S, Geenen DL, Sasson IE, et al. Myocyte apoptosis during acute myocardial infarction in the mouse localizes to hypoxic regions but occurs independently of p53. I Clin Invest. 1997:100:1363-1372.

5. Koopman $\mathrm{G}$, Reutelingsperger $\mathrm{CP}$, Kuijten $\mathrm{GA}$, et al. Annexin $\mathrm{V}$ for flow cytometric detection of phosphatidylserine expression on B cells undergoing apoptosis. Blood. 1994;84:5-20.

6. Martin SI, Reutelingsperger CP, McGahon AJ, et al. Early redistribution of plasma membrane phosphatidylserine is a general feature of apoptosis regardless of the initiating stimulus: inhibition by overexpression of Bcl-2 and Abl. I Exp Med. 1995; 182:552-556.

7. Vermes I, Haanen C, Steffens-Nakken $\mathrm{H}$, et al. A novel assay for apo-ptosis: flow cytometric detection of phosphatidylserine expression on early apoptotic cells using fluorescein labelled annexin V. I Immunol Methods. 1995:184:144-151.

8. Van den Eijnde SM, Luijsterburg AJM, Boshart L, et al. In situ detection of apoptosis during embryogenesis with annexin- $\mathrm{V}$ : from whole mount to ultrastructure. Cytometry. 1997;29:313-320.

9. Diaz C, Schroitt AJ. The role of translocases in the generation of phos-phatidylserine asymmetry. I Membr Biol. 1996;151:1-9.

10. Verhoven B, Schlegel RA, Williamson P. Mechanism of phosphatidyl exposure, a phagocyte recognition signal on apoptotic T lymphocytes. I Exp Med. 1995;182:1597-1601.

11. Maulik N, Kagan VE, Tyurin VA, et al. Redistribution of phosphati-dylethanolamine and phosphatidylserine precedes reperfusion-induced apoptosis. Am / Physiol, 1998; $\mathrm{H} 242-\mathrm{H} 248$.

12. Martin SI, Finucane DM, Amarantemendes GP, et al. Phosphatidylserine externalization during CD95-induced apoptosis of cells and cytoplasts requires ICE/CED-3 protease activity. I Biol Chem. 1996;271: 28753-28756.

13. Vanags DM, PornAres MI, Coppola S, et al. Protease involvement in fodrin cleavage and phosphatidylserine exposure in apoptosis. / Biol Chem. 1996;271:31075-31085.

14. McCarthy NJ. Whyte MKB, Gilbert CS, et al. Inhibition of Ced-3/ICE related proteases does not prevent cell death induced by oncogenes, DNA damage, or the Bcl-2 homologue Bak. I Cell Biol. 1997; 136:215-227.

15. Goldstein IC, Waterhouse NJ, Juin P, et al. The coordinate release of cytochrome c during apoptosis is rapid, complete and kinetically invariant. Nat Cell Biol, 2000;2:156-162.

16. Van den Eijnde SM, Boshart L., Reutelingsperger CPM, et al. Phosphatidyl-serine plasma membrane asymmetry in vivo: a pancellular phenomenon which alters during apoptosis. Cell Death Differ. 1997;4:311-316.

17. Hansson GK, Schwartz SM. Evidence for cell death in the vascular endothelium in vivo and in vitro. Am I Pathol. 1983;112:278-286. 
18. Buja LM, Entmann ML. Modes of myocardial cell injury and cell death in schemic heart disease. Circulation. 1998;98:1355-1357.

19. Kerr JF, Wyllie AH, Currie AR. Apoptosis, a basic biological phe-nomenon wit wide-ranging implications in tissue kinetics. Br / Cancer. 1972;26:239-257.

20. Ohno M, Takemura $G$, Ohno A, et al. Apoptotic myocytes in infarct area in rabit hearts may be oncotic myocytes with DNA fragmentation. Circulation. 1998;98:1422-1130.

21. Barinaga M. Stroke-damaged neurons may commit cellular suicde. Science. 1998;281:1302-1303.

22. Xiang J, Chao DT, Korsmeyer SI. Bax-induced cell death may not require intrleukin 1 beta converting enzyme-like proteases. Proc Natl Acad Sci U S A. 1996;93:1455-14563.

23. Lemasters JI, Nieminen AL, Qian T, et al. The mitochondrial perme-ability tunsition in cell death: a common mechanism in necrosis, apoptosis and autophagy. Biochin Biophys Acta. 1998;1366:177-196.

24. Blankenberg FG, Katsikis PD, Tait JF, et al. In vivo detection and imaging o phosphatidylserine expression during programmed cell death. Proc Natl Acad Sci US A. 1998;95: 6349-6354. 
CHAPTER 4

\section{REAL-TIME IMAGING OF APOPTOTIC CELL-MEMBRANE CHANGES AT THE SINGLE-CELL LEVEL IN THE BEATING MURINE HEART}




\section{ABSTRACT}

We report a novel real-time imaging model to visualize apoptotic membnne changes of single cardiomyocytes in the injured heart of the living mouse, usinf fluorescent labeled annexin-V. Annexin-V binds to externalized phosphatidylserine PS) of cells undergoing programmed cell death. With high-magnification (x100-10) real-time imaging, we visualized the binding of annexin- $V$ to single cardiomyoctes. Kinetic studies at the single-cell level revealed that cardiomyocytes started to bird annexin- $V$ within minutes after reperfusion, following an ischemic period of 30 rinutes. The amount of bound annexin- $V$ increased rapidly and reached a maximum vithin 20-25 minutes. Caspase inhibitors decreased the number of annexin- $V$-posive cardiomyocytes and slowed down the rate of PS exposure of cardiomyocytes thi still bound annexin- $\mathrm{V}$. This technology to study cell biology in the natural envinnment will enhance knowledge of intracellular signaling pathways relevant for cell-eath regulation and strategies to manipulate these pathways for therapeutic effect.

\section{INTRODUCTION}

The first effort to visualize physiological and pathological processes within the living organism was made by Wilhelm Conrad Röntgen in 1895. After this, many methods have followed, including magnetic resonance imaging (MRI) and positron emission tomography (PET) ${ }^{\mathrm{T}}$. All these methods have in common that the pathological substrate of disease can be studied at tissue level. However, the biological processes within single cells of an intact living organism, which form the basis of understanding a disease, cannot be studied with these techniques. There are numerous tools and techniques to study processes at the cellular and molecular level in vitro. One of the techniques to study intracellular processes and dynamic signals over time is the use of fluorescent probes $^{2}$. Recent reports demonstrated noninvasive detection of tumors and imaging of angiogenesis in implanted tumors in vivo in the living animal, using fluorescence-detection methods ${ }^{3,4}$. These model systems may become powerful tools to evaluate potential anti-tumor therapies. One of these studies showed that with strong green fluorescent protein (GFP) fluorescence, tumors could be visualized even at a depth of $2.2 \mathrm{~mm}$ (ref. 3). Using cardiac imaging of the ex vivo specimen, we have shown enhanced binding of annexin- $V$, labeled with the strong fluorescent probe Oregon Green (Anx-V-OG), to myocardial tissue of the left ventricle after ischemic injury ${ }^{5}$. Annexin- $V$ has strong affinity for phosphatidylserine (PS), a membrane phospholipid that is rapidly translocated from the inner to the outer leaflet of the cell membrane following activation of the cell-death program ${ }^{6}$. PS translocation is closely related to activation of key steps in the cell-death program such as mitochondrial release of cytochrome-C. (ref. 7.8) 


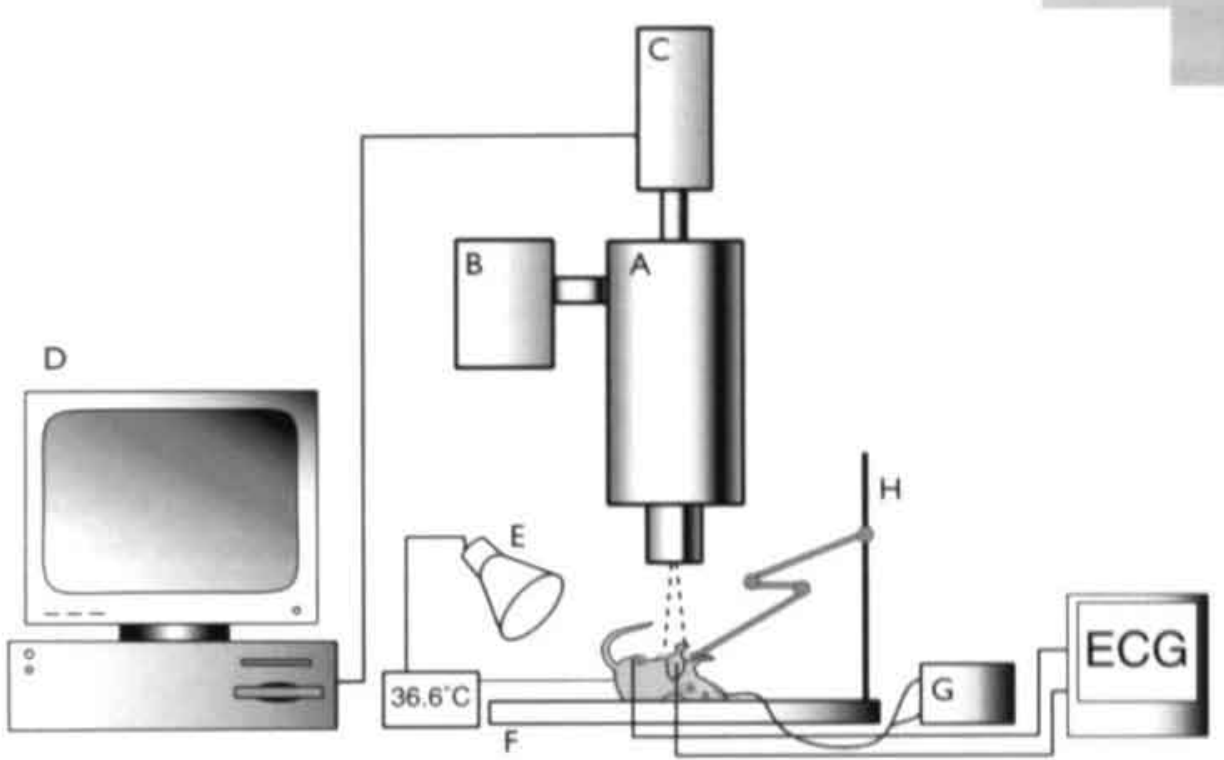

Figure1 Experimental setup. A, Stereomicroscope. B, Fluorescence module. C, CCD camera. D, Computer. E, Heating lamp. F, Heating pad. G, Respiration equipment. H. Micromanipulator.

Here, we report an imaging model system using Anx-V-OG (Fig. 1), which allows analysis of apoptotic cell-membrane changes at the level of the single cell in beating hearts of living mice after cardiac injury.

\section{DETECTION OF ANNEXIN-V BINDING AT THE SINGLE-CELL LEVEL}

During ischemia, we observed hardly any binding of Anx-V-OG to the myocardium. Because Anx-V-OG was given before ischemia, the absence of binding during ischemia is not due to the lack of annexin- $V$ in the ischemic area. However, soon after the start of reperfusion of the heart, we observed an area with distinct uptake of Anx-V-OG in the injured area.(Fig. 2a). In controls, including sham-operated animals and ischemia/reperfusion (I/R) experiments with Oregon Green-labeled annexin-V mutated for the binding site to PS, no uptake was seen. At high magnification ( $x 100-160$ ), binding of annexin- $V$ to rod-shaped cells was visible, which suggested binding of annexin-V to single cardiomyocytes. To strengthen this observation, we injected propidium iodide in the reperfusion phase, which specifically binds to DNA, but can only enter cells when the plasma membrane is permeabilized. In rod-shaped cells showing binding of Anx-V-OG to the cell membrane, we observed propidium iodine staining of two nuclei per cell, which is characteristic of murine cardiomyocytes 
(Fig. 2b). In addition, we measured the size of the rod-shaped cells by smultaneous imaging of a caliper. This revealed that the length of the rod-shaped cells vas approximately $70 \mu \mathrm{m}$, which is compatible with the size of murine cardiomyocytes. At maximal magnification ( $\times 160$ ), binding of annexin- $V$ to the site of the cell-cell junction was observed in vivo (Fig. 2C). Post-mortem analysis of annexin- $\mathrm{V}$ binding to individual car-diomyocytes showed similar images as obtained with real-time imaging(Fig. $2 d$ and e). We observed no binding of Anx-V-OG to other cell types than cardiomyocytes. As we previously observed that the binding of annexin- $V$ to cardiomyocytes within the area at risk starts in the mid-myocardium, a short axis slice was analyzed post-mortem ${ }^{5}$. This showed that annexin- $V$ binding was restricted to the mid-myocardiun of the left ventricle at a depth of $0.3-0.4 \mathrm{~mm}$ (Fig. $2 \mathrm{f}$ ) and not at the epicardial or endocardial layers. In experiments done without repeated administration of adenosine, there was a similar extent of Anx-V-OG binding to the myocardium. Together, these cata indicate that this model imaging system allows the study of binding of annexin- $V$ to individual cardiomyocytes in the beating heart of the living mouse following cardiac injury. Kinetics of annexin-V binding. At the tissue level, hardly any binding of Anx-V-OG was seen during the ischemic period of 30 minutes ( $n=5$, Fig. $3 a$ and b). However directly after reestablishment of blood flow, cardiac tissue in the area at risk of the left ventricle started to show binding of Anx-V-OG (Fig. 3c-f), which showed rapid propagation in a large area of the left-ventricular myocardium. Because in these experiments no glass plate was used to stabilize the heart, which theoretically could have produced local circulation disturbances and mechanical damage to superficial cardiomyocytes, the binding of Anx-V-OG had to be the consequence of reperfusion injury. With high magnification ( $x 160$ ), the kinetics of the binding of Anx-V-OG to single cardiomyocytes was monitored ( $n=10$ ). These results show that binding of annexin- $V$ to the individual cell started within minutes after the onset of reperfusion and reached a maximum level within 20-25 minutes (Fig. 4a-e). Fig. $4 f$ shows a representative graph of Anx-V-OG binding to four different cardiomyocytes obtained from one experiment. The graph allows the calculation of the rate of PS exposure as the increase in relative fluorescence intensity per minute. The mean rate of PS exposure was $4.9 \pm 0.6 \%$ per minute (mean \pm SD; $n=10$ ). These results show that the kinetics of PS exposure by single cardiomyocytes is rapid and kinetically invariant. To rule out that the saturation curve of Anx-V-OG binding was the result of pharmacokinetic behavior of Anx-V-OG, we injected Anx-V-OG 60 minutes after the onset of reperfusion. This showed a saturation of cardiomyocytes with Anx-V-OG within one minute. Given that these cells had maximal PS exposure, the saturation indicates that the time course of binding of Anx-V-OG to the cardiomyocytes reflects the kinetics of PS exposure and not the availability of Anx-V-OG in the injured area. To study whether our system could test the efficacy of cell-death-inhibiting therapy in ischemic cardiac injury, we pretreated mice with a pancaspase inhibitor (IDN $1529,10 \mathrm{mg} / \mathrm{kg}$ ) or a caspase inhibitor with specificity 

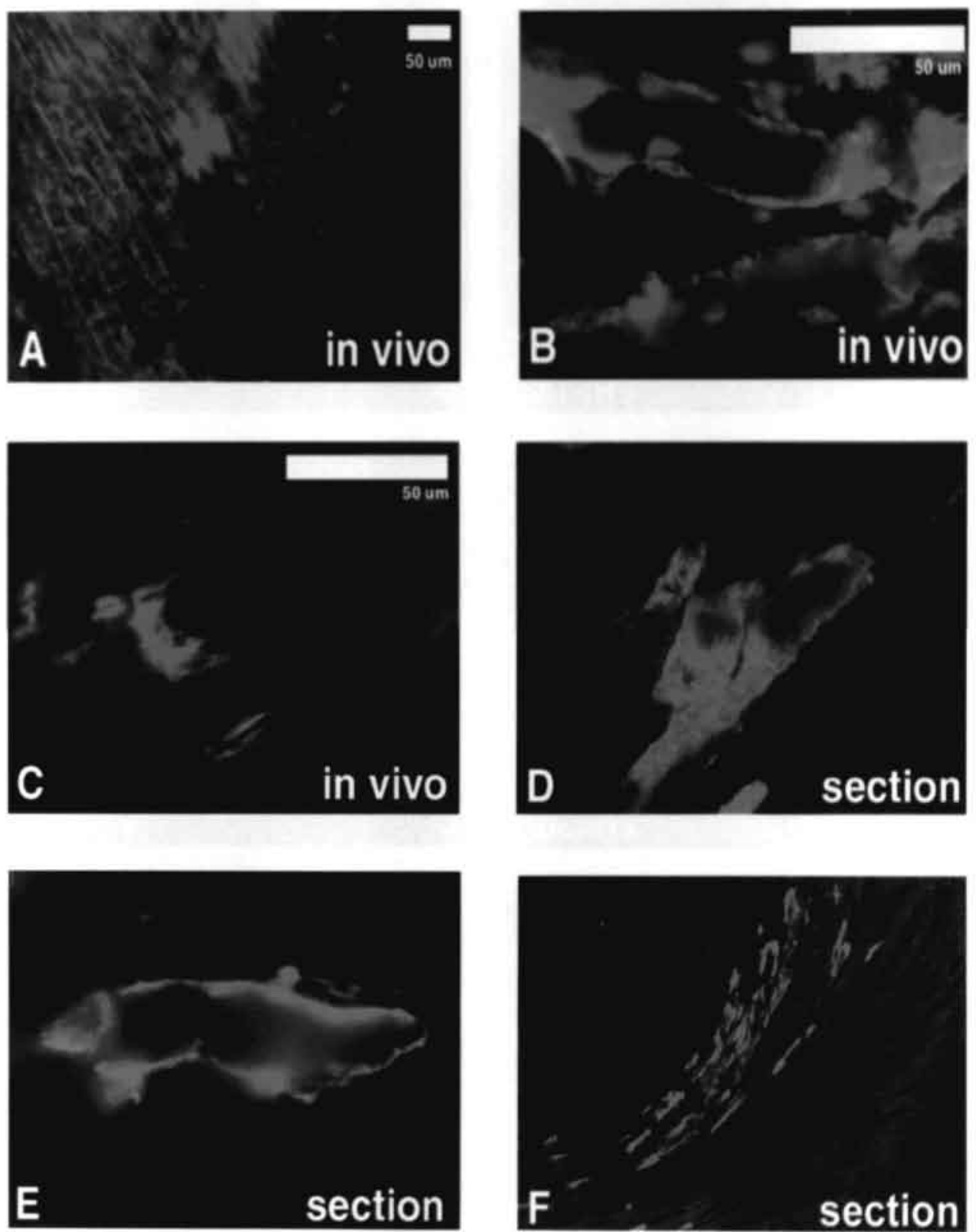

Figure 2 In vivo single-cell imaging. a, Front of Anx-V-OG (green) positive cardiomyocytes in the beating heart of a living mouse after $30 \mathrm{~min}$ of ischemia and $90 \mathrm{~min}$ of reperfusion $(1 / R=30 / 90)$, $\mathrm{b}$, An $x-V-O G$ positive cardiomyocyte shows two nuclei stained with propidium iodide (red) in the beating heart $(1 / R=30 / 90)$. $c$, Anx- $V$-OG positive intercalated disc in the beating heart $(1 / R=30 / 90)$. Post mortem: d, Histological section of Anx-V-OG positive cardiomyocytes. e, Anx- V-OG bound to cardiomyocyte cell membrane. $\mathrm{f}$, Short axis section shows Anx-V-OG positivity of cardiomyocytes in the mid-myocardium, Scale bars, $50 \mu \mathrm{m}$. 


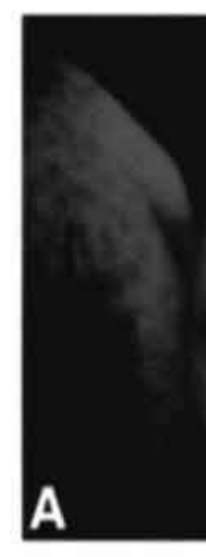

$\mathrm{I} / \mathrm{R}=14 / 0$
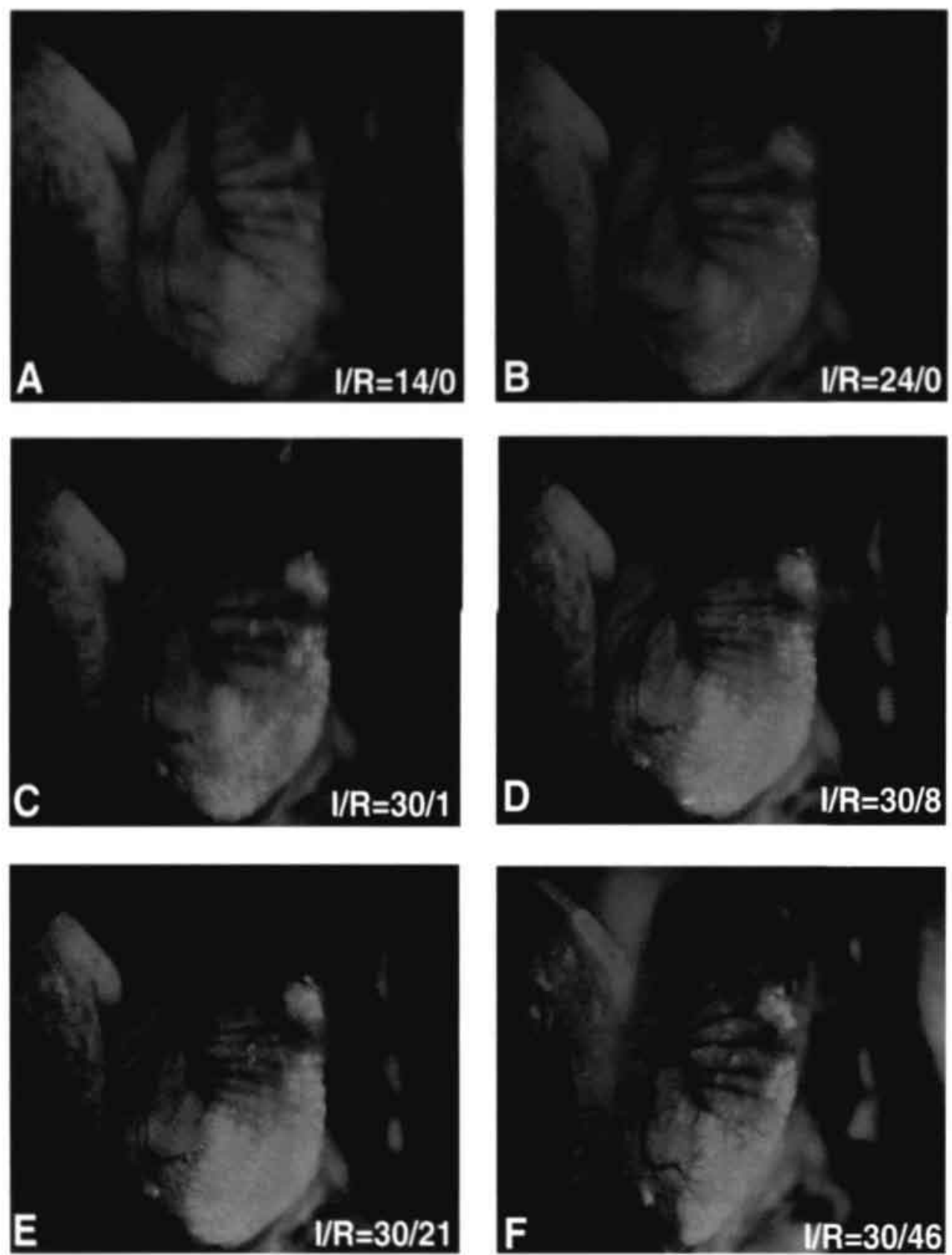

Figure 3 Kinetics of Anx-V.OG binding at the tissue level. a-f, Sequential images obtained with real-time imaging in the beating murine heart show rapid binding of Anx-V-OG in the whole heart. After repertusion (c) a rapid increase of binding of Anx-V-OG occurs. IR times: 14/0 (a), 24/0 (b), 30/1 (c), 30/8 (d). $30 / 21$ (e) and $30 / 46$ (i). 

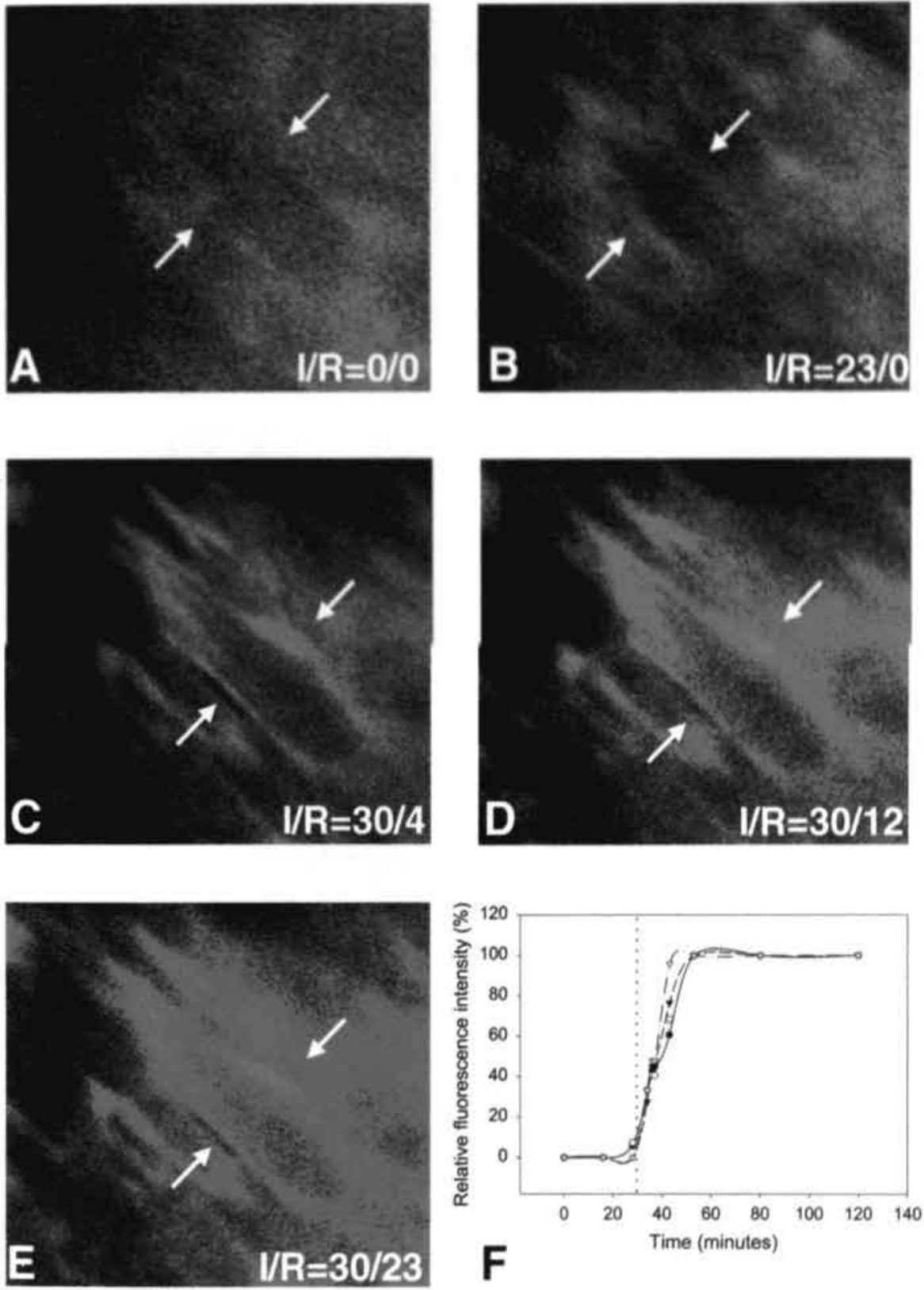

Figure 4 Kinetics of Anx-V-OG binding at the single-cell level. a-e, Sequential images obtained with real-time imaging in the beating murine heart show rapid binding of Anx-V-OG to a single cardiomyocyte during reperfusion. $1 / R$ times: $0 / 0$ (a), 23/0 (b), 30/4 (c), 30/12 (d) and 30/23 (e). Arrows indicate two points on a single cell circumference. $f$, Graph shows relative fluorescence intensity in-crease of four single cells with time ( $/ / R$, time in minutes). Upon reperfusion (dotted line) a rapid in-crease of binding of annexin- $\mathrm{V}$ is observed, which is completed within 20-25 minutes. Different symbols indicate individual cells. 

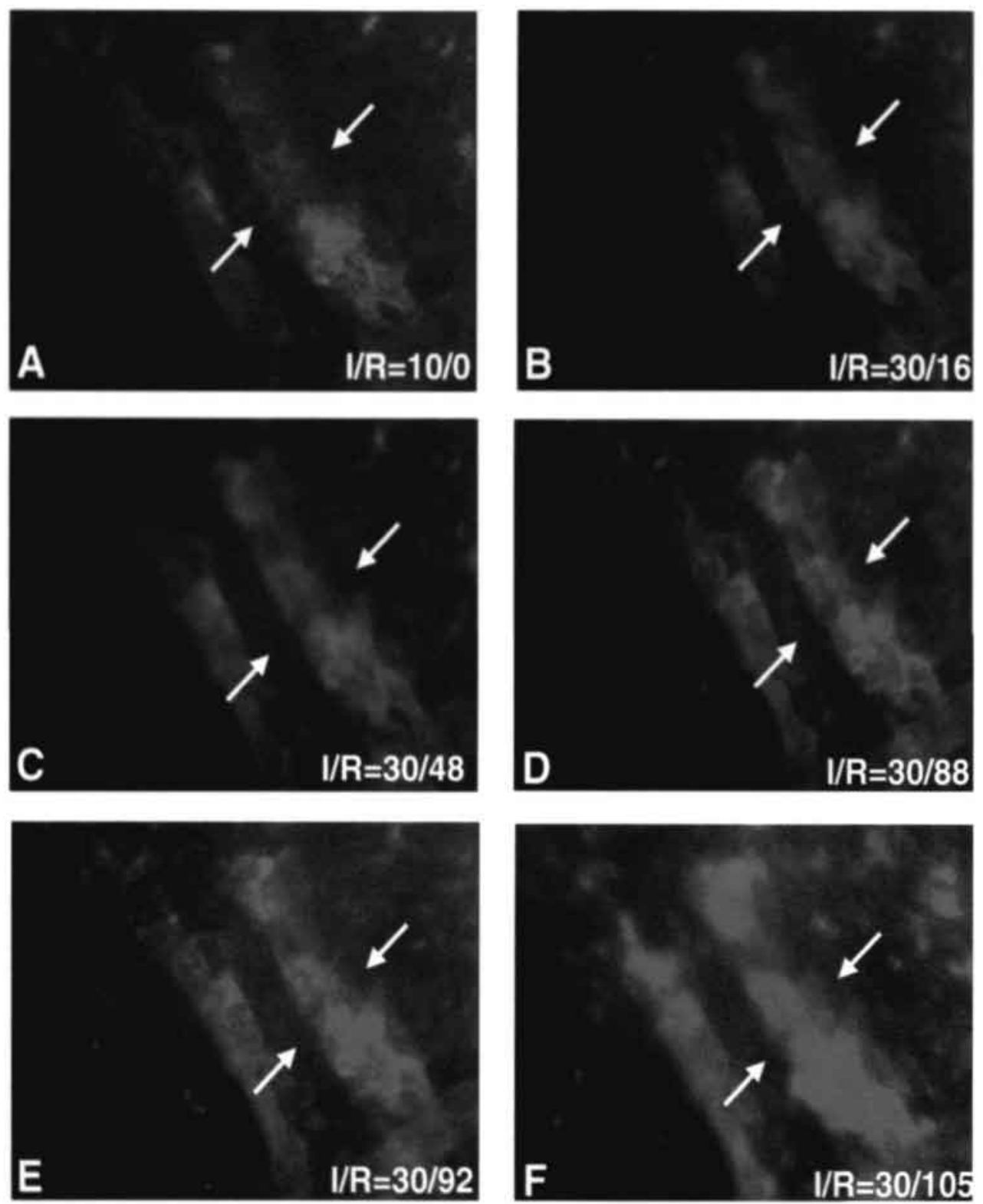

Figure 5 Caspase inhibition decreases Anx-V-OG binding. a-f, Pretreatment with a caspase blocker (IDN 1529) leads to a delayed Anx-V-OG binding to cardiomyocytes during ischemia and reperfusion in the beating murine heart in situ. I/R times: 10/0 (a), 30/16 (b), 30/48 (c), 30/88 (d), 30/92 (e), and 30/105 (i). Arrows indicate two points on a single cell circumference. 

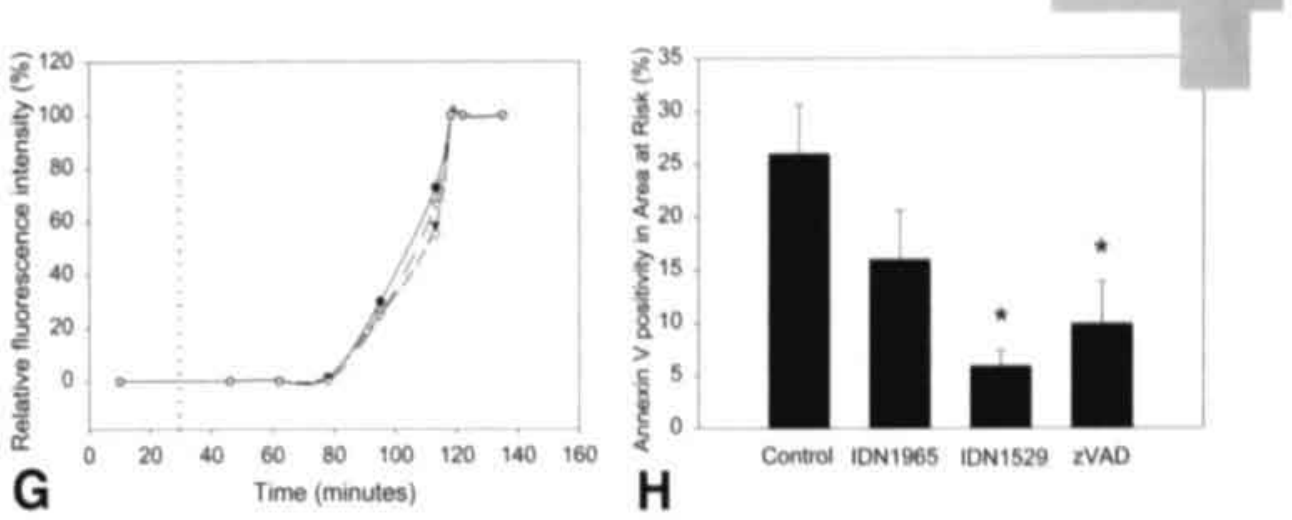

Figure 5 G, Graphic representation of delayed annexin-V binding to cardiomyocytes. Different symbols indicate individual cells. H. Caspase inhibition leads to a decreased number of annexin-V-positive cardiomyocytes as compared with controls in the area at risk after 30 min of ischemia and 90 min of reperfusion. $* P<0.01$.

for caspase-6, -8 and -9 (IDN 1965, $10 \mathrm{mg} / \mathrm{kg}$ ). At the tissue level, we observed a substantial decrease in annexin-V-positive cardiomyocytes in treated mice. The cells that still bound Anx-V-OG in the presence of caspase inhibitors showed a delayed start and a reduced rate of PS exposure (for IDN 1529: $2.5 \pm 0.1 \%$ per min, mean \pm SD, $P<$ 0.05 ; Fig. 5a-g). To validate the results obtained with caspase inhibitors in the in vivo system, we tested the efficacy of the caspase inhibitors using histological analysis of labeled annexin- $V$ showing similar results (Fig. 5h). Caspase inhibition with the pan-caspase inhibitor zVAD also decreased the number of propidium-iodide-positive cells to a similar extent. Together, these results suggest that the PS exposure and subsequent binding of Anx-V-OG to cardiomy-ocytes induced by ischemia and reperfusion in vivo is downstream from caspase activation. These experiments show that our imaging system will allow in vivo study of the effect of cell-death-inhibiting intervention in the heart.

\section{DISCUSSION}

Here we present real-time imaging of apoptotic plasma membrane changes at the single-cell level in the beating heart of a living animal. This should accelerate screening of potential inhibitors of cell death in the heart, which would be beneficial for patients suffering from acute myocardial infarction. In addition, our data provide novel insights into the kinetics of activation of the cell-death program in the heart following injury. Visualizing cardiomyocytes at the single-cell level in mice is possible especially 
because the left ventricle of the mouse heart approximately 0.9-1.0-mm thick, which allows penetration of strong fluorescent signals. Visualization of fluorescent probes in vivo up to $2.2-\mathrm{mm}$ depth has been reported in a mouse tumor model ${ }^{3}$. A recent study reported that the release of cytochrome-C from mitochondria - one of the key activators of the cell-death program - occurs rapidly and is kinetically invariable ${ }^{8}$. That study showed that cytochrome-C release always preceded PS exposure. It is therefore tempting to speculate that the rapid PS exposure in the heart is the result of the mitochondrial events crucial for the cell-death program. At the tissue level, treatment with caspase inhibitors decreased the number of cardiomyocytes binding annexin- $V$. This indicates that activation of the cell-death program can be inhibited in a large fraction of cells that would otherwise have died. In addition, in the cardiomyocytes that bound annexin- $V$, we observed a substantial delay in the onset of annexin- $V$ binding to car-diomyocytes and a slow saturation curve, indicating that PS exposure in vivo is downstream from caspase activation. The question is whether PS exposure in the presence of caspase inhibitors is the result of residual caspase activation or activation of a slower caspase-independent pathway ${ }^{9}$. The rapid activation of the cell-death program after the start of reperfusion implies that the window of opportunity to use cell-death-inhibiting compounds successfully is narrow. The possibility of investigating membrane alterations of cardiomyocytes induced by cardiac injury at the single-cell level provides the opportunity to study cell biology in the complex natural environment of the cell and under clinically relevant pathological conditions. The development of this kind of imaging techniques will help to rapidly translate major findings in molecular biology to in vivo models ${ }^{10}$. Other applications for this system may be the detection of gene expression, homing of stem cells and drug targeting in the heart ${ }^{11}$. Moreover, single-cell imaging may also be used investigate cell biology in vivo in other organ systems, such as the kidney and the liver. In addition, the possibility to study cell biology in the natural environment of the cell will increase our knowledge of cell-death pathways in vivo, and will advance strategies to manipulate these pathways for therapeutic effect.

\section{ACKNOWLEDGMENTS}

We thank N. Steinmetz and B. Armstrong for comments and suggestions. This study was supported from grants from the Dutch Heart Foundation (NHS 98.195 and NHS 2000-D035) and the Wynand-Pon Foundation. L.H. is a clinical research fellow for the Dutch Heart Foundation (NHS 2000-D035) 


\section{REFERENCES}

1. Tempany, C.M. \& McNeil, B.J. Advances in biomedical imaging. /AMA 285,562-567 (2001).

2. Plymale, D.R., Haskins, I.R. \& De La lglesia, F.A. Monitoring simultaneous sub-cellular events in vitro by means of coherent multiprobe fluorescence. Nature Med. 5, 351-355 (1999).

3. Sweeney. T.\}. et al. Visualizing the kinetics of tumor-cell clearance in living ani-mais. Proc. Natl. Acad. Sci. USA 96, $12044-12049$ (1999).

4. Yang, M. et al. Whole-body and intravital optical imaging of angiogenesis in or-thotopically implanted tumors. Proc. Natl. Acad. Sci. USA 98, 2616-2621 (2001).

5. Dumont, E. A. et al. Cardiomyocyte death induced by myocardial ischemia and reperfusion: measurement with recombinant human annexin- $\mathrm{V}$ in a mouse model. Circulation 102. $1564-1568$ (2000).

6. Koopman, $G$, et al. Annexin V for flow cytometric detection of phosphatidylserine expression on 8 cells undergoing apoptosis. Blood 84, 5-20 (1994).

7. Martin, S. . et d. Early redistribution of plasma membrane phosphatidylserine is a general feature of apoptosis regardless of the initiating stimulus: intubition by overexpression af Bd.2 and Abl. I. Exp. Med. 182, 552-556 (1995).

8. Goldstein, J.C., Waterhouse, N.J., Juin, P., Evan, G.I. \& Green, D.R. The coordinate release of cytochrome c during apoptosis is rapid, complete and kinetically invariant. Nature Cell Biol. 2, 156-162 (2000).

9. Xiang, J., Chao, D.T. \& Korsmeyer, S.J. Bax-induced cell death may not require interleukin 1 converting enzyme-like proteases. Proc. Natl. Acad. Sci. USA 93, 14559-14563 (1996).

10. Bell, J.I. Clinical research is dead; long live clinical research. Nature Med. 5, 477-478 (1999).

11. Contag, P. R., Olomu, I. N., Stevenson, D. K. \& Contag, C. H. Bioluminescent indicators in living mammals. Nature Med. 4, 245-247 (1998). 


\section{RECOVERY FROM APOPTOSIS IN THE ISCHEMIC HEART}

Ewald Dumont ${ }^{1,2}$ MD, Leo Hofstra ${ }^{1}$ MD PhD, Artiom Petrov ${ }^{2}$ MD, Navneet Narula ${ }^{3}$ MD PhD, Nezam Haider ${ }^{2}$ PhD, H. William Strauss ${ }^{4}$ MD PhD, F.G. Blankenberg ${ }^{4}$ MD PhD, Heidi Kenis ${ }^{1}$, Peter Frederik ${ }^{1}$ PhD, Harry Crijns ${ }^{1}$ MD PhD, Hein J. Wellens ${ }^{1}$ MD PhD, Neil Steinmetz ${ }^{5}$ MD, Jagat Narula ${ }^{2}$ MD PhD and Chris Reutelingsperger ${ }^{1} \mathrm{PhD}$

${ }^{1}$ Cardiovascular Research Institute, Maastricht, Netherlands

2 Drexel University College of Medicine, Philadelphia, PA, USA

${ }^{3}$ University of Pennsylvania Medical Center, Philadelphia, PA, USA

${ }^{4}$ Memorial Sloan-Kettering Cancer Institute New York, NY, USA

5 Theseus Imaging, Boston, Massachusets, USA

Submitted for publication 


\section{ABSTRACT}

Background: In the developing nematode C. elegans, cells programmed to die can recover from apoptosis in the absence of functional engulfment genes. We herein report that cardiomyocytes can also recover from apoptosis in vivo following brief ischemic episodes.

Methods and results: Annexin-A5, a marker of apoptosis, binds to cardiomyocytes in the beating mouse heart after 5-minutes ischemia, indicating externalization of phosphatidyl serine (PtdSer). Cardiomyocytes continue to expose PtdSer for at least 6 hours following ischemia. PtdSer externalization is secondary to activation of caspase-3, and can be prevented by systemic administration of a pan-caspase inhibitor, zVAD-fmk. Although caspase activation occurs, neither apoptosis completes nor necrosis is observed in the ischemic region. In the ischemic cardiomyocytes, Annexin-A 5 bound to exposed PtdSer is internalised within 20 minutes and accumulates in vesicles around the nucleus. It appears that Annexin-A5 binding to PtdSer and their internalization accelerates clearance of PtdSer from the cell membrane. PtdSer exposure following ischemia in the rabbit could be detected by radionuclide imaging, using technetium-99m labelled Annexin-A5.

Conclusion: Together, our data indicate that cardiomyocytes programmed to die can recover from apoptosis in the mammalian heart subjected to brief ischemia. Recovery from apoptosis in cardiomyocytes may allow development of novel therapeutic interventions and allow after the fact non-invasive radionuclide imaging of chestpain of ischemic origin.

\section{CONDENSED ABSTRACT}

In the nematode $C$ Elegans recovery from apoptosis has been demonstrated. We report here that cardiomyocytes can recover from apoptosis in vivo, induced by a brief ischemic episode followed by reperfusion. Despite activation of caspase-3, a key executioner caspase, and exposure of phosphatidyl serine, no cardiomyocyte cell death was observed. Furthermore, we show that the temporary exposure of phosphatidyl serine can be used as an ischemic memory sign for after the fact post-ischemic imaging.

\section{INTRODUCTION}

Ischemia is the most important cause of myocardial damage. Since the heart muscle cells have no significant regenerative capacity, up to $22-46 \%$ of patients with myocar- 
dial infarction eventually go on to develop heart failure. ${ }^{\prime}$ Therefore, every attempt to salvage myocardial damage is of paramount importance. Although it has been traditionally believed that during ischemia most cells are lost by necrosis, recent studies have shown that the doomed cells route through apoptosis. ${ }^{2}$ We have demonstrated extensive prevalence of apoptosis in acute myocardial infarction by technetium- $99 \mathrm{~m}$ labeled Annexin-A5 imaging. ${ }^{3}$ Intravenously administered, Annexin-A5 binds to sarcolemmal membranes of apoptotic cells. During apoptosis, an integral cell membrane phospholipid, PtdSer, to which Annexin-A5 binds with high affinity, is abnormally exteriorized. ${ }^{4}$ Unlike necrosis, cell death by apoptosis should be prone to regulation. ${ }^{5}$

Recently, recovery from cell death has been reported in the nematode Caenorhabditis elegans, where cells programmed to die can recover from apoptosis in the absence of functional engulfment genes ${ }^{6,7}$; recovery occurs even after shrinkage of the cells and activation of CED-3 (a caspase-3 homolog). Although no experimental evidence is available, a similar recovery from apoptosis has been hypothesized in mammalian cell systems. ${ }^{6}$ To investigate the likelihood of such a recovery from apoptosis in mammalian cells, we studied the evolution of apoptosis in mouse and rabbit hearts in response to ischemic injury; hypoxia and ischemia characteristically induce apoptosis in cardiomyocytes. ${ }^{8}$

\section{METHODS}

\section{PREPARATION OF RADIOLABELED ANNEXIN-A5}

Human Annexin-A5 was produced by expression in Escherichia coli as previously described; this material retains membrane bound PtdSer binding activity equivalent to that of native Annexin-A5. Hydrazinonicotinamide (HYNIC)-99m Technetium derivatized Annexin-A5 was prepared as previously described without affecting PtdSer binding activity. ${ }^{3}$ The radiolabeled material prepared as above had calculated specific activity ranging from $100-200 \mu \mathrm{Ci} / \mu \mathrm{g}$ protein.

\section{SURGICAL INDUCTION OF BRIEF ISCHEMIA IN MICE AND RABBITS}

Induction of ischemia was performed as described previously. 9 After left thoracotomy and exposure of the heart, the left anterior descending coronary artery (mice) or circumflex coronary artery (rabbits) was ligated for 5 and 10 minutes, respectively, and subsequently released.10 After the reperfusion time, the heart was removed for analysis. Biotinylated or radiolabelled Annexin-A5 was administered intravenously as indicated in the text. The data presented are based on at least 3 successfully operated mice. 


\section{HISTOPATHOLOGIC ANALYSIS OF MYOCARDIAL TISSUE}

Labeled Annexin-A5 (25 mg/kg, labeled with biotin, Oregon-Green, or Alex-Red) was injected through a venous line into the jugular vein. After excision of the heart and fixation in $2 \%$ paraformaldehyde and $0.2 \%$ glutaraldehyde in 2 calcium containing binding buffer (Apoptest), routine processing, and paraffin-embedding, 4- $\mu$ m-thick sections were cut perpendicular to the long axis of the heart. In case of the biotinylated Annexin A5 this was followed by staining with a standard avidin-biotin complex kit $A B C$ kit, Vector Laboratories). Diaminobenzidine was used as chromogen. Sections were counterstained with hematoxylin. The kidney was used as positive control, because Annexin-A5 is cleared by the kidney and always shows labelling after intravenous administartion.

\section{ULTRASTRUCTURAL ANALYSIS}

For electron microscopic analyses, murine hearts were fixed after Annexin-A5-biotin labelling of the heart with $2 \%$ paraformaldehyde and $0.2 \%$ glutaraldehyde in Apoptest binding buffer and processed as described above. The samples were embedded in Lowicryl HM20 (Electron Microscopy Sciences) and cut into ultrathin sections by using a Reichert-Jung Ultracut. Then immunolabelling was performed with rabbit anti-biotin IgG (Chemicon International) followed by incubation with goat anti-rabbit IgG (Aurion) conjugated with $10 \mathrm{~nm}$ gold. The labeled sections were air-dried and examined in a Philips CM 10 microscope at $80 \mathrm{keV}$.

\section{RESULTS}

\section{BRIEF MYOCARDIAL ISCHEMIA LEADS TO PTDSER EXPOSURE}

We developed a novel myocardial ischemia-reperfusion model in the beating mouse heart, based on a previously described infarct model. ${ }^{11}$ Under direct microscopic vision, the LAD coronary artery was occluded to induce 5-minute episode of ischemia (I-5), followed by 90 minutes of reperfusion (R-90). Biotinylated or fluoresceinated Annexin-A5 was administered intravenously 10 minutes before completion of reperfusion to identify apoptotic myocytes. ${ }^{12}$ The animals were sacrificed and the hearts harvested at this time for histopathological characterization. Abundant Annexin-A5 positive cardiomyocytes were observed in the ischemic territory (Fig 1A). The binding of Annexin-A5 to the plasma cell membrane of cardiomyocytes indicated that PtdSer was externalized and that the cell death program was activated. ${ }^{4,13}$ To determine the duration of persistence of PtdSer exposure after a brief episode of ischemia, we subjected mouse hearts in vivo to 5 -minute ischemia followed by 180 
minutes (I-5/R-180), 360 minutes (1-5/R-360), or 24 hours (I-5/R-24H) of reperfusion, respectively. Annexin-A5, injected 10 minutes before completion of reperfusion showed binding to the plasma membrane of numerous cardiomyocytes in the heart in both 1-5/R-180 and 1-5/R-360 groups; no uptake of Annexin-A5 was seen at 24 hours (Figure 1A). These data indicate that PtdSer exposed by a brief ischemic episode, persists for at least 6 hours after insult. Histological and histochemical analysis showed that apoptosis or necrosis did not occur up to 24 hours, even in Annexin-A5 positive cardiomyocytes, indicating that mammalian cells can escape cell death after PtdSer exposure.

\section{PTDSER EXPOSURE IS CASPASE DEPENDENT}

Apoptosis assays in vitro have shown that PtdSer exposure is downstream of critical events in the cell death program such as the activation of caspase-3 and release of cytochrome-C from mitochondria. ${ }^{14,15}$ To evaluate the relationship between ischemia and caspase activation, immunoblotting of caspase 3 was undertaken in I-5/R-90 hearts (Figure 1B). The presence of 12 and $17 \mathrm{kD}$ split active fragments of caspase-3, indicated activation of caspase-3; densitometric analysis confirmed a 4 -fold increase in activation of caspase-3. To further investigate the involvement of caspase activation in PtdSer exposure, mice subjected to brief cardiac ischemia received a pancaspase inhibitor, zVAD-fmk, before coronary occlusion. In these experiments Annexin-A5, uptake was not seen in the ischemic zone (Figure 1B). The above experiments indicated that PtdSer externalisation during ischemic injury is mediated by activation of caspases. Although PtdSer exposure and caspase-3 activation represent commitment of the cell to programmed death ${ }^{14,15}$, our data indicate that cardiomyocytes recover from activation of caspases and PtdSer exposure if reperfusion is restored early. The cell death program does not ensue if caspase inhibitors are delivered before the ischemic insult.

\section{PTDSER EXPOSURE IS A CONTINUOUS PROCESS}

The experiments described above demonstrated that PtdSer exposure persists at least for 6 hours after the ischemic insult. Possible mechanisms for this prolonged PtdSer exposure may include permanent PS exteriorisation at the onset of the insult or a continuous process during the injury and recovery phase. ${ }^{16,17}$ To distinguish between the two processes, Annexin-A5 labeled with two different fluorescent markers was injected before coronary artery occlusion (Annexin-A5 Alexa-Red) and before the completion of reperfusion (Annexin-A5 Oregon Green) in the I-5/R-360 model. These data showed the presence of both Annexin A5-Alexa-Red and Annexin A5-Oregon-Green within the cardiomyocytes (Figure 2 E-G). This suggests that PtdSer exposure occurred continuously for at least 360 minutes and did not abrogate after the initial externalization of 
PtdSer. This conclusion seems logical, since PtdSer exposure may continue to occur until activated caspase- 3 is exhausted from within the cell. However, the presence of Annexin-A5 in the cardiomyocytes rather than on the cell membrane suggested that the bound Annexin-A5 is internalized. Moreover, the process of internalization occurs after 10 minutes of binding, since in other experiments (wherein Annexin-A5 was injected only 10 minutes before completion of reperfusion and harvesting of the heart) was exclusively localized to the cell membrane.

\section{ANNEXIN-A5 BOUND TO EXPOSED PTDSER IS INTERNALIZED IN CYTOPLASMIC VACUOLES.}

To further study the kinetics of internalization of Annexin-A5, we injected Annexin-A5 at different time points before conclusion of reperfusion in 1-5/R-90 experiments. Annexin-A5 injected 10 minutes before sacrifice of the mouse hearts showed binding exclusively to cardiomyocyte membranes. However, injection of Annexin-A5 20 or more minutes before completion of reperfusion showed localization of Annexin-A5 within the cytoplasmic compartment of the cell (Figure 2A). This indicated that the PtdSer-Annexin-A5 complex internalized within approximately 10-20 minutes after Annexin-A5 binding. Immuno-electron microscopic analysis with the help of gold-labeled Annexin-A5 antibodies, showed that internalized Annexin-A5 preferentially localized around the nucleus in cytoplasmic vacuoles (Figure $2 \mathrm{~A}$ ). ${ }^{18}$ Further analysis showed that the internalization of Annexin A5 is the result of invagination of the plasma membrane and the subsequent formation of Annexin A5 containing vesicles (Figure 2 C,D). Although clearance of PtdSer may be a protective phenomenon for the cell, the functional importance and the fate of Annexin-A 5 bearing sarcolemmal vesicles remains to be understood.

\section{PROLONGED PTDSER EXPOSURE MAY REPRESENT AN ISCHEMIC MEMORY THAT IS AMENABLE TO NUCLEAR IMAGING}

The data from the mouse model indicated that the window of PtdSer exposure is at least 6 hours following a brief episode of ischemia. Therefore, PtdSer exposure may serve as a marker of ischemic memory in the myocardium. We reasoned that such prolonged PtdSer exposure could be potentially used to diagnose recent ischemic events in patients admitted to the emergency rooms. We and others, have previously shown that PtdSer exposure in the heart can be non-invasively imaged with radiolabeled Annexin-A5. 3,9,19 To investigate the potential of imaging ischemic memory in the heart, we subjected NZW rabbits to ischemic insult by left circumflex coronary artery occlusion for 10 minutes followed by 180-minute reperfusion (1-10/R-180 model). $99 \mathrm{~m}$ Tc-labeled Annexin-A5 ret. $20(12 \pm 1 \mathrm{mCi}$ with $30-40 \mu \mathrm{g} / \mathrm{kg}$ of protein) was adminis- 

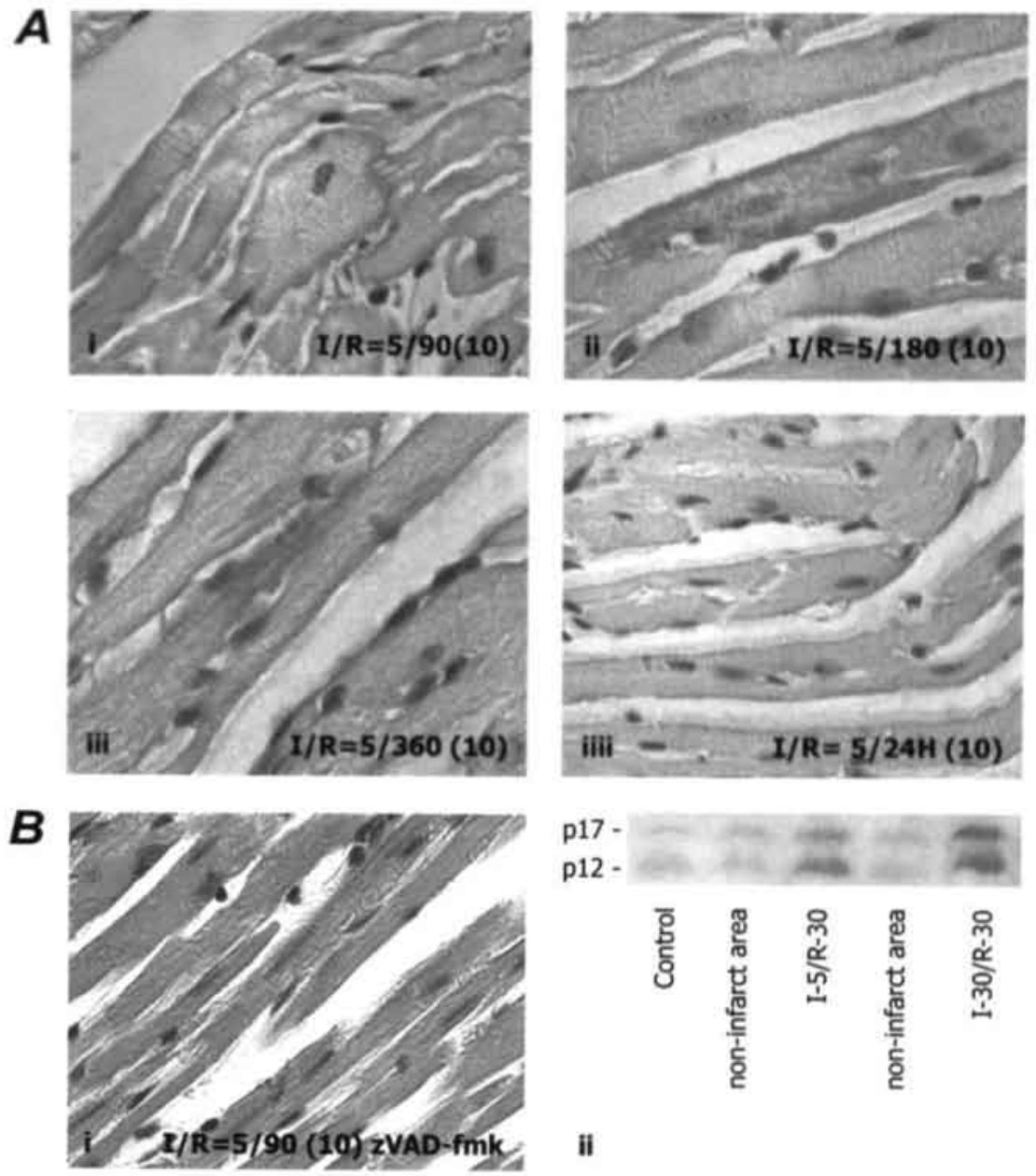

ii

Figure $1 \quad$ Cardiomyocytes recover from apoptosis following ischemia (A) (i) In the first set of experiments mice were sacrificed after 5 -minute ischemia and 90 -minute reperfusion and biotinylated Annexin-A5 was injected 10 minutes before sacrifice [I-5/R-90(10)]. Upon direct immunoperoxidase staining, Annexin-A5 was localized to the cell membrane. (ii) and (iii) demonstrate reperfusion for 180 and 360 minutes, respectively, with Annexin-A5 injected 10 minutes before sacrifice II-5/R-180(10), 1-5/R-360(10)]: Annexin-A5 binding continues to be localized to the cell membrane. (iv) At 24 hours of reperfusion |1-5/R-24H(10)], PtdSer exposure is not observed, and no apoptotic or necrotic cells were observed at 24 hours, indicating that PtdSer exposure following brief ischemic injury did not lead to execution of cell death.

(B). Caspase inhibition prevents PtdSer exposure upon brief ischemia. (i). In the ischemia-reperfusion model similar to A, pretreatment with zVAD-fmk results in complete abrogation of PtdSer externalization, as evidenced by lack of AnnexinA5 binding. (ii). In the model similar to A (i) instant activation of caspase- 3 is seen in the ischemic region. The first lane of the Western blot represents reperfused ischemic myocardium and lane 2 represents the normal myocardium; no caspase activation is seen in remote myocardium. These data were confirmed using densitometry. 

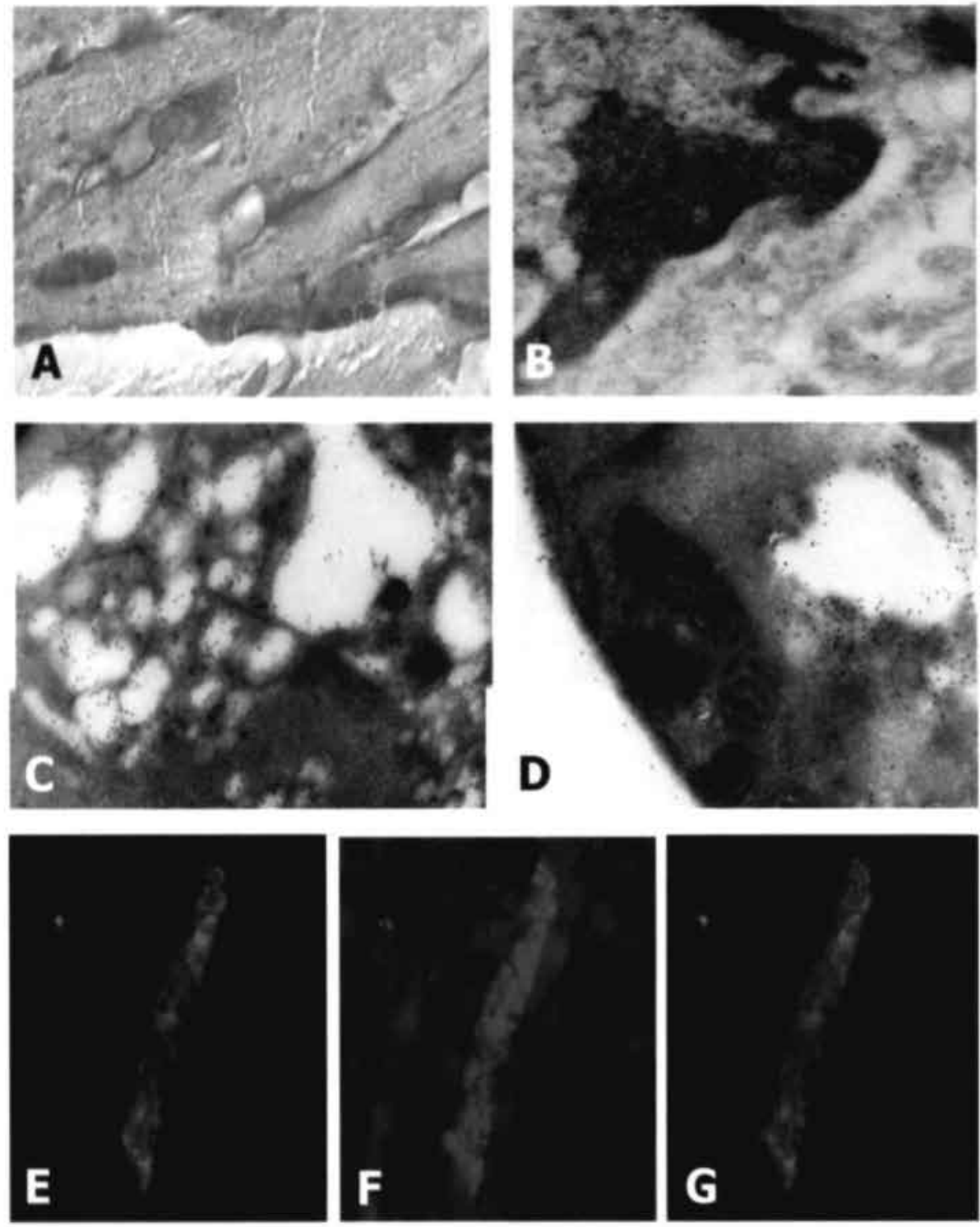

Figure 2 Following brief ischemia, bound Annexin A5 is internalized into the cytosol.

Whereas administration of biotinylated Annexin-A5 10 minutes before sacrifice in the 5 -minute ischemia and 90 -minute reperfusion model demonstrated binding to the cell membrane surface [see Fig $1 \mathrm{~A}(\mathrm{i})$ ]. administration of Annexin-A5 20 minutes before sacrifice demonstrates its localization intracellularly (A). The intracellular localization by immuno-EM is predominantly confined to in and around the nucleus (B). Further EM analysis (C) and (D) demonstrates formation of vesicles originating from the cell membrane, which show abundant Annexin A5 presence on the inner leaflet of the vesicle. The vesicles of Annexin-As move away from the cell membrane. E-G show the binding and uptake of Annexin A5-Alexa-Red adminstered before the brief ischemic episode (E), and binding and uptake of Annexin A5-Oregon-Green administered 160 minutes after reperfusion and 20 minutes before sacrifice (F). G show the combined image. 
tered intravenously at the time of reperfusion. Animals were killed 3 hours after administration of the radiotracer. Ex vivo imaging demonstrated significant radiolabeled Annexin-A5 uptake in the zone of initial ischemia (Figure 3). Annexin-A5 uptake of $0.27 \pm 0.16 \%$ injected dose/gram in the ischemic region was $9 \pm 3$ fold higher compared to $0.03 \pm 0.01 \%$ in normal myocardium. Moreover, more than $85 \%$ of the radioactivity was recovered from ultra-centrifugally isolated cytoplasmic and organelle compartment of the cells, confirming that Annexin-A5 bound to PtdSer was internalized. Although enhanced uptake of Annexin-A5 had occurred in the ischemic regions, no histologic evidence of apoptosis or necrosis in the hearts was observed. Together, these data indicate that PtdSer externalization, which occurs in briefly ischemic myocardium, can be potentially targeted for noninvasive imaging of ischemic myocardium. The data also confirmed that PtdSer exteriorization can occur without actual loss of cardiomyocytes.

\section{DISCUSSION}

Our data show that brief episodes of ischemia result in PtdSer exposure which normally lasts for at least 6 hours after the ischemic insult and is related to caspase activation. Since PtdSer exposure and caspase activation are the hallmarks of apoptosis ${ }^{16}$, our data suggest that cardiomyocytes can recover from apoptosis. The reversal of apoptosis has been reported previously in C.elegans. ${ }^{6,7}$ During developmental apoptosis, engulfment genes act in concert with CED-3 in cells destined to die in the anterior pharynx. In the absence of activation of the engulfment machinery, such cells showed all the features of apoptosis, but cell death did not occur; these cells recovered completely and remained viable thereafter. Our data confirm recovery from apoptosis in mammalian cells in vivo, despite activation of one of the key executioner caspases, caspase-3. Other examples of PtdSer exposure not associated with execution of apoptosis include activation of B cell lymphoma cells, which in response to cross-linking of the membrane immunoglobulin receptor stained positive for Annexin-A5, but were able to restore their phospholipid asymmetry and resume growth upon withdrawal of the stimulus. ${ }^{21}$

It seems that the phenomenon of recovery from apoptosis may be evolutionary conserved. However, in contrast to the $\mathrm{C}$. elegans the absence of engulfment gene activity may not be critical in recovery of cell death in the heart, since phagocytes enter the ischemic zone only after 24 hours. An interesting aspect of the binding of Annexin A5 to externalized PtdSer may be that this offers the cells protection from being recognized by phagocytes, since externalized PtdSer is necessary for engulfment of apoptotic cells and serves as an 'eat me signal'. ${ }^{16}$ Recent clinical studies have shown that plasma Annexin-A5 levels are elevated in patients with acute myocardial infarction. ${ }^{22}$ These 

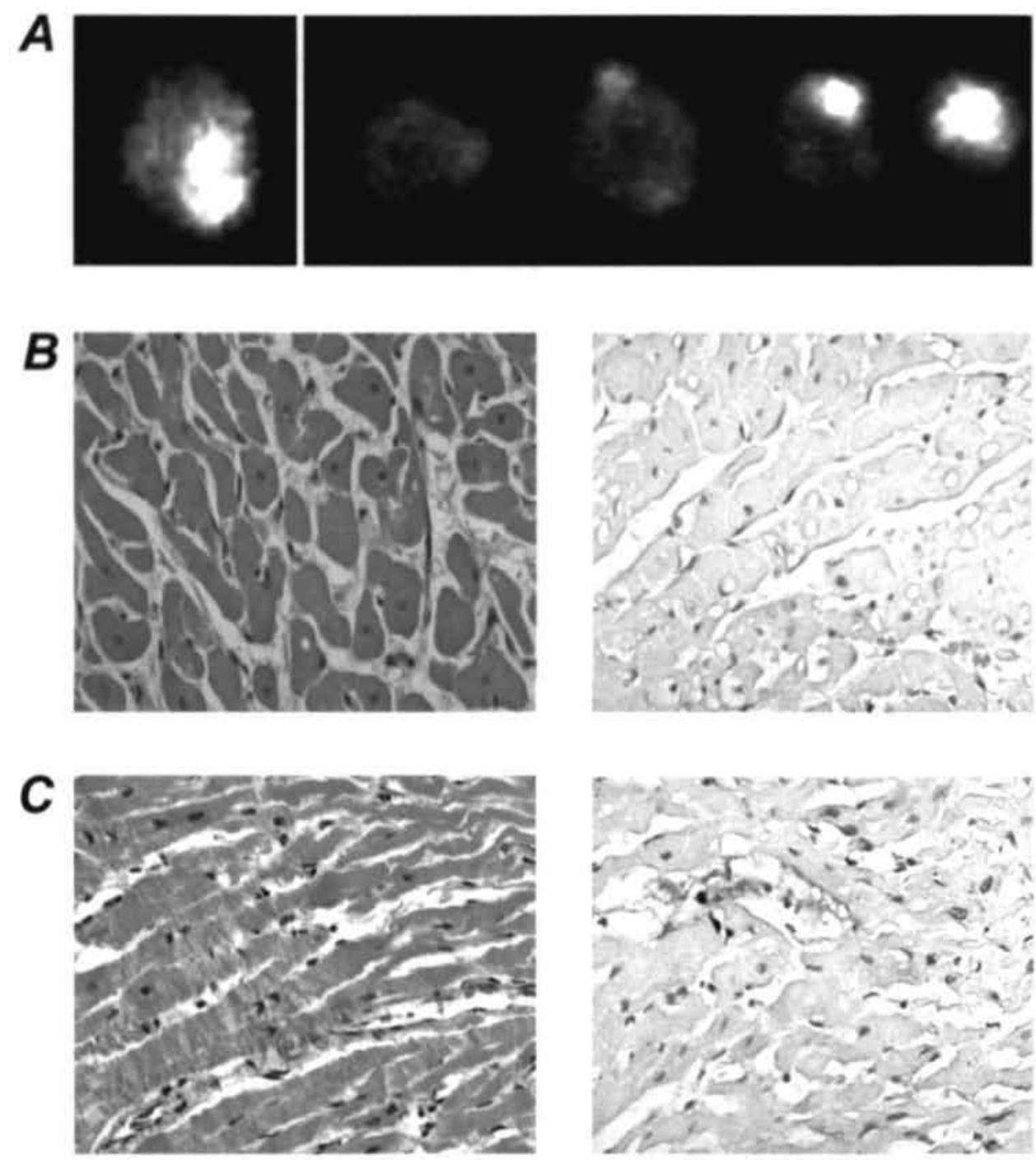

Figure 3 Externalized PtdSer allows radionuclide detection of ischemic myocardium.

(A), In a 10-minute ischemia and 3-hour reperfusion model in rabbit [1-10/R-180], radiolabeled Annexin-As clearly delineates the ischemic zone with a 9-fold higher uptake than in the remote myocardium. The uptake is seen in the gamma image of whole heart and bread-loaf slices (A). No apoptosis (left) or necrosis iright) was observed in the ischemic zone (B). In the prolonged ischemic model [I-40/R-180| (data not discussed in the manuscript) (C). apoptosis (left) and necrosis (right) are widely present. Necrosis is represented by contraction band alteration and apoptosis by in-situ end labeling. 
data suggest that Annexin-A5 may serve as an acute phase reactant, which may protect cells that are susceptible to engulfment. It also seems justified to hypothesize that exogenously administered Annexin-A5 may accelerate internalization of exteriorized PtdSer. The data on the internalization of PtdSer in the presence of Annexin A5 indicate that internalization is not the result of scrambling of single PtdSer molecules but is the result of invagination and vesicle formation of the patches of plasma cell membrane that expose PtdSer. Together, our data suggest a novel model of PtdSer exposure and internalisation, whereby PtdSer exposure is continuously driven by caspase mediated scramblase activation, whereas PtdSer internalisation is mediated by formation of vesicles. Cytoplasmic uptake of exogenous Annexin-A5 has been previously reported in animal studies of apoptotic cell death during embryogenesis ${ }^{23}$, tooth development ${ }^{24}$ and prolonged myocardial ischemia. ${ }^{10}$ The investigators in these studies concluded that the intracellular uptake of exogenous Annexin-A5 was due to ingestion of apoptotic vesicles coated with Annexin-A5 by neighboring cells. This mechanism in our model seems unlikely given the lack of apoptotic or necrotic cells in the hearts of animals subjected to brief ischemia. A question that remains to be answered is whether (and how) the Annexin A5 positive vesicles affect the biology within the cell.

Whatever be the purpose of PtdSer and concomitant Annexin-A5 internalization, it constitutes an attractive target for noninvasive detection of myocardial ischemia as a 'hot-spot' imaging agent in lieu of (or in addition to) stress myocardial perfusion imaging. ${ }^{25}$ Furthermore, persistence of PtdSer externalization for at least 6 hours after ischemic stress may allow retrospective diagnosis of cardiac chest pain and support the concept of 'ischemic memory'.

In conclusion, our data demonstrate that caspase-3 is activated and PtdSer is exteriorized in mammalian cells in response to brief ischemia of the heart. Cardiomyocytes destined to die recover from the initiation of the cell death program upon restoration of blood flow. The transient exposure of PtdSer by cardiomyocytes recovering from apoptosis may serve as an ischemic memory marker, which can be exploited for diagnostic imaging. Moreover, Annexin-A5 binding to PtdSer leads to cytoplasmic internalization of Annexin-A5. The role of Annexin-A5-PtdSer internalization remains to be understood.

\section{ACKNOWLEDGEMENT}

Ewald A. Dumont is a DiPalma fellow at Drexel University College of Medicine, Philadelphia, and supported by DiPalma-Brodsky Research Funds. L. Hofstra is Clinical Investigor of Dutch Heart Foundation (NHS2000-D35) and the Dutch Science Founda- 
tion (NWO2000-25). Supported in part the by Dutch Heart Foundation Grants 98.195 and Wynand M. Pon Foundation

\section{REFERENCES}

1. American Heart Association. Statistics on myocardial infarction and stroke. 2001. Report

2. Ohno M, Takemura G, Ohno A et al. Apoptotic myocytes in infarct area in rabbit hearts may be oncotic myocytes with DNA fragmentation. Circulation 1998; 98:1422-1430.

3. Hofstra L, Liem IH, Dumont $E$ et al. Visualisation of cell death in vivo in patients with acute myocardial infarction. Lancet 2000; 356:209-212.

4. Koopman G, Reutelingsperger CP, Kuijten GA et al. Annexin V for flow cytometric detection of phosphatidylserine expression on B cells undergoing apoptosis. Blood 1994; 84:5-20.

5. Leist $M$, Jaättela $M$. Four deaths and a funeral: from caspases to alternative mechanisms. Nat Rev Mol Cell Biol 2001; 2(8):589-598.

6. Reddien PW, Cameron S, Horvitz HR. Phagocytosis promotes programmed cell death in C. elegans. Nature 2001; 412(6843):198-202.

7. Hoeppner DI, Hengartner MO, Schnabel R. Engulfment genes cooperate with ced-3 to promote cell death in Caenorhabditis elegans. Nature 2001; 412(6843):202-206.

8. Tanaka M, Ito $\mathrm{H}$, Adachi S, Akimoto $\mathrm{H}$ et al. Hypoxia induces apoptosis with enhanced expression of Fas antigen messenger RNA in cultured neonatal rat cardiomyocytes. Circ Res $1994 ; 75(3): 426-433$.

9. Dumont EA, Reutelingsperger CP, Smits IF et al. Real-time imaging of apoptotic cell-membrane changes at the single-cell level in the beating murine heart. Nat Med 2001; $7(12): 1352-1355$.

10. Dumont E, Reutelingsperger C, Van Heerde WL et al. Apoptosis of cardiomyocytes induced by ischemia and reperfusion; Early detection with Annexin-V. Lancet 353, s27, 1999.

11. Dumont EA, Hofstra L, Van Heerde WL, van Den Es et al. Cardiomyocyte death induced by myocardial ischemia and reperfusion : measurement with recombinant human annexin- $\mathrm{V}$ in a mouse model. Circulation 2000; 102(13):1564-1568.

12. Bialik S, Geenen DL, Sasson IE et al. The caspase family of cysteine proteases mediate cardiac myocyte apoptosis during myocardial infarction. Circulation 96[8], 552-553. 21-10-0097.

13. Fadok VA, Voelker DR, Campbell PA et al. Exposure of phosphatidylserine on the surface of apoptotic lymphocytes triggers specific recognition and removal by macrophages. J Immunol 1992; 148(7):2207-2216.

14. Goldstein IC. Waterhouse NJ. Juin P et al. The coordinate release of cytochrome c during apoptosis is rapid, complete and kinetically invariant. Nature Cell Biology 2000;2:156-162.

15. Martin SI, Reutelingsperger CP. McGahon AJ et al. Early redistribution of plasma membrane phosphatidylserine is a general feature of apoptosis regardless of the initiating stimulus: inhibition by overexpression of Bcl-2 and Abl. I Exp Med 1995; 182:552-556.

16. Savill I. Fadok V. Corpse clearance defines the meaning of cell death. Nature 2000; 407(6805):784-788. 
17. Bratton DL, Fadok VA, Richter DA et al. Appearance of phosphatidylserine on apoptotic cells requires calcium- mediated nonspecific flip-flop and is enhanced by loss of the aminophospholipid translocase. J Biol Chem 1997; 272(42):26159-26165.

18. Bialik S, Cryns VL, Drincic A et al. The mitochondrial apoptotic pathway is activated by serum and glucose deprivation in cardiac myocytes. Circ Res 1999; 85(5):403-414.

19. Narula I. Acio ER, Narula $\mathrm{N}$ et al. Annexin-V imaging for noninvasive detection of cardiac allograft rejection. Nat Med 2001; 7(12);1347-1352.

20. Bristow MR, Gilbert EM, Abraham WT et al. Carvedilol produces dose-related improvements in left ventricular function and survival in subjects with chronic heart failure. MOCHA Investigators [comment]. Circulation 1996; 1996 Dec 1; 94:11-16.

21. Hammill AK, Uhr JW, Scheuermann RH. Annexin V staining due to loss of membrane asymmetry can be reversible and precede commitment to apoptotic death. Exp Cell Res 1999; 251(1):16-21.

22. Kaneko N, Matsuda R, Hosoda $S$ et al. Measurement of plasma annexin V by ELISA in the early detection of acute myocardial infarction. Clin Chim Acta 1996; 251(1):65-80.

23. Van den Eijnde SM, Luijsterburg AJM, Boshart L et al. In situ detection of apoptosis during embryogenesis with Annexin-V: From whole mount to ultrastructure. Cytometry 1997; 29:313-320.

24. Bronckers AL, Goei W, Van Heerde WL et al, Phagocytosis of dying chondrocytes by osteoclasts in the mouse growth plate as demonstrated by annexin-V labelling. Cell Tissue Res 2000; 301(2):267-272.

25. Wackers FJ, Zaret BL. Radionuclide stress myocardial perfusion imaging: the future gatekeeper for coronary angiography. J Nucl Cardiol 1995; 2(4):358-359. 


\section{VISUALISATION OF CELL DEATH IN VIVO IN PATIENTS WITH ACUTE MYOCARDIAL INFARCTION}

Leo Hofstra, Ing Han Liem, Ewald A Dumont, Hendrikus $\mathrm{H}$ Boersma, Waander L van Heerde, Pieter A Doevendans, Ebo DeMuinck, H J J Wellens, Gerrit J Kemerink, Chris P M Reutelingsperger, Guido A Heidendal

Departments of Cardiology (L Hofstra MD, E Dumont MD, P Doevendans MD, E DeMuinck MD, Prof H Wellens MD), Nuclear Medicine (I Liem MD, G Kemerink PhD, Prof G Heidendal MD), Biochemistry ( $W$ van Heerde PhD, C Reutelingsperger PhD), and Clinical Pharmacy (H Boersma PharmD), University Hospital Maastricht, Maastricht, The Netherlands. 


\section{SUMMARY}

Background. In-vivo visualisation and quantification of the extent and time-frale of cell death after acute myocardial infarction would be of great interest. We sidied in-vivo cell death in the hearts of patients with an acute myocardial infarctionising imaging with technetium-99m-labelled annexin- $\mathrm{V}$ protein that binds to cells ndergoing apoptosis. Methods Seven patients with an acute myocardial infarction ar one control were studied. All patients were treated by percutaneous transluminal comnary angioplasty (six primary and one rescue), resulting in thrombolysis in myocardial Ifarction (TIMI) III flow of the infarct-related artery. $2 \mathrm{~h}$ after reperfusion, $1 \mathrm{mg}$ annxin-V labelled with $584 \mathrm{MBq}$ Tc-99m was injected intravenously. Early (mean $3.4 \mathrm{~h}$ ) ad late (mean 20.5 h) single-photon-emission computed tomo-graphic (SPECT) images the heart were obtained. Routine myocardial resting-perfusion imaging was also dne to verify infarct localisation. Findings in six of the seven patients, increased uptke of Tc-99m- labelled annexin- $V$ was seen in the infarct area of the heart on early ad late SPECT images. No increased uptake was seen in the heart outside the infarct ara. All

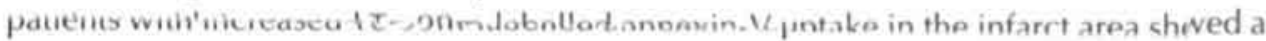
matching perfusion defect. In a control individual, no increased uptake in the heart was seen. Interpretation Increased uptake of Tc-99m-labelled annexin-V is present in the infarct area of patients with an acute myocardial infarction, suggesting that programmed cell death occurs in that area. The annexin- $V$ imaging protocol might allow us to study the dynamics of reperfusion-induced cell death in the area at risk and may help to assess interventions that inhibit cell death in patients with an acute myocardial infarction.

\section{INTRODUCTION}

In patients with an acute myocardial infarction, cardiomyocyte death occurs in the infarct area, leading to loss of contractile function of the heart. Several animal studies have shown that ischaemia of the heart, followed by reperfusion, results in a substantial loss of cardiomyocytes through apoptosis (programmed cell death). ${ }^{1-3}$ This observation implies that cardiomyocytes in the infarct area might be rescued if efficient blockade of the cell-death programme is possible, ${ }^{4}$ In cardiac biopsy samples obtained from patients with an acute myocardial infarction, DNA fragmentation-a hallmark of apoptotic cell death - has been shown. ${ }^{5.6}$ However, since cardiac biopsy samples are necessary to show DNA fragmentation, information about the extent and time-frame of programmed cell death is difficult to obtain after an acute myocardial infarction. Hence, new therapeutic strategies that target myocardial cell death are difficult to assess owing to the lack of knowledge about the dynamics of cell death early after reperfusion. 
One of the earliest events in programmed cell death is the externalisation of phosphatidylserine from the inner leaflet of the plasma membrane to the outer leaflet. Externalisation of phosphatidylserine is closely related to activation of important components of the cell death programme, and occurs, at least in vitro, downstream from the release of cytochrome $\mathrm{C}$ by mitochondria and activation of executioner caspases. ${ }^{8,9}$ We and others have shown that labelled annexin-V, which has a high affinity for phosphatidylserine, is a specific and reliable tool for the detection of apoptotic cells under various conditions, including ischaemia and reperfusion in the murine heart. ${ }^{10-13}$ On the basis of these studies, we decided to test radionuclide imaging with technetium-99m-labelled human recombinant annexin- $V$ to visualise cardiac cell death after reperfusion therapy in patients with an acute myocardial infarction.

\section{METHODS}

\section{PATIENTS}

Seven patients with a first acute myocardial infarction who presented within $6 \mathrm{~h}$ of the onset of symptoms, were candidates for the study. The diagnosis of an acute myocardial infarction was made by electrocardiographic criteria and confirmed by biochemical detection of cardiac enzyme release. Six patients underwent primary percutaneous transluminal coronary angioplasty (PTCA) of the infarct-related vessel, resulting in thrombolysis in myocardial infarction (TIMI) III flow. In one patient, after unsuccessful thrombolysis, rescue PTCA was done, resulting in restored blood flow. One healthy man was used as a control. Since annexin- $V$ is mainly cleared by the kidney, only individuals with normal kidney function were included. Written informed consent was obtained from all patients and the control. The medical ethics committee of the University Hospital of Maastricht approved the study.

\section{METHODS}

Human recombinant annexin- $V$ (Nexins, Kattendijke, Netherlands) was modified to annexin V-n-1-imino-4-mercaptobutyl (Mallinckrodt, Petten, Netherlands). After labelling with pertechnetate, radiochemical purity was measured by column chromatography with a Sephadex PD-10 column (Pharmacia, Upsalla, Sweden) and $1 \%$ bovine serum albumin (Sigma, St Louis, MO, USA) in saline. Radiochemical purity was $79.4 \%$ (SD 3.4). For scintigraphy, $584 \mathrm{MBq}$ (SD 87; $1 \mathrm{mg}$ ) Tc-99m-labelled annexin-V was given intravenously $2 \mathrm{~h}$ after reperfusion. All scintigraphic studies were done with MultiSPECT2 dual-head gamma cameras (Siemens, Hoffman Estate, IL, USA) with low energy, high resolution collimators, and an energy peak of $140 \mathrm{keV}$ and a window of 
$20 \%$. In each patient, early single-photon-emission computed tomo-graphs (SECTs) were acquired after a mean of $3.4 \mathrm{~h}$ (SD 1.2), and late SPECTs after a mean of $0.5 \mathrm{~h}$ $(1.8)$ post injection to measure intensity and location of uptake in the heart. Weised a 6464 matrix and 60 angle views, counting each angle for 45 s. Studies wereeconstructed with a back-projection filtered method, by means of a Butterworth filtewith a cut-off frequency of 0.55 and an order of 5. Since the SPECT imagn of Tc-99m-labelled annexin- $V$ showed focal uptake only in the infarction area, recientation of the SPECT images as done in routine myocardial perfusion scintigraphy ws difficult. Therefore, all SPECT studies were converted to transverse slices to compre the location of Tc-99m-labelled annexin-V uptake with the perfusion defect After discharge from the hospital, six patients underwent routine myocardial strss-rest scintigraphy by means of Tc-99m-labelled radiopharmaceuticals (tetrofosin or sestamibi), to verify infarct localisation. A three-dimensional reconstruction sinilar to the annexin-V SPECT reconstruction was applied to compare the localisatiorof the defect in myocardial perfusion and the site of increased Tc-99m-labelled anexin-V uptake.

\section{RESULTS}

We studied five men and two women (table). The mean age was 55.9 years (SD 6.6). In six of the seven patients, increased uptake of Tc-99m-labelled annexin-V in the infarct area was seen on early and late SPECT images. Figure 1 shows an example of increased annexin- $\mathrm{V}$ uptake in the anteroseptal area of the late SPECT of a patient with an acute anterior-wall myocardial infarction (patient 1). Increased annexin- $V$ uptake was seen in the anteroseptal area on the images obtained $22 \mathrm{~h}$ after injection. An example of a patient with an anterior wall infarction is given in figure 2 (patient 4). Increased uptake of Tc-99m-labelled annexin-V can be seen in the anterior wall of the heart on the late SPECT. Increased uptake of annexin- $V$ was not seen in the heart outside the infarct area. In all infarct patients, sestamibi imaging 6-8 weeks after hospital discharge showed a defect that corresponded to the area of increased uptake of annexin- $V$ in all cases (figures 1 and 2). In the control, no increased uptake of annexin- $V$ was found in the heart, and a normal sestamibi scintigram was obtained. On early SPECT images (mean $3.4 \mathrm{~h}$ after injection), blood-pool activity was still high, which complicated visualisation of Tc-99m-labelled annexin-V uptake in the myocardium. The best images were obtained with late SPECT images (mean $20.5 \mathrm{~h}$ after injection). 

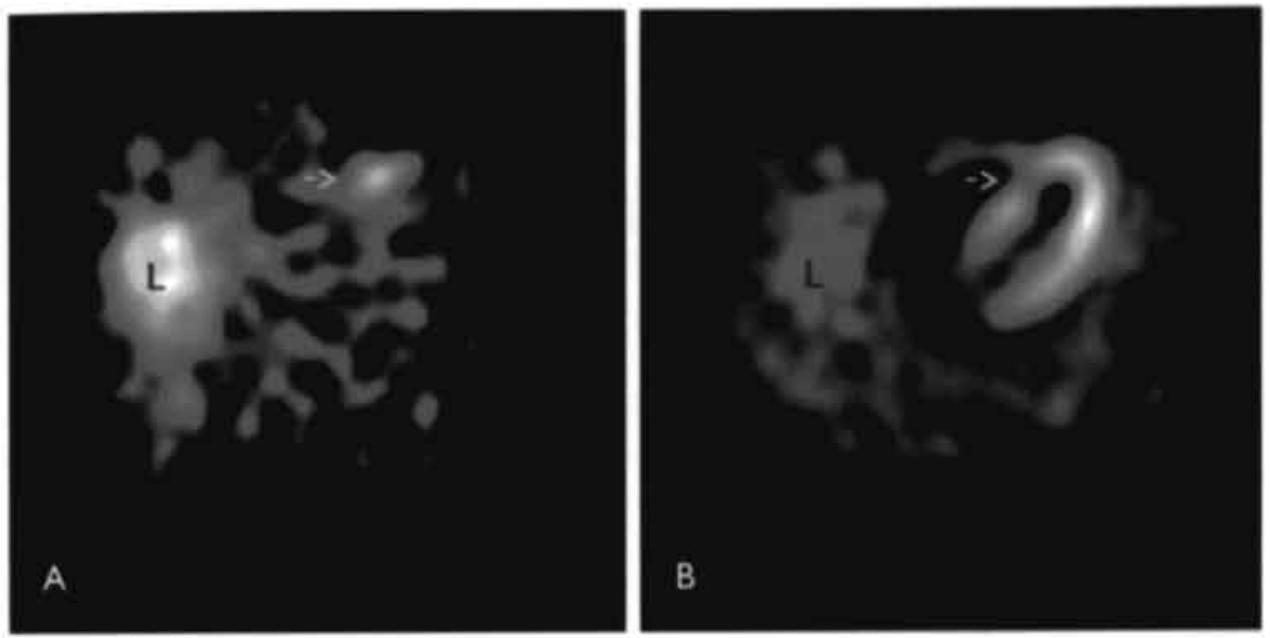

Figure 1 Transverse tomographic images of acute anteroseptal infarction in patient 1

A: Arrow shows increased Tc-99m-labelled annexin-V uptake in the anteroseptal region $22 \mathrm{~h}$ after reperfusion. B: Perfusion scintigraphy with sestamibi $6-8$ weeks after discharge shows an irreversible perfusion defect which coincides with the area of increased Tc- $99 \mathrm{~m}$-labelled annexin-V uptake (arrow).
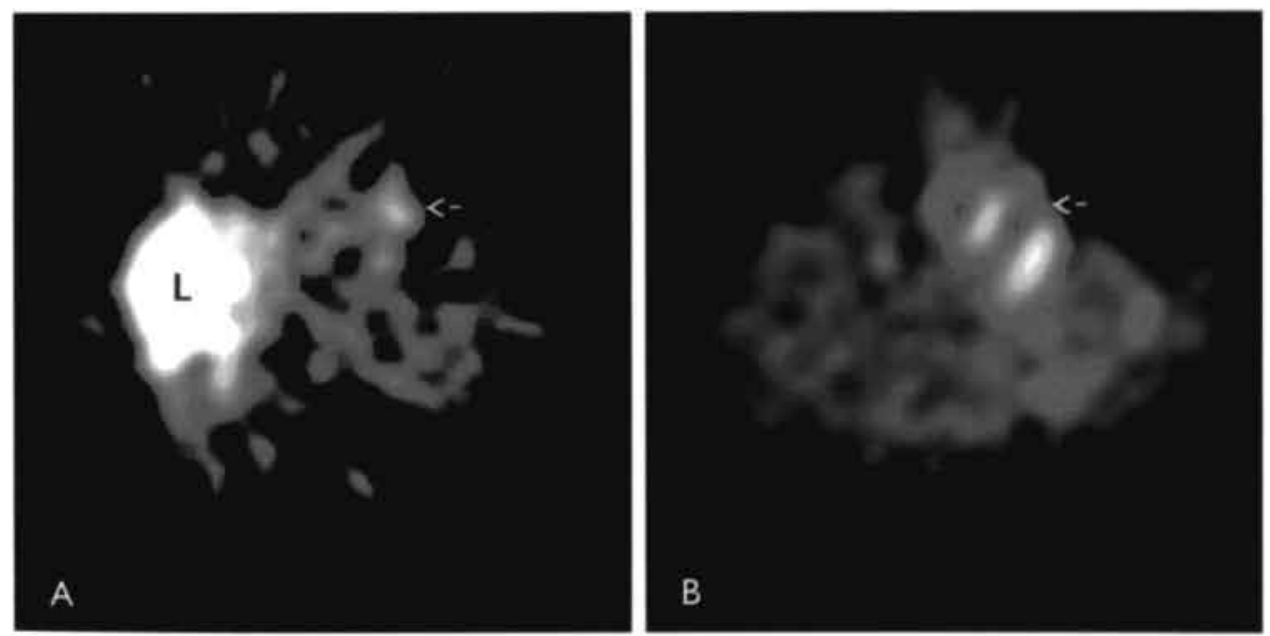

Figure 2 Transverse tomographic images of acute anterior-wall myocardial infarction in patient 4 A: Arrow shows increased uptake of Tc-99m-labelled annexin $V$ in the infarct area $17.5 \mathrm{~h}$ after reperfusion. B: Perfusion defect on sestamibi perfusion scintigraphy $6-8$ weeks after discharge matches uptake of annexin-V (arrow). 
Tabel 1 Patients' characteristics and infarct localisation

\begin{tabular}{|c|c|c|c|c|c|c|c|c|}
\hline Patient & Sex & Age & $\begin{array}{l}\text { Infarct } \\
\text { localisa- } \\
\text { tion }\end{array}$ & $\begin{array}{l}\text { PTCA } \\
\text { result }\end{array}$ & $\begin{array}{l}\text { Maximum } \\
\text { ASAT } \\
\text { concentra- } \\
\text { tion (U/) }\end{array}$ & $\begin{array}{l}\text { Maximum } \\
\text { CK } \\
\text { concen- } \\
\text { tration } \\
\text { (U/t) }\end{array}$ & Echo result & $\begin{array}{l}\text { Timeo } \\
\text { repei } \\
\text { fusio (h) }\end{array}$ \\
\hline 1 & Male & 47 & $\begin{array}{l}\text { Antero- } \\
\text { septal } \\
\text { LAD-mid }\end{array}$ & TIMI III & 140 & 1681 & $\begin{array}{l}\text { LVEF } 65 \% \text {, } \\
\text { anteroseptal } \\
\text { hypokinesia }\end{array}$ & $5 \cdot 0$ \\
\hline 2 & Male & 65 & $\begin{array}{l}\text { Inferopos- } \\
\text { terior } \\
\text { RCA-mid }\end{array}$ & TIMI III & 41 & 166 & .. & $2 \cdot 8$ \\
\hline 3 & Female & 66 & $\begin{array}{l}\text { Inferior } \\
\text { RCA-mid }\end{array}$ & TIMI III & 219 & 2275 & $\begin{array}{l}\text { LVEF } 61 \% \text {, } \\
\text { inferior } \\
\text { akinesia }\end{array}$ & $2 \cdot 3$ \\
\hline 4 & Female & 60 & $\begin{array}{l}\text { Anterior } \\
\text { LAD-mid }\end{array}$ & TIMI III & 189 & 1457 & $\begin{array}{l}\text { LVEF } 70 \% \text {, no } \\
\text { hypo/akinesia }\end{array}$ & $2 \cdot 3$ \\
\hline 5 & Male & 62 & $\begin{array}{l}\text { ineior } \\
\text { RCA } \\
\text { proximal }\end{array}$ & " INvithe" & $14+1$ & .1017 & $\begin{array}{l}\text { IVFF } 54 \% \\
\text { inferior } \\
\text { akinesia }\end{array}$ & 2.5 \\
\hline 6 & Male & 54 & $\begin{array}{l}\text { Anterola- } \\
\text { teral LAD } \\
\text { proximal }\end{array}$ & TIMI III & 340 & 13500 & $\begin{array}{l}\text { LVEF } 50 \% \text {, } \\
\text { hypokinesia } \\
\text { apex }\end{array}$ & $4 \cdot 8$ \\
\hline 7 & Male & 58 & $\begin{array}{l}\text { Infero- } \\
\text { posterior } \\
\text { CX } \\
\text { proximal }\end{array}$ & TIMI III & 479 & 4080 & $\begin{array}{l}\text { LVEF } 48 \% \text {, } \\
\text { posterolateral } \\
\text { akinesia }\end{array}$ & $4 \cdot 0$ \\
\hline
\end{tabular}

$\mathrm{LAD}=$ left anterior descending artery, $\mathrm{CX}=$ circumflex artery, $\mathrm{RCA}=$ right coronary artery, ASAT=aspartate aminotransferase, $\mathrm{LVEF}=$ left ventricular ejection fraction, PTCA=percutaneous transluminal coronary angioplasty, $\mathrm{CK}=$ creatine kinase.

\section{DISCUSSION}

Animal studies have shown detection of cell death in vivo with Tc-99m-labelled annexin- $\mathrm{V}$ and nuclear imaging. Blankenberg and colleagues reported detection of cell death in the heart in a cardiac transplant model in rats. ${ }^{14}$ Increased uptake of annexin-V was seen in transplanted hearts, which correlated with the in-vitro detection of DNA fragmentation by terminal deoxynucleotidyl-mediated- UTP nick-end labelling (TUNEL). We have previously shown that reperfusion of the infarct area of the mouse heart induces programmed cell death, which can be visualised non-invasively with Tc-99m-labelled annexin-V. 10.15 These findings triggered us to extend our studies to 
human beings using the annexin- $V$ imaging protocol, In six of the seven patients with an acute myocardial infarction, increased uptake of annexin- $V$ was seen in the infarct area in the heart. No increased uptake was seen outside that area nor in the heart of the control. A possible explanation for the absence of increased uptake of Tc-99m- labelled annexin- $V$ in patient 6 may be the fact that this patient was defibrillated because of primary ventricular fibrillation. This procedure resulted in substantial local skin and muscle injury in the area of the heart, which may have obscured imaging in the chest region. In the patients with increased uptake of annexin- $\mathrm{V}$, myocardial sestamibi scintigraphy, done after discharge, showed a defect that corresponded to the area of increased uptake of annexin- $V$ in all cases. Therefore, our data suggest that the increased uptake of annexin- $V$ is specific and reflects binding to cardiomyocytes that have surface-expressed phosphatidylserine, and thus activation of the cell death programme. The co-localisation of the sestamibi defect and uptake of annexin- $V$ indicates that in the long term, reperfusion is associated with irreversible cell death in the infarct area, which is marked by annexin- $V$ early after reperfusion. Since annexin- $V$ is a dynamic cell-death probe which binds to cells from the early stage of programmed cell death, its binding probably reflects cell death similar to our findings in the mouse model of ischaemia and reperfusion. In this model, we saw that annexin-V binding was associated with the laddering of nucleosomal DNA, which is indicative of activation of the cell-death programme. Furthermore, intervention in the cell-death programme in our experimental model substantially reduced the number of annexin-V-positive cardiomyocytes, indicating that phosphatidylserine externalisation and subsequent binding of annexin- $V$ are the consequence of an active cell-death programme. 10,15 However, the morphology of the annexin- $\mathrm{V}$ - positive cardiomyocytes in our mouse model showed characteristics of both apoptotic and oncotic cell death the stage preceding necrosis). This finding suggests that a complex and large cell, such as the cardiomyocyte, may not be able to show the classical morphological characteristics of apoptosis, as was originally described by Kerr and Wyllie, despite activation of the cell-death programme. ${ }^{16}$ This concept is supported by work from Ohno, who found DNA fragmentation in cardiomyocytes subjected to ischaemia which did not show the typical apoptotic characteristics. ${ }^{17}$ Similar findings have been seen in neuronal cells in experimental models of ischaemia of the brain. ${ }^{18}$ On the basis of our previous work in mice, we believe that the uptake of technetium-labelled annexin- $V$ in the hearts of patients with an acute myocardial infarction is the consequence of an active form of cell death. However, the question remains whether all the uptake of annexin-V in the heart reflects ongoing execution of the cell-death programme or whether it is the result of the presence of necrotic cells that have reached the final stage of cell death. Investigations of the heart at necropsy would have shed light on this issue, but fortunately, no patient died because of the infarction or subsequent treatment. Clinical investigations with cell-death inhibitors in combination with the annexin- $V$ imaging protocol should solve 
this problem. Moreover, this combination would establish the benefit of treating patients with acute myocardial infarction with cell-death blockers during reperfusion. The results presented here show the feasibility of monitoring non-invasively the dynamics of cell death in humans. This technique allows measurement of the efficacy of therapies targeting cell death, such as anti-tumour therapies, on an individual basis. Hence, the annexin- $V$ imaging protocol might contribute to the growing propensiy to base clinical decisions on the biological properties of the individual rather than on the statistics of a population. 19

\section{CONTRIBUTORS}

Leo Hofstra was responsible for the design and coordination of the study, and wrote a major part of the paper; Ing Han Liem did the SPECT imaging and analysis; Evald Dumont analysed annexin- $V$ biodistribution in ischaemic reperfused mouse hearts; Hendrikus Boersma prepared the Tc-99m-labelled annexin-V, and Waander van Heerde prepared the recombinant annexin- $V$ for use in human beings; Feter Doevendans and Ebo DeMuinck recruited patients and did percutaneous transluninal coronary angioplasty; Hein Weffens was responsible for management of patients, Gerrit Kernink contributed to the SPECT analysis; Chris Reutelingsperger was responsible for the conception of the study, the preparation of annexin- $V$ for use in human beings, and the writing of a major part of the paper; Guido Heidendal developed the initial concept in human beings.

\section{ACKNOWLEDGMENTS}

This study was supported by grants from the Dutch Heart Foundation (NHS 98.195 and NHS D96.025). We thank M.T. Pakbiers for technical support.

\section{REFERENCES}

1. Gottlieb RA, Burleson KO, Kloner RA, Babior BM, Engler RL. Reperfusion injury induces apoptosis in rabbit cardiomyocytes. / Clin Invest 1994: 94:1621-28.

2. Kajstura I, Cheng W, Reiss K, et al. Apoptotic and necrotic myocyte cell deaths are independent contributing variables in infarct size in rats. Lab Invest 1996; 74: 86-107.

3. Fliss H. Gattinger D. Apoptosis in ischemic and reperfused rat myocardium. Circ Res 1996; 79: 949-56.

4. Yeh ET. Life and death in the cardiovascular system. Circulation 1997: 95: 782-86.

5. Veinot IP, Gattinger DA. Fliss H. Early apoptosis in human myocardial infarcts. Hum Pathol 1997; 28: 485-92.

6. Saraste A, Pulkki K, Kallajoki M, Henriksen K, Parvinen M, Voipio Pulkki LM. Apoptosis in human acute myocardial infarction. Circulation 1997; 95: 320-23. 
7. Fadok VA, Savill IS, Haslett C, et al. Different populations of macrophages use either the vitronectin receptor or the phosphatidylserine receptor to recognise and remove apoptotic cells. I Immunol 1992; 149: 4029-35.

8. Goldstein IC, Waterhouse NI, Juin P. Evan GI, Green DR. The coordinate release of cytochrome c during apoptosis is rapid, complete and kinetically invariant. Nat Cell Biol 2000; 2: 156-62.

9. Martin S\}. Finucane DM, Amarantemendes GP, Obrien GA, Green DR. Phosphatidylserine externalization during CD95-induced apoptosis of cells and cytoplasts requires ICE/CED-3 protease activity, I Biol Chem 1996; 271: 28753-56.

10. Van Heerde WL, Robert-Offerman S, Dumont E, et al. Markers of apoptosis in cardiovascular tissues: focus on Annexin-V. Cardiovasc Res 2000; 45: 549-59.

11. Koopman G, Reutelingsperger CP, Kuijten GA, Keehnen RM, Pals ST, van Oers MH. Annexin $\checkmark$ for flow cytometric detection of phosphatidylserine expression on B cells undergoing apoptosis. Blood 1994: 84: 5 20.

12. Van den Eijnde SM, Luijsterburg AJM, Boshart L, et al. In situ detection of apoptosis during embryogenesis with Annexin-V: from whole mount to ultrastructure. Cytometry 1997; 29: 313-20,

13. Vermes I, Haanen $C$, Steffens $\mathrm{NH}$, Reutelingsperger $\mathrm{C}$. A novel assay for apoptosis: flow cytometric detection of phosphatidylserine expression on early apoptotic cells using fluorescein labelled Annexin V. I Immunol Methods 1995; 184: 144-51.

14. Blankenberg FG, Katsikis PD, Tait IF, et al, In vivo detection and imaging of phosphatidylserine expression during programmed cell death. Proc Natl Acad Sci USA 1998; 95: 6349-54.

15. Dumont E, Reutelingsperger C, Van Heerde WL, Smits JF, De Muinck E, Hofstra L. Cardiomyocyte apoptosis induced by ischemia and reperfusion in murine hearts: early detection with annexin-V. Lancet 1999; 353 (suppl 3): s27.

16. Kerr JF, Wyllie AH, Currie AR. Apoptosis, a basic biological phenomenon with wide-ranging implications in tissue kinetics. Br / Cancer 1972; 26: 239-57.

17. Ohno M, Takemura G, Ohno A, et al. Apoptotic myocytes in infarct area in rabbit hearts may be oncotic myocytes with DNA fragmentation. Circulation 1998; 98: 1422-30.

18. Barinaga M. Stroke-damaged neurons may commit cellular suicide. Science 1998; 281 : 1302-03.

19. Schwaiger M, Melin J. Nuclear medicine; cardiological applications of nuclear medicine, Lancet 1999; 354: 661-66. 


\section{IN VIVO DETECTION OF APOPTOSIS IN AN INTRACARDIAC TUMOR}

L. Hofstra ${ }^{1}$, MD, PhD, E. A. Dumont, MD1, P. W. L. Thimister, MD², PhD, G. A. K. Heidendal, $\mathrm{MD}^{2}, \mathrm{PhD}, \mathrm{A}$. P. DeBruine ${ }^{3}, \mathrm{MD}, \mathrm{PhD}, \mathrm{T}$. W. O. Elenbaas ${ }^{4}, \mathrm{MD}, \mathrm{H} . \mathrm{H}$. Boersma, PharmD 5 , W. L. van Heerde ${ }^{6}$, PhD, C. P. M. Reutelingsperger, PhD ${ }^{6}$

Department of Cardiology 1 , Department of Nuclear Medicine ${ }^{2}$, Department of Pathology ${ }^{3}$, Department of Cardiac Surgery ${ }^{4}$, Department of Clinical Pharmacy and Toxicology $y^{5}$ and Department of Biochemistry ${ }^{6}$ 


\section{IN VIVO DETECTION OF APOPTOSIS IN AN INTRACARDIAC TUMOR}

We previously demonstrated in vivo imaging of cell death in the myocardia of patients with acute myocardial infarction using technetium Tc $99 \mathrm{~m}$-labeled annexin- $\mathrm{V}(99 \mathrm{~m}$ Tc-p-annexin-V [Apomate], Theseus Imaging, Cam-bridge, Mass) and nuclear imaging. 'Because high proliferation and apoptotic indices have been reported in rapidly growing malignant tumors, ${ }^{2}$ information about the extent of apoptosis in the tumor may also provide insight into the tumor's biology and prognosis. Report of a Case. A 65-year-old man was referred to our hospital for treatment of a tumor of the left ventricle (Figure 1). Prior to surgery, we attempted to visualize apoptosis in the tumor using $99 \mathrm{~m}$ Tc-p-annexin-V. To localize possible $99 \mathrm{~m}$ Tc-p-annexin- V uptake, a thallous chloride TI 201 perfusion scintigram was performed simultaneously using a dual-isotope imaging technique. This imaging protocol showed a large area of enhanced $99 \mathrm{~m}$ Tc-p- annexin- $\mathrm{V}$, which localized to the cardiac region, as indicated by 201 TI perfusion scintigraphy, and resembled the echo-cardiographic image of the tumor (Figure 1). The tumor could not be completely excised, and scintigraphic imaging of the tumor after surgery showed $99 \mathrm{~m}$ Tc-p-annexin- $\mathrm{V}$ but not $201 \mathrm{TI}$ activity. Immunostaining of the excised tumor tissue using a poly-clonal antibody against annexin-V (Hyphen Biomed, Villejuif, France) showed specific binding of annexin- $V$ to the plasma membrane of cells with apoptotic morphology (Figure 2). This colocalized with the presence of activated caspase-3 in corresponding sections (CM1 antibody, IDUN Pharmaceuticals, La Jolla, Calif ), suggesting that annexin-V was bound to cells with apoptosis, which was confirmed by double staining with both antibodies (Figure 2). Histologic analysis of the tumor revealed high-grade undifferentiated sarcoma. The patient re-fused further treatment and died 2.5 months after surgery. Post-mortem analysis showed a large intracardiac tumor mass and multiple metastases. Comment. Our data indicate that $99 \mathrm{~m}$ Tc-p-annexin- $V$ accumulated in the tumor because it bound to a large number of cells with phosphatidylserine on the surfaces, which results from apoptosis. ${ }^{3}$ Because a high apoptotic index is found mainly in malignant tumors and may be related to poor prognosis, $99 \mathrm{~m}$ Tc-p-annexin- $V$ imaging may be helpful to obtain prognostic information about tumors in a noninvasive way. ${ }^{1,4}$ This could help select the best therapeutic approach. Another promising application for $99 \mathrm{~m}$ Tc-p-annexin- $V$ imaging may be to monitor the effect of antitumor treatment. ${ }^{5}$ We observed a large number of apoptotic cells within the tumor, indicating that these cells still contain essential parts of the cell death program and suggesting that they may still be susceptible to chemotherapeutic agents. Therefore, this technique may aid diagnosis and therapy selection in localized malignant tumors. 


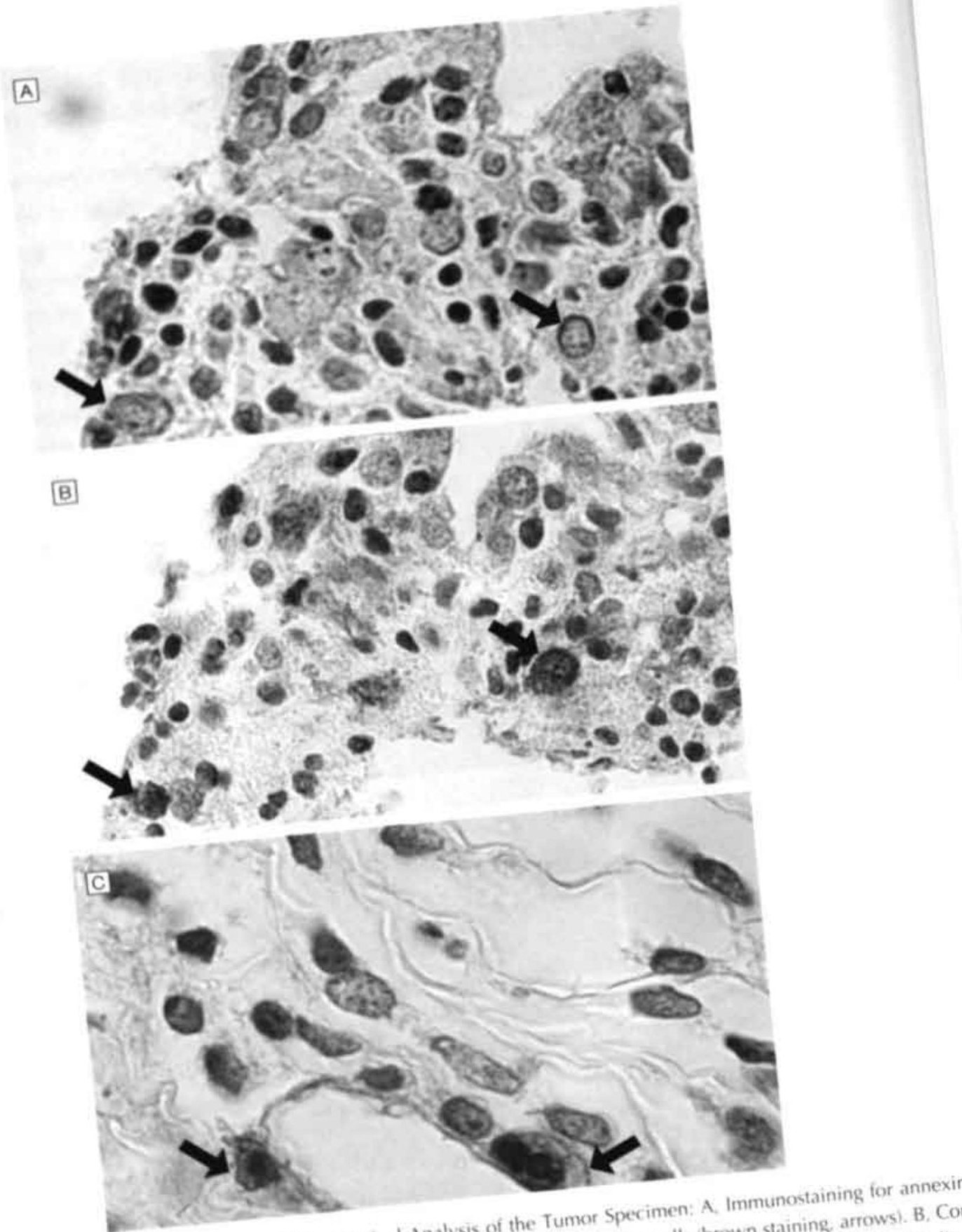

Figure 2 Immunohistochemical Analysis membrane of tumor cells (brown staining ane shows binding of annexin- $\mathrm{V}$ to the plativedy specific for activated caspase-3 shows extensing arrows sponding section stained with CMI alize with annexin-V-positive (ells in A t bibody (red staining) sh the cytosol of cells, which colocalin. $\mathrm{V}$ antibody ibrown staining and Double staining with annesin specific binding of annexin: $v$ or the plasma membrane 


\section{FUNDING/SUPPORT}

This study was supported by grant 98.195 from the Dutch Heart Foundation and grant D96.025 from the NHS. The CM1 antibody used was a gift from IDUN pharmaceuticals, La Jolla, Calif.

\section{ACKNOWLEDGMENT}

We thank M. T. Pakbiers and J. Habets for technical support.

\section{REFERENCES}

1. Hofstra L, Liem IH, Dumont $\mathrm{E}$, et al. Visualisation of cell death in vivo in patients with acute myocardial infarction. Lancet. 2000;356:209-212.

2. Gisbertz IA, Schouten HC, Bot FI, Arends JW. Cell turnover parameters in small cell and large cell varieties of primary intestinal non-Hodgkin's lymphoma. Cancer. 1998;83:158-165.

3. Martin SI, Reutelingsperger CP, McGahon AJ, et al. Early redistribution of plasma membrane phosphatidylserine is a general feature of apoptosis regardless of the initiating stimulus. I Exp Med. 1995; 182:552-556.

4. Naresh KN, Lakshminarayanan K, Pai SA, Borges AM. Apoptosis index is a predictor of metastatic phenotype in patients with early stage squamous carcinoma of the tongue. Cancer. 2001;91:578-584.

6. Belhocine TZ, Hustinnx R, Jerusalem G, et al. $99 \mathrm{~m}-\mathrm{Tc}$ RH Annexin-V (Apomate) as a marker resulting from chemotherapy: preliminary results. Abstract presented at: 47 th annual meeting of the Society of Nuclear Medicine; 2000; St Louis, Mo. 
CHAPTER 8

\section{DISCUSSION}


In the first part of the thesis we evaluated the ability of Annexin-A5 to etect programmed cell death in vivo during ischemia and reperfusion of the heart. Thesdata showed that the Annexin-A5 assay is a reliable and relatively easy method to etect programmed cell death, both in experimental models of ischemia and in patientwith acute myocardial infarction. Second, we aimed to define the kinetics of prograrmed cell death following ischemia and reperfusion of the heart. With the use of a ovel optical imaging technology, we observed that binding of Annexin-A5, as a reflecton of activation of the cell death program, starts within minutes after the onset of reperfsion. These data indicate that the cell death program is rapidly activated following ischmia. Finally, we have tried to address whether Annexin-A5 binds to cells before or aft the point of no return in the cell death program, using a brief cardiac injury model. hese data showed that Annexin-A5 binding to cardiomyocytes in the ischemic area $\mathrm{c}$ be observed already after a 5 -minute episode of ischemia. The binding of Annexin-A was associated with activation of caspase-3. Surprisingly however, the cells that took $\mathrm{v}$ the Annexin-A5 did not die, which leads to the conclusion that cardiomyocytes in tharea at risk can recover from programmed cell death if perfusion is restored rapidly enogh.

Although the findings in the thesis are intriguing, many questions are still unresolved. First, we only have clues how the Annexin-A5 assay can discriminate between apoptotic and primary necrotic cell death. Second, we do not know how recovery from cell death is regulated in the heart following ischemia, and what the clinical significance is of this phenomenon. Finally, it is still unclear what the added value of Annexin-A5 is in patients with acute myocardial infarction. In the following section we will discuss these questions in relation to the findings in the thesis and we will outline a strategy to address unresolved issues.

\section{NECROSIS VS APOPTOSIS}

The present studies demonstrate that Annexin-A5 provides an alternative and reliable method to detect cell death in situ in cells in vitro and in vivo, both in animal models and in humans. One of the major points of discussion is the discriminative property of Annexin-A5 between apoptotic and necrotic cell death. We demonstrated in a mouse model of 30 minutes of ischemia and 90 minutes of reperfusion that $20.2 \%$ of the cardiomyocytes stained positive for Annexin-A5. Immunostaining for intracellular immunoglobuline G (IgG) was performed to investigate the presence of plasma cell membrane leakage. Within these hearts, $4 \%$ of the cells had internalized igG, indicative of primary or secondary necrosis. The same cells also bound Annexin-A5. These results indicate that Annexin-A5 also stains cells which have a permeable cell membrane. This raises the question whether the Annexin-A5 binding is to primary or secondary necrotic 
cells. In vitro data show that Annexin-A5 has very low binding capacity to primary necrotic cells probably due to proteolysis of the PS receptor (personal communications C. Reutelingsperger). In secondary necrotic cells, Annexin-A5 has already bound to the PS receptor. It has been shown that binding of Annexin-A5 to the PS receptor is a stable complex. When becoming secondary necrotic after initial apoptotic cell death (eg due to ATP depletion), Annexin-A5 is still bound to these secondary necrotic cell remnants. Taken together the in vitro data and the data presented in chapter 3 , suggest that the Annexin-A5 binding to the cells that also show plasma membrane leakage, as indicated by the positive IgG staining, are secondary necrotic cells rather than primary necrotic cells. This is further suggested by the time course of Annexin-A5 uptake, which precedes the uptake of IgG substantially. Therefore, we believe that cardiomyocytes following ischemia and reperfusion, start out to activate the apoptotic program and become secondary necrotic during the course of reperfusion. Further evidence for this thought is provided in chapter 4 , in which the kinetics of the binding of fluorescently labeled Annexin-A5 are visualized in detail following ischemia and reperfusion of the mouse heart in vivo, using a novel optical imaging model system. These data show, for the first time, that the binding of Annexin-A 5 to the cardiomyocytes in the area at risk starts within minutes after the onset of reperfusion, and that the binding of Annexin-A5 is completed within 20 minutes. Since in vitro studies have shown that the binding of Annexin-A5 occurs rapidly after the onset of apoptosis activation, it seems reasonable to assume that the binding observed within minutes after the onset of reperfusion is the consequence of the activation of the cell death program. In addition, it is unlikely that this rapid and massive binding is the consequence of primary necrotic cell death (Chapter 3).

Further evidence for activation of the apoptotic program as the primary way for the cardiomyocytes to get killed is provided by the positive DNA gel electrophoresis assay, which shows laddering, which is typical of activation of the apoptotic program. Laddering of DNA is mediated by caspase activated DNAse (CAD) which cleaves DNA at specific sites, resulting in DNA cleavage products with a typical base pair length or 180-200, or multiples. Further evidence for the fact that in the heart following ischemia and reperfusion cell death starts out as apoptotic cell death is provided in both chapter 3 and 4 , showing that inhibition of key steps in the apoptotic program, such as inhibition of caspase activation, results in a substantial decrease in the number of Annexin-A5 positive cells. This functional approach is supported by other researchers, suggesting that that the terms necrosis and apoptosis should be redefined as 'passive cell death' and 'active cell death', respectively, thereby putting emphasis on the pathological and therapeutic implications and less on morphology. Taken together, the data presented in the thesis provide strong evidence for the apoptotic nature of cells binding Annexin-A5 in the initial phase during reperfusion, following an ischemic episode. 


\section{ANNEXIN-A5 BINDING IN PATIENTS WITH ACUTE MYOCARDIAL INFARCTION}

In chapter 5 we showed, for the first time that detection of apoptosis using technium labeled Annexin-A5 is possible. Using nuclear imaging, enhanced uptake of ternetium labeled Annexin-A5 was seen in 6 out of 7 patients suffering from acute my-ardial infarction, and undergoing immediate reperfusion therapy. The uptal of Annexin-A5 could be co-localized to the perfusion defect as seen on perfusion im;ing using MIBI. The data from the studies in animal models suggest that the bindis of Annexin-A5 following ischemia and reperfusion of the mouse heart in the early stars of reperfusion is the consequence of activation of the apoptotic program. In later sges binding of Annexin-A5 may be the consequence of secondary necrosis. How dor the information of the pre-clinical study translate to the studies in humans? One limition in trying to translate the pre-clinical studies to the studies in humans is the timg of administration of Annexin-A5 and the timing of imaging. In the studies in huans Annexin-A5 was always given at least one hour after the onset of reperfusion. Imjing

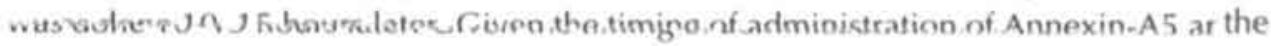
timing of imaging in humans, it is likely to assume that a larger proportion of the Annexin-A5 binds to secondary necrotic cells as compared to the experimental models. One of our recent clinical studies gives some intriguing insight into this discussion. In that study we compared the amount uptake of Annexin-A5 in the acute phase to the size of the MIBI defect measured one week after the acute event. Remarkably, in a subset of patients with short ischemia times the amount of uptake of Annexin-A5 was substantially more than the size of the perfusion defect one week after the acute event. These data suggest that only a small sized infarction occurred in this patient, despite the fact that a large fraction of the area at risk bound Annexin-A5. These results indicate that part of the cells that took up Annexin-A5 did not undergo cell death, but survived after the restoration of blood flow in the infarct related artery. Along the same lines, one may argue that even more cells may be rescued from undergoing cell death, if a cell death inhibiting compound would have been given. This leaves the question whether the uptake of Annexin-A5 in patients with acute myocardial infarction is preventable by the administration of novel anti-apoptotic compounds, such as the caspase inhibitors. However, the only way to prove such a point is to perform a large scale clinical trial, testing the efficacy of these novel cell death inhibiting compounds. A question that arises from these clinical data is whether the externalization of PS, and the subsequent binding of Annexin-A5, occurs before of after the point of no return in the cell death program.

The data above indicate that imaging of Annexin A5-technetium provides us with a valuable research tool to study cell death in patients with AMI. This may help to give us 
information on the timing of intervention with cell death inhibitors. In addition, this way of imaging may be of help to assess the therapeutic value of anti-apoptotic compounds in patients with AMI.

Another issue is whether Annexin-A5 imaging provides incremental clinical value at this point in time for patients with AMI. This would depend on whether Annexin-A5 technetium imaging is going to change the therapeutic or diagnostic management of the patients with AMI. In cardiology many tools are already available to assess the amount of damaged tissue, including the electrocardiogram, enzyme release, SPECT of the perfusion defect and echocardiographic assessment of infarct size. At this point Annexin-A5 imaging could only provide extra clinical information, as will be discussed later, by using it for for visualizing an area, which has gone through a short lasting ischemic episode.

\section{A NOVEL PHASE IN THE CELL DEATH PROGRAM: ESCAPOPTOSIS}

The data from chapter 4, showing substantial binding of Annexin-A5 to the area at risk within minutes after the onset of reperfusion, triggered the question whether all PS exposure and subsequent Annexin-A5 binding occurs beyond the point of no return. Based on observations in C Elegans, where recovery from cell death is found in the absence of engulfment genes, despite the activation of caspase-3, we hypothesized that cardiomyocytes may recover from activation of the cell death program if reperfusion is restored rapidly enough. Using a brief ischemia protocol (chapter 6), we observed that cardiomyocytes in the area at risk bound Annexin-A5 and activated caspase-3, without progressing to cell death. These data indicate that we observed a mammalian analogue of the recovery from cell death in the C Elegans model. This finding has several interesting implications. First, the finding indicates that some of the binding of Annexin-A5 as seen in our previous studies is not equivalent to activation of the cell death program beyond the point of no return. Especially in chapter 4, where rapid binding of Annexin-A5 was observed following the onset of reperfusion, we interpreted this as being a rapid onset of the apoptotic program, and consequently, only a narrow window for intervention with cell death inhibitors. Based on the findings of chapter 5 , we now know that especially in the early phase of binding of Annexin-A5 to cardiomyocytes, following ischemia and reperfusion, cardiomyocytes may recover from activation of the cell death program. As a consequence, we changed our vision on the meaning of Annexin-A5 binding. We now believe that in the early phase of activation of the cell death program Annexin- $V$ binding occurs, which is a probable consequence of activation of caspase -3 . 
In all our studies performed previous to the discovery of PS reversibility, the dogma existed that all Annexin-A5 positive cells were committed to die. In in vitro systems the group of Green et al. implicated a strong relation between cytochrome c release and subsequent PS exteriorization on the outer leaflet of the cell membrane. In contrast, some of our in vivo data show that after a short duration of ischemia, activated caspase- 3 can be upregulated about 2-3 times compared to baseline values, leading to temporary PS exteriorization, but the cells remain viable. Possibly, this difference is due to the nature and intensity of the apoptosis inducing stimulus. When exceeding a certain threshold, inhibitory mechanisms of apoptosis could be overruled (escapoptosis). These data further suggest that the point of no return is not solely dependent on the activation of a key step in the apoptosis cascade, but dependent on exceeding a threshold of key activators that cannot be counteracted by anti-apoptotic factors.

The key question now is how the activation of caspase- 3 is counterbalanced, and how the cell is saved. One attractive possibility is that the activity of pro-apoptotic proteins is overruled by anti-apoptotic proteins, such as the family of inhibitors of apoptosis protein (IAP's). In one of our current projects we aim to find out how the Annexin-A5 positive cells are rescued from execution. These data may provide answers as to how intervention in the cell death program may have to be designed.

Another intriguing aspect of the recovery of cell death despite the externalization of PS is the possibility to image cells that have been subjected to ischemia, but do not die. The fact that the PS positivity extends up to 6 hours after a brief ischemic episode, provides an attractive window for imaging of these cells with technetium-labeled Annexin-A5. Our preliminary results indicate that such an approach may indeed be possible. Using nuclear imaging, we observed uptake of technetium-labeled Annexin-A5 in the area at risk in a rabbit model, following a 10-minute episode of cardiac ischemia. In line with the observations in the mouse model, no cell death was seen in these animals. These findings open up a new avenue for the identification of patients at risk, who are admitted in the first 6 hours after an episode of chest pain. As such, Annexin-A5 may provide a new opportunity for after the fact imaging of patients with chest pain.

A final consideration is that we have, for the first time, identified a reversible phase in the cell death program in mammalian cells. Based on these findings, we propose a novel differentiation of the phases in apoptosis. In the first phase of cell death the apoptotic process is initiated, morphologically characterized by no changes in the nucleus, but biochemically a low increase of activated caspase- 3 activation in the cell and transient PS exteriorization. When the cell death trigger is withdrawn from these 
cells, they will recover completely and regain function (escapoptosis); the inhibitory mechanisms of apoptosis have prevailed.

The phase of escapoptosis can be added to the 4 modes of cell death as described by Leist et al. The first mode of cell death is classical apoptosis. This is defined by globular chromatin condensation in the nucleus, PS exposure, shrinkage of the cell and formation of apoptotic bodies and is primarily caspase mediated. In the second mode, apoptosis-like-programmed cell death is characterized by lump shaped chromatin condensation, display of phagocytosis-recognition molecules. In the third mode necrosis-like programmed cell death is characterized by absence of chromatin condensation, exteriorization of PS and is not caspase initiated. This route is also called 'aborted apoptosis'. The fourth mode of cell death is necrosis which is associated with cellular oedema and devoid of zeiosis.

In ischemia and reperfusion injury in the heart, when the phase of escapotosis has been passed, the cells with low ATP levels switch from apoptosis to secondary necrotic cell death eliciting a secondary inflammatory response.

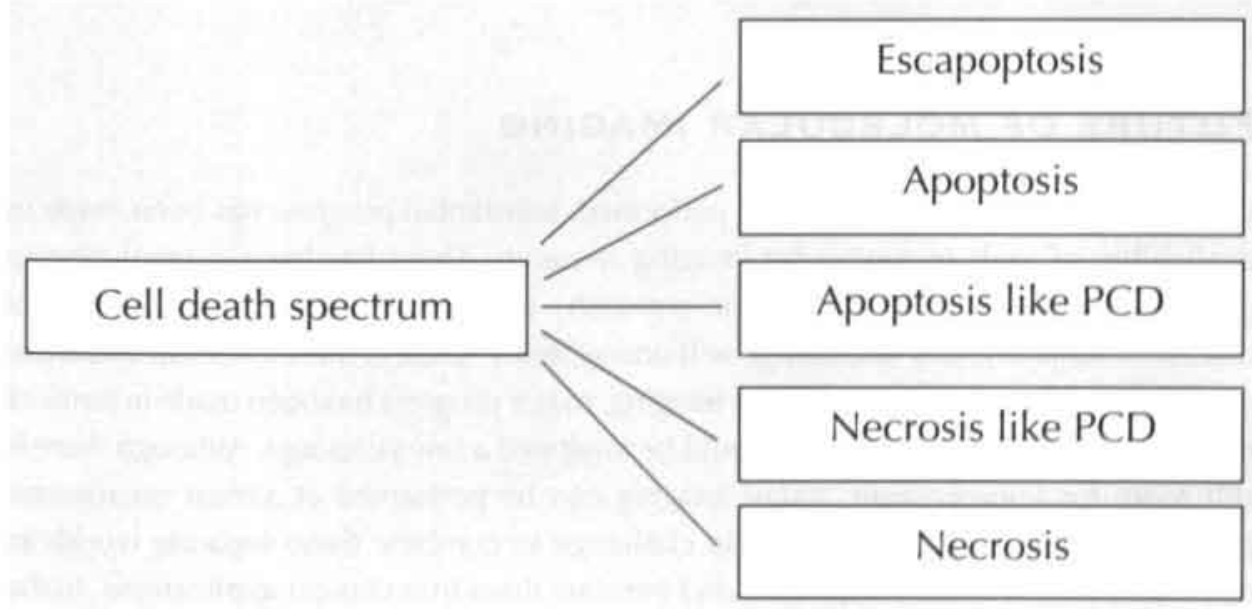

\section{CLINICAL IMPLICATIONS}

The short term clinical implication of the findings in the present thesis are concentrated on three different aspects. First, the experimental models may provide a rapid tool for the evaluation of the efficacy of novel anti-apopotic compounds, such as caspase inhibitors. By using these in vivo assays a more rapid translation from initial drug discovery to in vivo screening of these compounds is possible. This increases, at least in theory, the 
chance of finding the most efficient anti-apoptotic compound to be used in paents with AMI. Second, as discussed previously in this thesis, PS exteriorization folloing the ischemia insult could be used for the after the fact recognition of an short ischmic insult in the heart. After prolonged duration of ischemia the Annexin-A5 protococan be used to delineate the affected area in the heart. As the apoptosis mechanin is thought to last for about 4 hours to reach the point of no return and ischemic meiory lasts for about 6 hours, the Annexin- $V$ protocol does not seem suitable to be usd as follow up in apoptosis modulating therapies in the heart.

Third in the field of oncology, Annexin-A5 imaging performed on the day after eatment with pro-apoptotic compounds may provide an early prognostic marker fo the efficacy of these compounds. The unique property of the Annexin-A5 imaging achnique to measure therapy-effectiveness within hours, opens the possibility to sitch swiftly to another therapy regimen inducing higher Annexin-A5 uptake. This stregy has already proven effective and is associated with decreased mortality in patier. At this moment, a large clinical phase II study is performed, which evaluates the te of

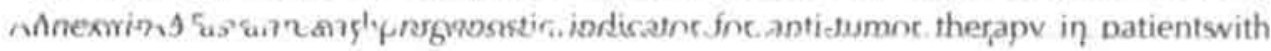
non-small cell lung cancer.

\section{FUTURE OF MOLECULAR IMAGING}

While the studies in the thesis were performed, substantial progress has been made in availability of tools in molecular imaging research. There has been a revolution in genetic engineering and molecular research, unraveling molecular pathways of disease. Ultimately, this knowledge will undoubtedly result in more effective treatment and better patient care. In the field of imaging, major progress has been made in terms of resolution and speed, which only could be imagined a few years ago. Although there is still room for improvement, today imaging can be performed at almost micrometer precision. Now there emerges a new challenge to combine these separate worlds to combine these novel developments and translate them into clinical applications. In the US, the importance of these developments is identified and this year the National Institution of Health $(\mathrm{NIH})$ have allocated $\$ 70$ million and the National Cancer Institute \$20 million for molecular imaging research. This research is expected to improve knowledge of molecular mechanisms in vivo and lead to improved disease detection. 


\section{REDUCED 'LICENSE TO KILL'}

Today there is a growing resistance among the general population against the use of animals in medical research. Researchers have to be responsible to reduce animal suffering to a minimum. An emerging additional benefit of in vivo molecular imaging is, that the same process can be followed in time within the identical cell in the same animal. In conventional research methods, animals had to be sacrificed at different points in time to obtain the same information. These new techniques have the advantage to obtain the same information out of one animal experiment, thereby reducing animal use and animal discomfort. 
110 
CHAPTER 9

SUMMARY

SAMENVATTING

DANKWOORD / ACKNOWLEDGEMENTS

ABOUT THE AUTHOR

LIST OF PUBLICATIONS 


\section{SUMMARY}

Myocardial infarction is a major killer in the Western world and continuous to increase in the third world. In the USA alone, 1.5 million people suffer from a myocardia infarction each year. During myocardial infarction, cardiac cells in the ischemc area undergo cell death. Since the heart has minimal regenerative capacity, many atients suffering from AMI develop heart failure, leading to high morbidity and mortalit. In the last decade it has become clear that many cells during infarction die from apptosis, so-called programmed cell death. In contrast to necrosis, or accidental cel death, apopatssis is shataviterized hv tightly orchestrated activation of apoptosis inducing proteins and/or enzymes within the cell, which results in the execution of the cell. The extensive knowledge about the signaling events during apoptosis, generated in the last decade, provides us with potential targets for intervention. However, application of this knowledge into clinical therapeutic modalities in patients suffering from acute myocardial infarction is hampered by lack of insight into the regulation and kinetics of programmed cell death in the heart during infarction. First of all, it is unknown which proportion of cardiac cells die from apoptotic or necrotic cell death. This question is critical, since this will determine the potential benefit of anti-apoptotic treatment. An important aspect in this discussion is that cells undergoing programmed cell death may not always end up as a typical apoptotic cell, but may also exhibit necrotic characteristics. Second, essential information with respect to the kinetics of cell death is still lacking. This information is needed to define the duration of efficacy of cell death inhibiting therapy. A critical element in the assessment of the duration of efficacy is the definition of the 'point of no return' and the kinetics of activation of the cell death program during cardiac ischemia. Finally, before apoptosis inhibiting compounds can be used in patients, we need to know if, and to what extent, apoptosis occurs in human myocardial infarction.

When this study was started, the in vivo assessment of apoptosis was mainly done with DNA laddering and/or the terminal dUTP nick end-labelling assay (TUNEL). These methods are hampered by the fact that tissue samples from the organ of interest are needed to measure apoptosis. As a consequence, the spatial resolution of these methods is limited. In addition, no in vivo imaging can be done using DNA laddering and/or the 
TUNEL assay. The aim of our research project was to develop a method to visualize programmed cell death with high spatial resolution, which could also be developed as an in vivo imaging tool. To achieve this goal we started to use labelled Annexin-A5 for the detection of cell death in an ischemia and reperfusion model in the mouse. Annexin-A5 is a protein with high affinity for phosphatidyl serine (PS), which is externalized by cells undergoing apoptosis. In the first project we show that biotinylated Annexin-A5 is an easy marker to assess programmed cell death in the heart subjected to ischemia and reperfusion in vivo. Further, in this study we verified that Annexin-A5 binding to cardiomyocytes correlated with other apoptosis measuring fechniques, such as DNA laddering and TUNEL. In addition these data showed that Annexin-A5 can be used to evaluate anti-apoptotic drugs in ischemia mediated injury of the heart in vivo. In a second study, we developed an imaging model system, which allowed for the first time to detect binding of fluorescent labeled Annexin-A5 at the level of the single cell in the beating heart of the living mouse. These observations showed that Annexin-A5 binds to cardiomyocytes in the area at risk within minutes after the onset of reperfusion. These data indicate that the duration of efficacy of cell death inhibiting drugs may have a narrow time frame. In a third study we attempted to define whether PS externalisation in the heart occurs before or after the 'point of no return' in the cell death program. This study showed that Annexin-A5 binds to cardiomyocytes in the area at risk after brief episodes of ischemia, but that these cells do not undergo cell death, Intriguingly, the binding of Annexin-A5 was associated with activation of one of the key executioners of the cell death program, caspase-3. Together, these results demonstrate that cardiomyocytes can be resuscitated from initial activation of the cell death program, if reperfusion is restored rapidly enough. These data provide a novel concept on how the cell death process is regulated in mammalian cells. In the final part of the thesis we attempted to visualize programmed cell death in patients suffering from acute myocardial infarction. Using technetium labeled Annexin-A5 and nuclear imaging, these data show, for the first time, that programmed cell death can be visualized in the ischemic area of the heart in patients with acute myocardial infarction. Furthermore, these data suggest that a form of cell death occurs in human myocardial ischemia that should be amenable to anti-apoptotic intervention. In a final study we observed that enhanced uptake of Annexin-A5 can possibly be used to diagnose essential diagnostic information of intra-cardiac tumors. A high level of apoptosis, and thus uptake of Annexin-A5, is seen in malignant tumors. Therefore, high uptake of Annexin-A5 in an unknown intra-cardiac mass may provide essential diagnostic information as to the pathology of the tumor, which may have a direct effect on the management of the patient.

Together, the studies presented in this thesis provide new insights in the kinetics and extent of programmed cell death in the heart subjected to ischemia and reperfusion in vivo. This may help to guide anti-apoptotic strategies in patients with acute myocardial 
infarction. In addition, the thesis describes for the first time recovery from cell death in the mammal heart in vivo. Regulation of recovery from programmed cell death may help to develop novel strategies to prevent loss of cells during ischemia. Finally, the visualization of programmed cell death in vivo in patients with acute myocardial infarction, using technetium labeled Annexin-A5, provides a major contribution to the field of molecular imaging of apoptosis. This technology is close to be used in clinical practice. 


\section{SAMENVATTING}

Het hartinfarct is de belangrijkste doodsoorzaak in de westerse wereld. Alleen al in de Verenigde Staten krijgen 1,5 miljoen mensen per jaar een hartinfarct. Bij een hartinfarct sterven hartspiercellen in het aangedane, ischemische gebied. Omdat het hart slechts een geringe regeneratieve capaciteit heeft, ontwikkelen veel patiënten na een acuut hartinfarct hartfalen, wat leidt tot een hoge morbiditeit en mortaliteit. In de laatste 10 jaar is het duidelijk geworden dat tijdens het hartinfarct veel cellen in het hart dood gaan door apoptose, ook wel geprogrammeerde celdood genoemd. In tegenstelling tot necrose, ofwel accidentele celdood, wordt apoptose gekarakteriseerd door een nauw gereguleerde en geprogrammeerde activatie van apoptose-inducerende eiwitten en/of enzymen binnen de cel, wat uiteindelijk resulteert in het afsterven van de cel. De uitgebreide kennis opgedaan in de laatste 10 jaar over signalering gedurende apoptose biedt echter mogelijkheden om in te grijpen in dit proces, maar het vertalen van deze kennis in klinische en therapeutische toepassing bij patiënten die een acuut hartinfarct hebben, wordt bemoeilijkt door het ontbreken van inzicht in de regulatie en de kinetiek van geprogrammeerde celdood ten tijde van het hartinfarct. Ten eerste is het niet bekend welk deel van de hartspiercellen dood gaan via apoptose of necrose. Deze vraag is van groot belang, aangezien dit het potentieel voordeel bepaalt van anti-apoptotische behandeling bij hartziekten. Een belangrijk punt hierbij is dat hartspiercellen die geprogrammeerde celdood ondergaan niet altijd eindigen als een typisch apoptotische cel, maar dat deze ook necrotische eigenschappen kunnen vertonen. Ten tweede is de snelheid van het optreden van celdood, de kinetiek, niet bekend. Deze informatie is nodig om de werkzame periode van celdood-remmende therapie te kunnen vaststellen. Een kritisch element in de bepaling van deze werkzame periode is de definitie van het punt van onomkeerbare schade, ofwel het point of no return' en de kinetiek van activatie van het celdoodprogramma gedurende cardiale ischemie. Tenslotte, voordat apoptose-inhiberende stoffen gebruikt kunnen worden in patiënten, is het nodig te weten welk aandeel apoptose heeft gedurende het hartinfarct bij de mens.

Bij het starten van dit onderzoek, werd apoptose voornamelijk bepaald met "DNA laddering" en/of de "terminal dUTP nick end-labelling" methode (TUNEL). De 
toepasbaarheid van deze methoden is beperkt, omdat weefselbiopten uit het betreffende orgaan nodig zijn om apoptose aan te tonen. Als gevolg zijn het tijdsverlop en de uitgebreidheid ervan niet goed te bepalen. Een additioneel probleem is da er géén in vivo beeldvorming kan plaatsvinden met DNA laddering en/of TUNEL.

Eén van de doelen van dit onderzoek was dan ook het ontwikkelen van een methode om geprogrammeerde celdood zichtbaar te maken in vivo met een hoge temporeli en spatiële resolutie. Om dit doel te bereiken zijn we gestart met het gebruik van gelaleld Annexine-A5 voor de detectie van celdood in een model van ischemie en reperisie van het hart in de muis. Annexine-A5 is een eiwit met een hoge affiniteit oor fosfatidylserine (PS), een fosfolipide dat op de buitenzijde van de celmembraar tot expressie komt in cellen die apoptotische celdood ondergaan.

In het eerste project hebben we aangetoond dat gebiotinyleerd Annexine-A5 een gede marker is voor geprogrammeerde celdood in het hart dat blootgesteld is aan ischenie en reperfusie in vivo. Daarnaast correleert Annexine-A5 binding met andere apopose meettechnieken zoais DNA laddering en IUNEL, waarDij Annexine-As ecriter reeus in een eerder stadium aan de apoptotische cel bindt. Hieruit blijkt dat Annexine-A5 gebruikt kan worden om anti-apoptotische therapieën bij ischemisch gemedieerde schade van het hart in vivo te testen.

In de tweede studie hebben we een nieuw beeldvormingssysteem ontwikkeld, waarmee de binding van fluorescent gelabeld Annexine-A5 voor de eerste keer op het niveau van de enkele cel in het kloppende muizenhart van de levende muis is waargenomen. Hier wordt aangetoond dat Annexine-A5 binnen enkele minuten na het begin van de reperfusiefase bindt aan harspiercellen in het aangedane gebied. Verder laat deze studie zien dat apoptose remmende therapie effectief is ondanks het feit dat de werkzame periode van celdood-inhiberende medicijnen in een klein tijdsinterval moet plaatsvinden.

In een derde studie hebben we getracht te bepalen of PS externalisatie in het hart gebeurt vóór of na het 'point of no return' in het celdoodprogramma. Deze studie liet zien dat Annexine-A5 tijdelijk bindt aan cardiomyocyten in het aangedane gebied na een korte periode van ischemie, maar dat deze cellen niet dood gaan. Opmerkelijk is dat de binding van Annexine-A5 geassocieerd is met de activatie van één van de belangrijkste apoptose-inducerende eiwitten van het celdoodprogramma, namelijk caspase-3. Deze gegevens suggereren dat harspiercellen zich kunnen herstellen (geresusciteerd kunnen worden) van celdood, indien de reperfusie snel genoeg wordt hersteld. Deze gegevens vormen de basis voor een nieuw concept (escapoptose) op welke wijze het celdoodprogramma gereguleerd is in zoogdiercellen. 
In hoofdstuk 7 van dit proefschrift hebben we gepoogd om celdood zichtbaar te maken in patiënten na een acuut hartinfarct. Met Technetium gelabeld Annexine-A5 en nucleaire beeldvorming konden we voor de allereerste keer laten zien dat geprogrammeerde celdood zichtbaar gemaakt kan worden in het ischemische gebied in het hart van patiënten met een acuut hartinfarct. Deze bevindingen suggereren dat er een vorm van celdood optreedt in hartspiercellen die toegankelijk is voor een anti-apoptotische behandeling.

In de laatste studie hebben we gezien dat een verhoogde opname van Annexine-A5 mogelijk gebruikt kan worden om de pathologie te bestuderen van intra-cardiale tumoren. Veel apoptose, en dus veel Annexine-A5 opname, wordt onder andere gezien in kwaadaardige tumoren. Hoge opname van Annexine-A5 in een intra-cardiale tumor van onbekende maligniteitsgraad kan essentiële diagnostische informatie bieden over de pathologie van de tumor, hetgeen een direct effect heeft op de behandeling van de patiënt.

Samengenomen bieden de gepresenteerde studies in dit proefschrift nieuwe inzichten in de kinetiek en uitgebreidheid van geprogrammeerde celdood in het hart dat blootgesteld is aan ischemie en reperfusie in vivo. Daarnaast wordt in dit proefschrift voor de eerste keer beschreven, dat hartspiercellen in vivo kunnen herstellen van de initiatie van geprogrammeerde celdood. Kennis van de voorwaarden voor herstel kan ons helpen om nieuwe behandelingsstrategieën te ontwikkelen om celverlies gedurende cardiale ischemie te voorkomen. Het in vivo zichtbaar maken van geprogrammeerde celdood in patiënten met een acuut hartinfarct, gebruikmakend van Technetium gelabeld Annexine-A5, is een bijdrage tot moleculaire beeldvorming van apoptose. Een eerste toepassing van deze technologie staat nu dicht bij de introductie in de dagelijkse klinische praktijk. 
118 


\section{DANKWOORD / ACKNOWLEDGEMENTS}

Nu het schrijven van mijn proefschrift is voltooid, ligt een toekomst open, maar dit kan niet zonder degenen te bedanken op wiens schouders dit proefschrift gebouwd is. Het is dan ook met grote dankbaarheid dat ik een aantal mensen noem. Een dankwoord schrijven lijkt een eenvoudige klus, maar het is eigenlijk onmogelijk om in enkele zinnen iedereen te bedanken voor hun vertrouwen en inzet. Toch zal ik het via deze weg proberen.

Co-promotor en begeleider Leo Hofstra. Graag wil ik je bedanken voor de mogelijkheid die je me hebt geboden en het vertrouwen dat je me hebt geschonken om mijn eigen richting te geven aan het onderzoek. Dank voor een schitterende tijd en ik prijs me zeer gelukkig dat ik binnen en buiten het werkveld van je heb mogen leren. Op de mountainbike en op de sneeuw ben ik je nu nog te snel af, met squash moet ik je ooit nog eens verslaan. Verder ook dank aan mijn tweede co-promotor Chris Reutelingsperger, een goede wijn behoeft geen krans. Jij hebt me geholpen om een beetje wegwijs te raken in het zwarte woud van de biochemie, binnenkort hoogleraar?

Promotor Prof.dr. H.J.J. Wellens, $U$ bent het lichtend voorbeeld van immense kennis een dynamische carrière. Dank voor de behulpzame discussies, mede gevoerd op de autoritten naar de Ridderzaal in Den Haag. Promotor Prof.dr. Jos Smits, jarenlang heb ik je afdeling onveilig mogen maken en gebruik kunnen maken van de faciliteiten. Ik hoop in de toekomst nog vaak terug te mogen komen.

Professor Narula, dear Jagat, I am most grateful for having the privilege of working with you at Drexel University in Philadelphia, USA. I very much appreciate the continued enthousiasm and support. It was a pleasure starting up the in vivo imaging lab from scratch and now producing wonderful results. I would also like to thank Dr. DiPalma, Sabu, Dagmar, Han, Artiom, and Nezam. All of you were always available for consultation and advice. I look forward to developing successful research projects again with you in the future. 
De leden van de beoordelingscommissie H.J.G.M. Crijns, Prof.dr. W.D. Boeckx, Prof.dr. M. Borgers, Prof.dr. C.E. Hack en Prof.dr. E.E. v.d. Wall wil ik bedanken voor hun bereidheid het manuscript kritisch door te lezen.

Mijn paranimfen Nicole Bitsch en Richard Dumont hebben me bijgestaan bij de organisatie van deze promotie. Een handje hulp is altijd welkom.

Alle collega's hebben in belangrijke mate bijgedragen tot een plezierige werksfeer. Het zijn er nogal wat geweest in de afgelopen jaren: Abdel Kader, jij hebt de scepter overgenomen in het molecular imaging lab, jouw nieuwe resultaten zullen zeker leiden tot een mooi proefschrift. Johan, jij zet het onderzoek voort in Philadelphia, ik zei toch al dat je het naar je zin zou hebben en zeker langer daar zou blijven? Ik mis wel de "one dollar" hamburgers bij Wendy's! Bas, het vertalen van gegevens van lab naar kliniek gaat goed samen met een biertje. Eva en Vanessa, jullie maken congres een feest. Alle collega's van de afdeling Farmacologie, Ben, Matthijs, Jacques, Jos, Peter, Agnieska, Nicole, Veerle, Céline, Susanne, Kim, Tijl, Gregorio, Els, Mia, bedankt voor alle hulpzame discussies en een helpende hand als dat nodig was. Nico, Heidi, Petra en Hugo, jullie hebben "liters" Annexine-A5 voor mij gemaakt. Toch kwam ik altijd weer zeuren om meer, of in een andere kleur. Peter Frederik en Hans, elektronenmicroscopie is zeer tijdrovend, maar het heeft wel schitterende resultaten opgeleverd. Stefan, jouw promotieonderzoek heeft mede de basis gelegd voor dit proefschrift. Van de afdeling pathologie, Prof.dr. Mat Daemen, dankzij onze hulpzame discussies hebben we goed richting kunnen geven aan het Molecular Imaging onderzoek. Anique, bedankt voor alle TUNEL kleuringen, Esther, en natuurlijk de "kippenkamer" Kitty, Linda, Marjo, Natasja, Judith en Suzanne.

Mamma en Hein, Richard en Karin en natuurlijk Suzanne, niet alleen voor jullie niet aflatende hulp ben ik jullie grote dank verschuldigd, maar vooral ook voor de kansen die jullie me hebben geboden en hebben geleerd wat doorzettingsvermogen is. Verder ben ik blij met ieder van jullie die dit feest met mij kan vieren en denk aan m'n vader die er bij had moeten zijn. 
The author of this thesis was born on March $19^{\text {th }}, 1973$ in Berg en Terblijt, The Netherlands. He obtained his secondary education degree at leanne D'Arc College in Maastricht, The Netherlands. In 1993 he enrolled in the Medical School at Maastricht University where he participated for four years in research alongside his medical studies at the departments of General Surgery and Cardiology. He obtained his MSc degree in 1997. He was an organizer of the first 'Maastricht Medical Students Research Conference' in 1997. The same year he started internships and from September 1998 enrolled in the MD-PhD program funded by The Netherlands Heart Foundation, during which he performed the studies presented in this thesis. In October 2000 he received his MD degree. He has presented original research and invited papers at many international conferences. The author has been awarded Dr. Pelerin students-science price 1999. The Lancet Investigators Award 1999, NIH/ National Institute of Neurological Disorders and Stroke grant 2000, Lucille Parker Fellowship 2001 and the Drexel University DiPalma Fellowship 2002. In April 2003 he started his specialization in Plastic and Reconstructive Surgery at the Academic Hospital Maastricht. 


\section{LIST OF PUBLICATIONS}

\section{ARTICLES}

1. Visualization of cell death in vivo with the annexin A5 imaging protocol. Reutelingsperger C.P., Dumont E.A., Thimister P.W., van Genderen H., Kenis, H., van den Eijnde S.M., Heidendal G., Hofstra L J immunol Methods. 2002 Jul 1;265(1-2):123-32

2. Real time imaging of apoptotoc cell membrane changes at the single-cell level in the beating murine heart. Dumont E.A., Reutelingsperger C.P., Smits J.F., Daemen M.J., Doevendans P.A., Wellens H.J., Hofstra L. Nature Medicine 2001 Dec; 7(12):1352-5

3. In vivo detection of apoptosis in an intracardiac tumor. Hofstra L., Dumont E.A., Thimister P.W., Heidendal G.A., De Bruine A.P., Elenbaas T.W., Boersma H.H., van Heerde W.L., Reutelingsperger C.P. JAMA. 2001 April 11; 285 (14): 1841-2

4. Cardiomyocyte death induced by myocardial ischemia and reperfusion: measurement with recombinant human annexin- $V$ in a mouse model. Dumont E.A., Hofstra L., van Heerde W.L., Van den Eijnde S.M., Doevendans P.A., DeMuinck E., Daemen M.A., Smits J.F., Frederik P., Wellens H.J., Daemen M.J., Reutelingsperger C.P. Circulation. 2000 September 26; 102(13): 1564-8

5. Visualisation of cell death in vivo in patients with acute myocardial infarction. Lancet. 2000 July 15; 356 (9225):209-12. Hofstra L., Liem I.H., Dumont E.A., Boersma H.H., van Heerde W.L., Doevendans P.A., DeMuinck E., Wellens H.J., Kemerink G.J., Reutelingsperger C.P., Heidendal G.A.

6. Phagocytosis of dying chondrocytes by osteoclasts in the mouse growth plate as demonstrated by annexin-V labelling. Cell Tissue Res. Bronckers A.L., Goei W., van Heerde W.L., Dumont E.A., Reutelingsperger C.P., Van den Eijnde S.M.

7. In situ detection of apoptosis in dental and peridontal tissues of the adult mouse using annexin-V-biotin. Histochem. Cell. Biol. 2000. April; 113(4):293-301. Bronckers A.L. Goei S.W., Dumont E.A., Lyaruu D.M., Woltgens J.H., van Heerde W.L., Reutelingsperger C.P., Van den Eijnde S.M.

8. Markers of apoptosis in cardiovascular tissues: focus on Annexin V. Cardiovasc. Res. 2000 Feb; 45(3):549-59. van Heerde W.L., Robbert-Offerman S., Dumont E.A., Hofstra L., Doevendans P.A., Smits J.F., Daemen M.J., Reutelingsperger C.P

9. Molecular imaging of cell death in intracardiac tumours. Kietselaer B.L., Thimister P.W., Reutelingsperger C.P., Heidendal G.A., Dumont E.A., Boersma H.H., de Bruine A.P., Hofstra L. Netherlands Heart journal vol 10 number $7 / 8$ august 2002 
10. Recovery from apoptosis in the ischemic heart. Dumont E.A. Hofstra L., Petrov A., Narula., Haider N., Strauss H.W., Blankenberg F., Steinmetz N., Kenis H., Freriks P., Crijns H., Wellens H.J., Narula I., Reutelingsperger C.P., submitted

11. Bringing cell death alive. Dumont E.A., Reutelingsperger C.P., Heidendal G.A., Hofst L. Cardiovascular Toxicology 2003, invited review, accepted

12. Annexin V, the novel tool in in vivo molecular imaging. Dumont E.A, Hofstra L., Crijnt., Wellens H.J., Reutelingsperger C.P., Current Molecular Medicine, invited review, in prepration

13. The role of labeled Annexin $A 5$ in imaging of programmed cell death: from animal to clical imaging. B.L.J.H. Kietselaer, MD; L. Hofstra. MD, PhD; E.A.W.J. Dumont, MD; C.M. Reutelingsperger, PhD; G.A.K. Heidendal, MD, PhD. Quarterly Journal of Nuclear Mdicine, accepted

\section{BOOK CHAPTER}

1. Membrane Alterations in Dying cells. Book: Cell Proliferation and Apoptosis. Van Gendren

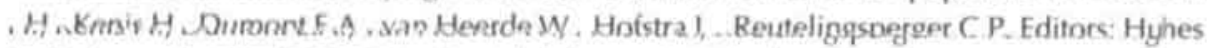
D. Mehmet H. 2003 BIOS Scientific Publishers Ltd, Oxford p. 185-200

\section{AWARDS}

1. Dr. Pelerin students-science price 1999, MMSRC, March 10, 1999, Maastricht, The Netherlands

2. The Lancet Investigators Award 1999, The Lancet conference 1999, The challenge of acute coronary syndromes June 10-11, 1999, Copenhagen, Denmark

3. NIH/ National Institute of Neurological Disorders and Stroke grant 2000, Mitichondrial Dysfunction in Pathogenesis. Jan 15-20, 2000 Santa Fe, New Mexico, USA.

4. Lucille Parker Fellowship 2001, Keystone Symposia, Colorado, USA

5. DiPalma Fellowship 2002, Oct-Dec 2002, Drexel University Philadelphia, Pennsylvania, USA 



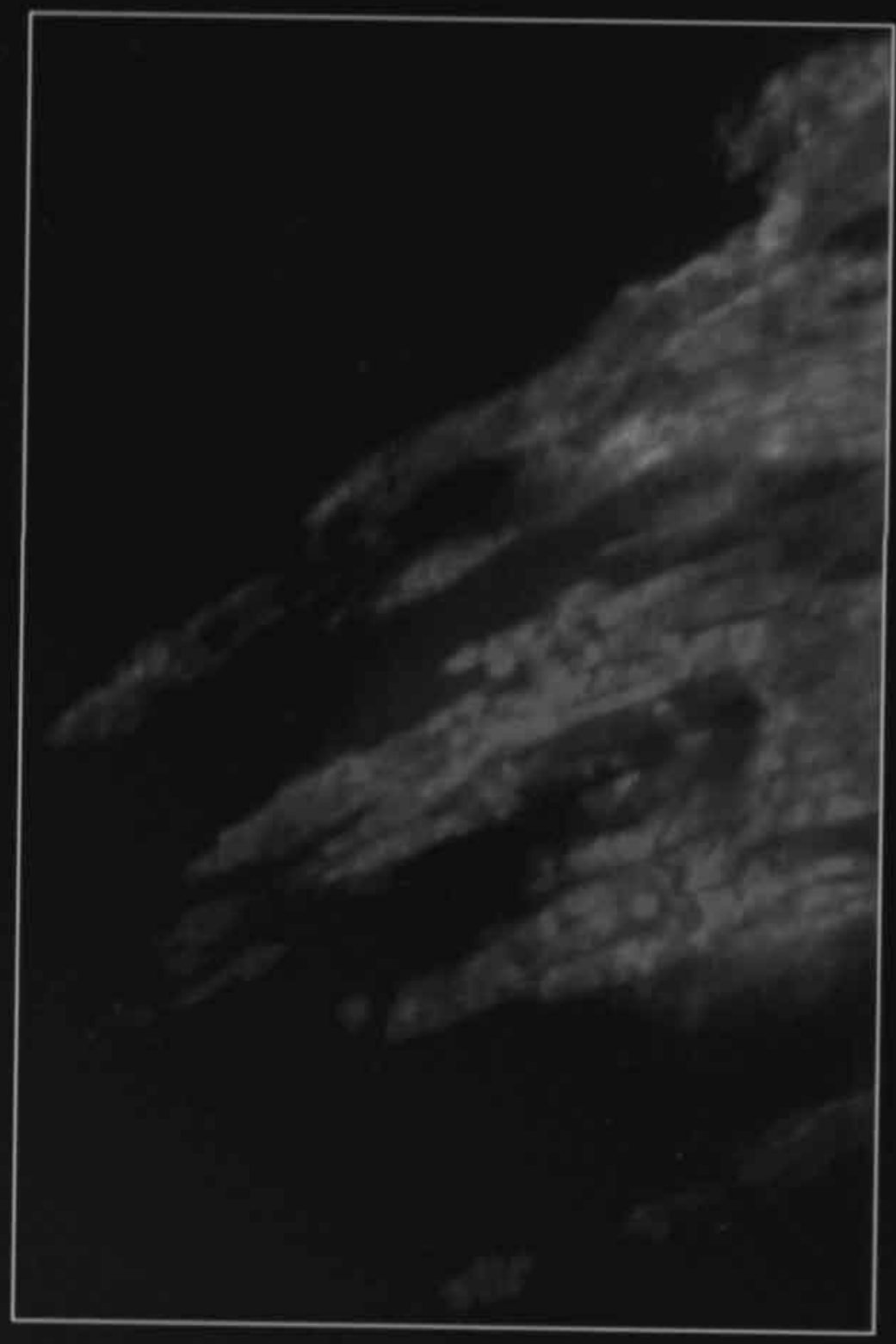

